
This document has been reproduced directly from the best available copy.

Available to DOE and DOE contractors from the Office of Scientific and Technical Information, P.O. Box 62, Oak Ridge, TN 37831; (423) 576-8401.

Available to the public from the U.S. Department of Commerce, Technology Administration, National Technical Information Service, Springfield, VA 22161; (703) 487-4650.

Order No. DE97000789 


\section{DISCLAMMIXR}

Portions of this document may be illegible in electronic image products. Images are produced from the best available original document. 


\section{Foreword}

This Handbook describes a recommended implementation process for core training as outlined in the DOE Radiological Control Manual (RCM). The Handbook is to assist those individuals, both within the Department of Energy (DOE) and Managing and Operating $(M \& O)$ contractors, identified as having responsibility for implementing the core training recommended by the $R C M$. This training may also be given to radiological workers using tritium to assist in meeting the job specific training requirements of 10 CFR 835 .

This Handbook contains recommended training materials consistent with other DOE standardized core radiological training courses. The training material consists of the following documents:

Program Management Guide - This document contains detailed information on how to use the Handbook material.

Instructors Guide - This document contains a lesson plan for instructor use, including notation of key points for inclusion of site specific information.

Student's Guide - This document contains student handout material and also should be augmented by site specific information.

Overhead Transparencies - This document contains recommended overhead transparencies that may be used to augment classroom presentation.

Lessons Learned - This document provides a holding point for inclusion of site specific lessons learned information.

This Handbook was produced in WordPerfect 6.1 and has been formatted for printing on an HP III (or higher) LaserJet printer. The overhead transparencies were produced in Harvard Graphics 3.0 for windows. Copies of this Handbook may be obtained from either the DOE Radiation Safety Training Home Page Internet site (http://tis-nt.eh.doe.gov/wpphm/rst/rst.html) or the DOE Technical Standards Program Internet site (http://apollo.osti.gov/html/techstds/techstds.html). Documents downloaded from the DOE Radiation Safety Training Home Page Internet site may be manipulated using the software noted above (current revision or higher). 
DOE-HDBK-1105-96

This page intentionally left blank 


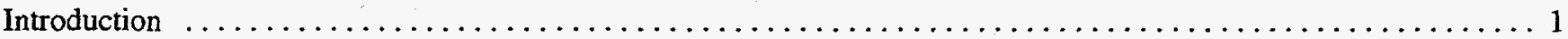

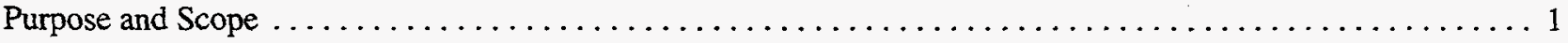

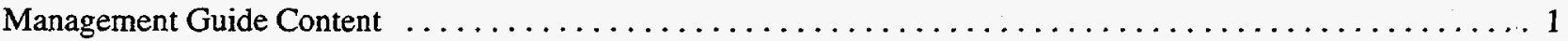

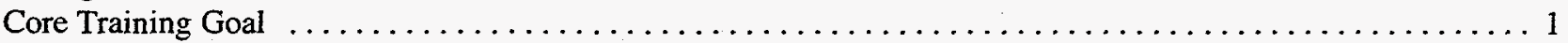

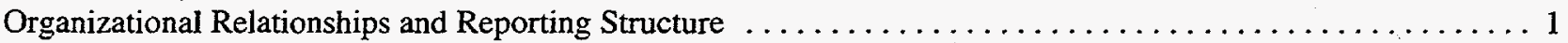

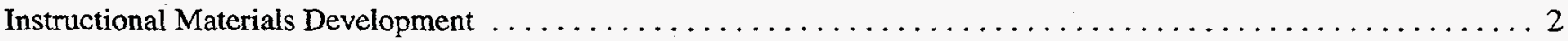

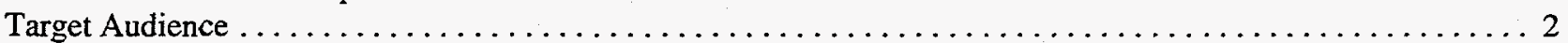

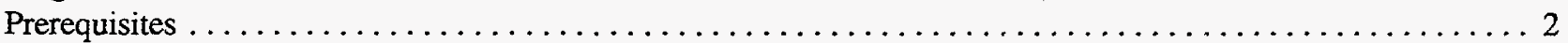

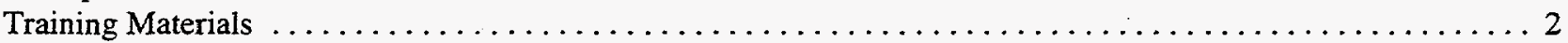

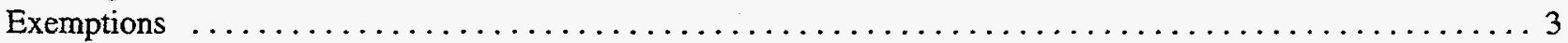

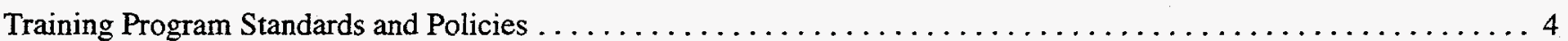

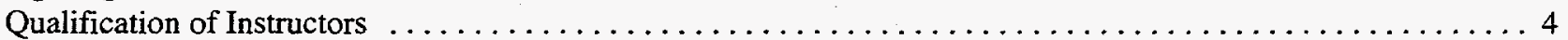

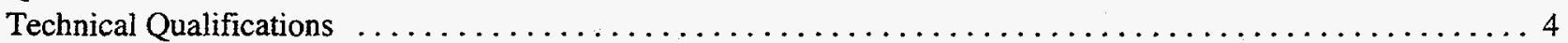

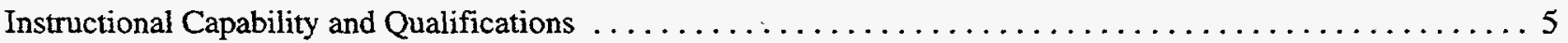

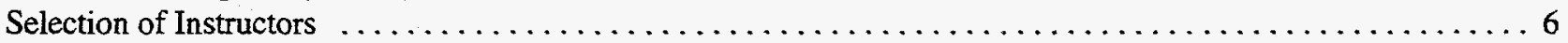

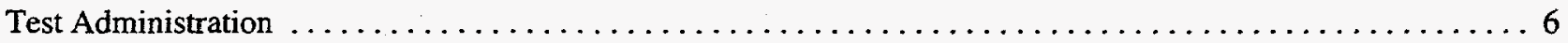

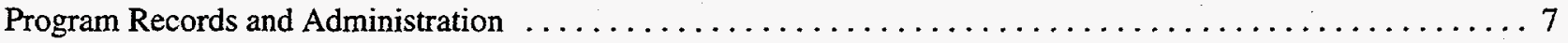

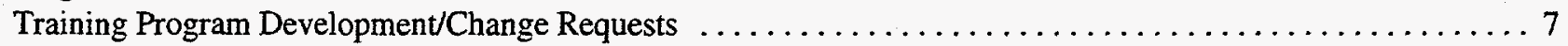

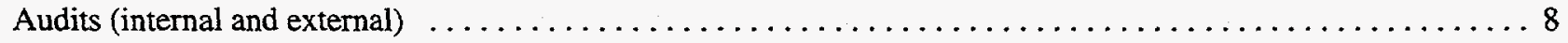

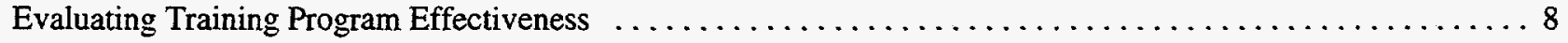

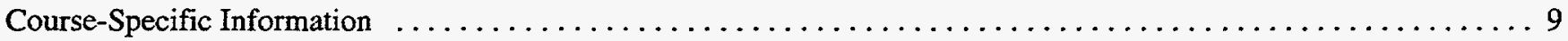

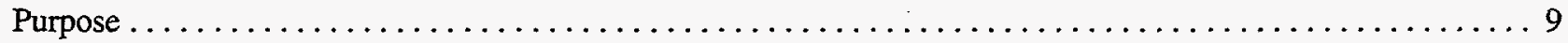

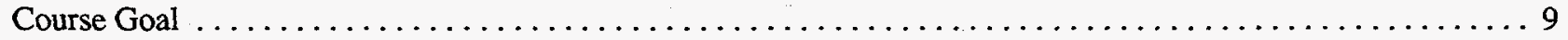

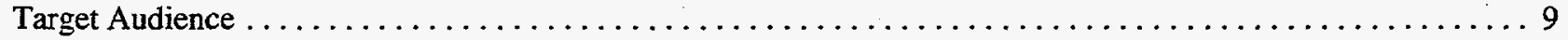

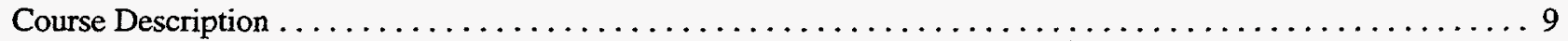

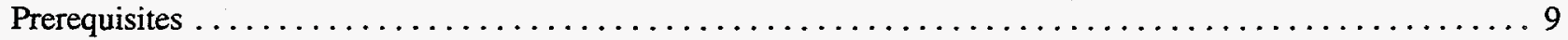

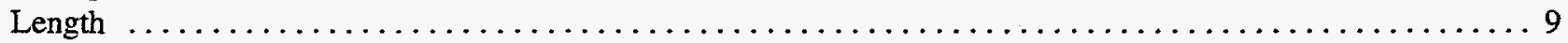

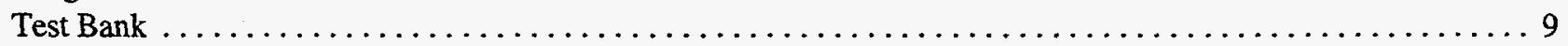

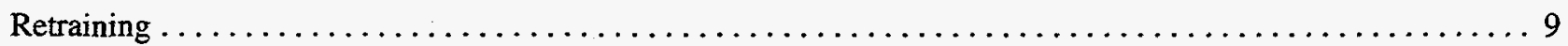

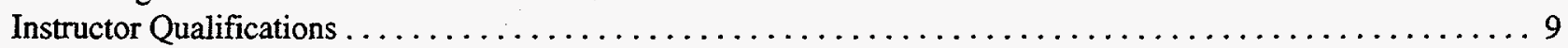

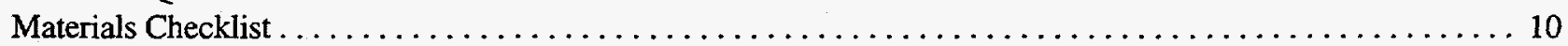

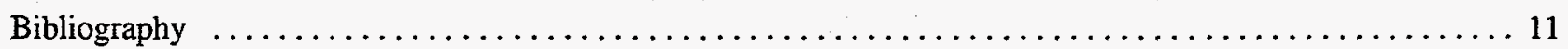


DOE-HDBK-1105-96

This page intentionally left blank. 
(PART 1 OF 5)

\title{
Radiological Training for Tritium Facilities
}

\author{
Program Management Guide
}

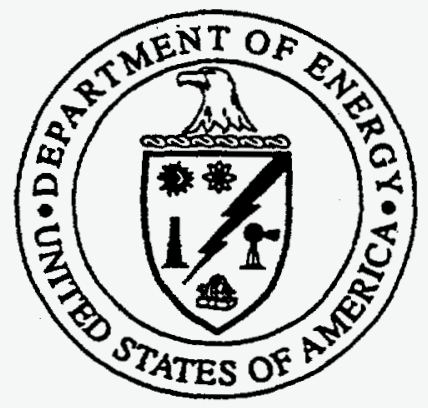

Coordinated and Conducted for Office of Environment, Safety \& Health U.S. Department of Energy 


\section{Course Developers}

Richard Carison

Kevin Connolly

Jack Foster

Gary Mansfield

Burk D. Marler

Peter O'Connell

Doug Riddle

Doug Serpa

Paula Trinoskey
Los Alamos National Laboratory

Westinghouse Savannah River Company

-.. Program Management, Inc.

Lawrence Livermore National Laboratory

EG\&G Idaho, Inc.

U.S Department of Energy

EG\&G Idaho, Inc.

Lawrence Livermore National Laboratory

Lawrence Livermore National Laboratory

\section{Course Reviewers}

John Hehmeyer

James Patterson

Tritium Focus Group

EG\&G Mound Applied Technologies

DOE Chicago Operations Office

U.S. Department of Energy

Technical Standard

Managers

U.S. Department of Energy

Janet Westbrook 
Introduction

Purpose and Scope

Management Guide Content

Core Training Goal

Organizational

Relationships and

Reporting Structure
This program management guide describes a recommended implementation standard for core training as outlined in the DOE Radiological Control Manual (RCM). The standard is to assist those individuals, both within the Department of Energy (DOE) and Managing and Operating $(\mathrm{M \& O})$ contractors, identified as having responsibility for implementing the core training recommended by the DOE Radiological Control Manual (RCM). This training may also be given to radiological workers using tritium to assist in meeting their job specific training requirements of 10 CFR 835 .

The management guide is divided into the following sections:

- Introduction

- Instructional Materials Development

- Training Program Standards and Policies

- Course Specific Information

The goal of the core training program is to provide a standardized, baseline knowledge for those individuals completing the core training. Standardization of the knowledge provides personnel with the information necessary to perform their assigned duties at a predetermined level of expertise. Implementing a core training program ensures consistent and appropriate training of personnel.

The DOE Office of Worker Protection Programs and Hazards Management (EH-52) is responsible for approving and maintaining the standardized core training materials associated with the core training program. A Training Oversight Group (TOG) consisting of representatives from the major contractors will review comments and recommend program changes to DOE EH.

The establishment of a comprehensive and effective contractor site radiological control training program is the responsibility of line management and their subordinates. The training function can be performed by a separate training organization, but the responsibility for quality and effectiveness rests with the line management. 
Target Audience

\section{Prerequisites}

Training Material
Course instructional materials were developed for specific employees who are responsible for knowing or using the knowledge or skills for each course. With this in mind, the participant should never ask the question, "Why do I need to learn this?" However, this question is often asked when the participant cannot apply the content of the program. It is the responsibility of management to select and send workers to training who need the content of the program. When workers can benefit from the course, they can be motivated to learn the content and apply it on their jobs. Care should be taken to read the course descriptions along with the information about who should attend. Participants and DOE facilities alike will not benefit from workers attending training programs unsuitable for their needs.

A background and foundation of knowledge facilitates the trainee in learning new knowledge or skills. It is much easier to learn new material if it can be connected or associated to what was previously learned or experienced. Curriculum developers who have been involved in preparing instructional materials for the core training know this and have established what is referred to as "prerequisites" for each course.

Certain competencies or experiences of participants were also identified as necessary prior to participants attending a course. Without these competencies or experiences, the participants would be at a great disadvantage and could be easily discouraged and possibly fail the course. It is not fair to the other participants, the unprepared participant, and the instructor to have this misunderstanding.

Training materials for the core program consist of lesson plans, study guides, training aids, handouts and in some cases, video. The core training content should be presented in its entirety. Overhead transparencies are sometimes provided in support of the core training content and may be substituted or supplemented with updated or site-specific information.

Supplemental material and training aids may be developed to address site-specific radiological concerns and to suit individual training styles. References are cited in each lesson plan and may be used as a resource in preparing site-specific information and training aids.

Each site is responsible for establishing a method to differentiate the site-specific information from the standardized core lesson plan material. When additional or sitespecific information is added to the text of the core lesson plan material, a method should be used to differentiate site information from core material. 
Instructional Materials Development (continued)

Exemptions

Qualified personnel can be exempted from training if they have satisfactorily completed training programs, (i.e., facility, college or university, military, or vendor programs) comparable in instructional objectives, content, and performance criteria. Documentation of the applicable and exempted portions of training should be maintained.

Training Program Standards and Policies Next 


\section{Qualification of} Instructors

Technical Qualifications
The technical instructor plays a key role in the safe and efficient operation of DOE facilities. Workers must be well qualified and have a thorough understanding of the facility's operation, such as processing, handling, and storage of materials, and maintenance of equipment. Workers must know how to correctly perform their duties and why they are doing them. They must know how their actions influence other worker's responsibilities. Because workers' actions are so critical to their own safety and the safety of others, their trainers must be of the highest caliber. The technical instructor must understand thoroughly all aspects of the subjects being taught and the relationship of the subject content to the total facility. Additionally, the instructor must have the skills and knowledge to employ the instructional methods and techniques that will enhance learning and successful job performance. While the required technical and instructional qualifications are listed separately, it is the combination of these two factors that produces a qualified technical instructor.

The qualifications are based on the best industry practices that employ performancebased instruction and quality assurances. These qualifications are not intended to be restrictive, but to help ensure that workers receive the highest quality training possible. This is possible only when technical instructors possess the technical competence and instructional skills to perform assigned instructional duties in a manner that promotes safe and reliable DOE facility operations.

Instructors must possess technical competence (theoretical and practical knowledge along with work experience) in the subject areas in which they conduct training. The foundation for determining the instructor's technical qualifications is based on two factors:

- the trainees being instructed, and

- the subject being presented

The following is an example of a target audience, subject to be taught, and instructor technical qualifications.

\begin{tabular}{|l|l|l|}
\hline \multicolumn{1}{|c|}{$\begin{array}{c}\text { TARGET } \\
\text { AUDIENCE }\end{array}$} & $\begin{array}{c}\text { SUBJECT BEING } \\
\text { TAUGHT }\end{array}$ & \multicolumn{1}{c|}{$\begin{array}{c}\text { INSTRUCTOR } \\
\text { TECHNICAL QUALIFICATIONS }\end{array}$} \\
\hline $\begin{array}{l}\text { Pritium Facilities } \\
\text { DOE Employees }\end{array}$ & $\begin{array}{l}\text { Tritium Hazards and } \\
\text { Safety Training }\end{array}$ & $\begin{array}{l}\text { Demonstrated knowledge and skills in radiation protection, above } \\
\text { the level to be achieved by the trainees, as evidenced by previous } \\
\text { training/education and through job performance, } \\
\text { AND }\end{array}$ \\
Completion of all qualification requirements for the senior-level \\
radiation protection technician position at the trainees' facility or a \\
similar facility.
\end{tabular}


Technical Qualifications (continued)

Instructional Capability and Qualifications
Methods for verifying the appropriate level of technical competence may include the review of prior training and education, observation, and evaluation of recent related job performance, and oral or written examination. Other factors that may be appropriate for consideration include DOE, NRC, or other government qualification, certification by the American Board of Health Physics and/or registration by the National Registry of Radiation Protection Technologists, vendor or facility certification, and most importantly, job experience. To maintain technical competence, a technical instructor should continue to perform satisfactorily on the job and participate in continuing technical training.

Qualifications of instructional capability should be based on demonstrated performance of the instructional tasks for the specific course requirements and the instructor's position. Successful completion of instructor training and education programs, as well as an evaluation of on-the-job performance, is necessary for verification of instructional capability. Instructional capability qualification should be granted as the successful completion of an approved professional development program for training instructors. The program should contain theory and practice of instructional skills and techniques, adult learning, planning, conducting, and evaluating classroom, simulator, laboratory, and on-the-job training activities.

Illustrated talks, demonstrations, discussions, role playing, case studies, coaching, and individual projects and presentations should be used as the principal instructional methods for presenting the instructional training program. Each instructional method should incorporate the applicable performance-based principles and practices. Every effort should be made to apply the content to actual on-the-job experience or to simulate the content in the classroom/laboratory. The appropriate methodology required to present the instructional content will indicate a required level of instructional qualification and skill.

Current instructors' training, education, and job performance should be reviewed to determine their training needs for particular courses. Based on this review, management may provide exemptions based on demonstrated proficiency in performing technical instructor's tasks.

Through training or experience, technical instructors should be able to*:

- Review instructional materials and modify them to fully meet the needs of the training group.

- Arrange the training facility (classroom/laboratory or other instructional setting) to meet the requirements for the training sessions.

- Effectively communicate, verbally and non-verbally, lessons to enhance learning.

- Invoke student interaction through questions and student activity. 
Training Program Standards and Policies (continued)

\section{Instructional Capability and Qualifications (continued)}

\section{Selection of Instructors}

Test Administration $\circ$

Use appropriate instructional materials and visual aids to meet the lesson objectives.

- Administer performance and written tests.

- Ensure that evaluation materials and class rosters are maintained and forwarded to the appropriate administrative personnel.

- Evaluate training program effectiveness.

- Modify training materials based on evaluation of training program.

*Stein, F. Instructor Competencies: The Standards. International Board of Standards for Training, Performance and Instruction; 1992.

Selection of instructors should be based on the technical and instructional qualifications specified in the Course Specific Information section of this guide. In addition to technical and instructional qualifications, oral and written communication skills, and interpersonal skills, should be included in the process of selecting and approving instructors.

Since selection of instructors is an important task, those who share in the responsibility for ensuring program effectiveness should:

- interview possible instructors to ensure they understand the importance of the roles and responsibilities of technical instructors and are willing to accept and fulfill their responsibilities in a professional manner

- maintain records of previous training, education, and work experience

Procedures for program evaluation will include documentation of providing qualified instructors for generic and site-specific training programs.

A test bank of questions for each course which has an exam should be developed and the content validated. As the test banks are used, statistical validation of the test bank should be performed in order to fully refine the questions and make the tests as effective as possible. The questions contained in the test bank are linked directly to the objectives for each course. In this way, trainee weaknesses can be readily identified and remedial procedures can be put into place. The test outcomes can also be used to document competence and the acquisition of knowledge.

The test banks should also be used by the instructors to identify possible weaknesses in the instruction. If numerous trainees fail to correctly answer a valid set of questions for an objective, the instruction for that objective needs to be reviewed for deficiencies. 
Training Program Standards and Policies (continued)

Test Administration (continued)

Program Records and Administration

Training Program Development/Change Requests
Written examinations should generally be used to demonstrate satisfactory completion of theoretical classroom instruction. The following are some minimal requirements for the test banks and tests:

- Tests are randomly generated from the test bank.

- Test items represent all objectives in the course.

- All test bank items are content-validated by a subject matter expert.

- Test banks are secured and are not released either before or after the test is administered.

- Trainees receive feedback on their test performance.

- Test banks undergo statistical analysis.

- For the first administrations of tests, a minimum passing score of $80 \%$ should be required for a passing score. As statistical analysis of test results is performed, a more accurate percentage for a passing score should be identified.

Test administration is critical in accurately assessing the trainee's acquisition of knowledge being tested. Generally, the following rules should be followed.

- Tests should be announced at the beginning of the training sessions.

- Instructors should continuously monitor trainees during completion of tests.

- All tests and answers should be collected at the conclusion of each test.

- No notes can be made by trainees concerning the test items.

- No talking (aside from questions) should be allowed.

- Answers to questions during a test should be provided but answers to test items should not be provided or alluded to.

- Where possible, multiple versions of each test should be produced from the test bank for each test administration.

- After test completion, trainees may turn in their materials and leave the room while other trainees complete their tests.

- Trainee scores on the tests should be held as confidential.

Training records and documentation shall meet the requirements of 10 CFR 835.704.

All requests for program changes and revisions should be sent to DOE EH-52 using the form "Request for Changes to Standardized Core Training Materials" provided with each program management guide. 
Training Program Standards and Policies (continued)

Audits (internal and external)

Evaluating Training
Program Effectiveness
Internal verification of training effectiveness should be accomplished through senior instructor or supervisor observation of practical applications and discussions of course material. All results should be documented and maintained by the organization responsible for Radiological Control training.

The core training program materials and processes should be evaluated on a periodic basis by DOE-HQ. The evaluation should include a comparison of program elements with applicable industry standards and requirements.

Verification of the effectiveness of Radiological Control training should be accomplished per DOE/EH-0258T-1, "General Employee Radiological Training and Radiological Worker Training, Program Management Manual". In addition, DOE/EH has issued guidelines for evaluating the effectiveness of radiological training through the DOE Operations Offices and DOE Field Offices. For additional guidance, refer to DOE STD 1070-94 "Guide for Evaluation of Nuclear Facility Training Programs." 
Purpose

Course Goal

Target Audience

Course Description

Prerequisites

Length

Test Bank

Retraining

Instructor Qualifications
This section of the program management guide is to assist those individuals assigned responsibility for implementing the Radiological Training for Tritium Facilities. Standardized implementation of this training ensures consistent and appropriate training for all personnel.

Upon completion of this training, the student will have a basic understanding of the characteristics of tritium and understand the precautions and safeguards needed for working in a tritium facility.

Individuals who have assigned duties in tritium facilities.

This course illustrates and reinforces the skills and knowledge needed to provide personnel with an understanding of the characteristics of tritium and the precautions needed for working with or around it in a DOE facility. This course is designed to meet Article 663 of the DOE Radiological Control Manual for individuals who have assigned duties in a tritium facility.

Training which is considered commensurate with site-specific hazards. Radiological Worker II or the equivalent is recommended prior to receiving or concurrently with this tritium facilities safety training. Some of those basic concepts contained in Radiological Worker II are used extensively throughout this training.

2 - 4 hours (depending on site-specific information)

Test banks, as applicable, are to be developed by the sites, incorporating site-specific information.

Retraining is not required for this course.

Instructors of this course have a major role in making it successful and meeting the specified objectives. Instructors must have related experience and be technically competent. In this course it is imperative that the instructor have the background and experience of working in a tritium facility. Instructors must be able to relate their own work experience to the workers in a tritium facility. Instructors must be able to answer specific questions and use a variety of instructional material to meet the objectives. 
Instructor Qualifications

(Continued)

\section{Education:}

Minimum of B.S. degree in Health Physics or related discipline is preferred.

Certification:

Certification by American Board of Health Physics (ABHP) or National Registry of Radiation Protection Technologists (NRRPT) preferred.

Experience:

At least five years of applied radiological protection experience in an operating radiological facility is preferred. The areas of experience should include:

- Tritium hazards

- Radiological controls associated with tritium

- Conducting surveys and monitoring for tritium

Comprehensive knowledge of Federal regulations and guidance and best nuclear industry practices pertaining to radiological protection.

The following checklist should be used to ensure all training materials are available. The Program Management Guide, Instructor's Guide, Student's Guide, and Lessons Learned section are provided in WP 6.1 \& format. The Overhead Transparencies are provided in Harvard Graphics 3.0 for Windows \&ormat

- Program Management Guide

- Instructor's Guide

- Student's Guide

- Overhead Transparencies

- Lessons Learned

The following checklist should be used before training is provided to ensure that equipment is available and working.

- Overhead projector

- Screen

- Flip chart

- Markers 
Course-Specific Information (continued)

Bibliography

U.S. Department of Energy, Guide to Good Practices for Training and Qualification of Instructors, DOE-NE-STD-1001-91, Washington, D.C. (1991).

U.S. Department of Energy, Health Physics Manual of Good Practices for Tritium Facilities, MLM-3719, Washington, D.C. (1991)

Lawrence Livermore National Laboratory, Draft Technical Guide - Control of Tritium Exposure at DOE Sites, Livermore, CA (1993)

U.S. Department of Energy, Radiological Control Manual, DOE/EH-0256T Rev. 1, Washington, D.C. (1994).

U.S. Department of Energy, DOE Handbook - Primer on Tritium Safe Handling Practices, DOE-HDBK-1079-94, Washington, D.C. (1994)

U.S. Department of Energy, Guide for Evaluation of Nuclear Facility Training Programs, DOE-STD-1070-94, Washington, D.C. (1994) 
DOE-HDBK-1105-96

This page intentionally left blank. 


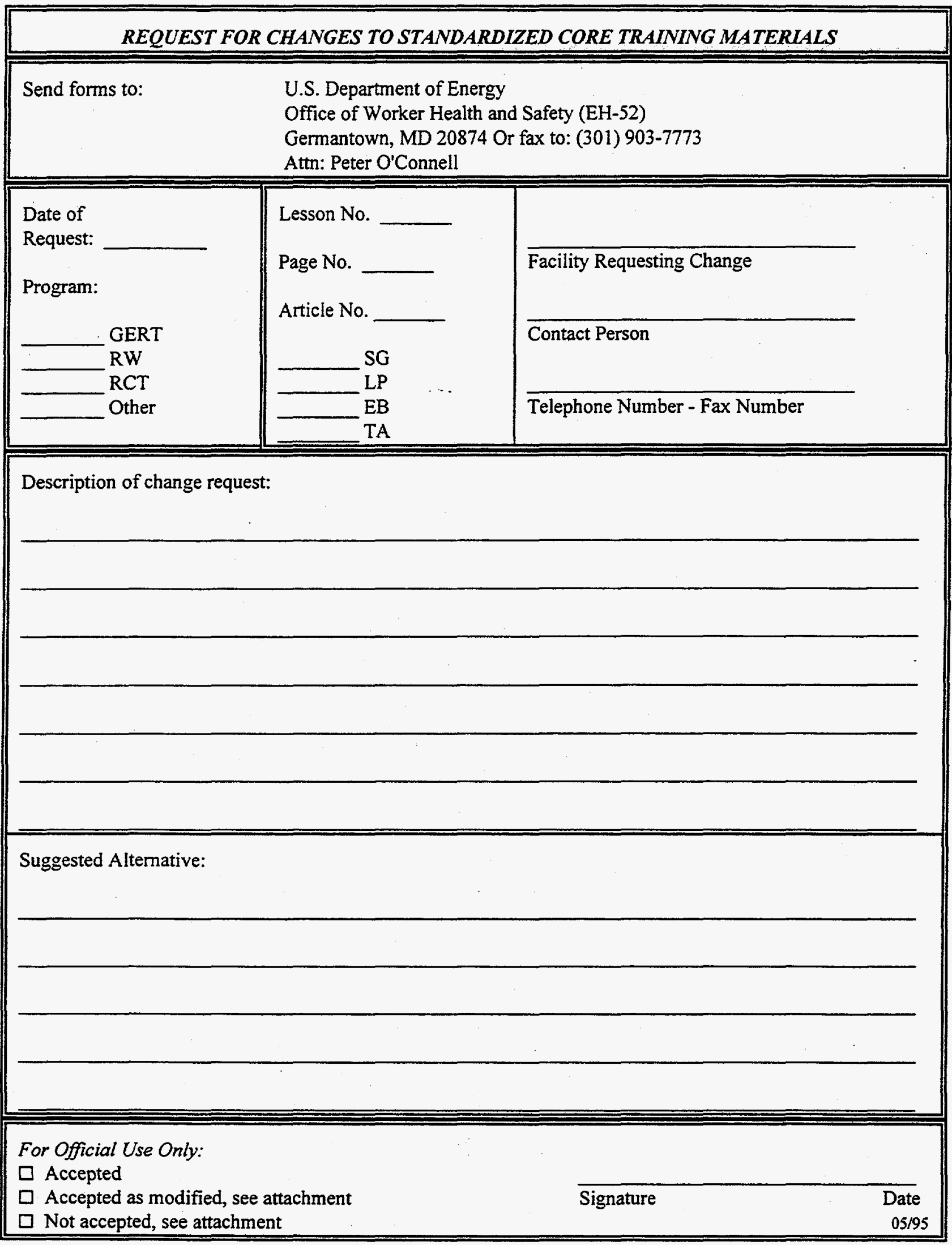


DOE-HDBK-1105-96

This page intentionally left blank. 
(Part 2 of 5)

\title{
Radiological Training for Tritium Facilities
}

\author{
Instructor's Guide
}

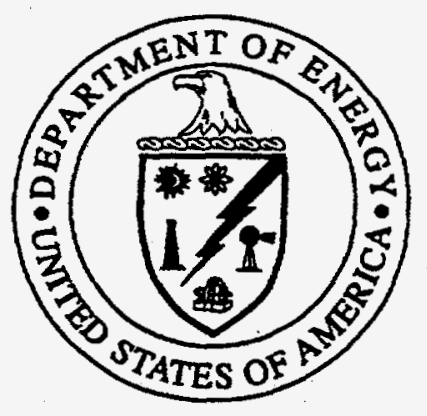

Coordinated and Conducted for

Office of Environment, Safety \& Health

U.S. Department of Energy 


\section{Course Developers}

Richard Carison

Kevin Connolly

Jack Foster

Gary Mansfield

Burk D. Marler

Peter O'Connell

Doug Riddle

Doug Serpa

Paula Trinoskey
Los Alamos National Laboratory

Westinghouse Savannah River Company

Program Management, Inc.

Lawrence Livermore National Laboratory

EG\&G Idaho, Inc.

U.S. Department of Energy

EG\&G Idaho, Inc.

Lawrence Livermore National Laboratory

Lawrence Livermore National Laboratory

Course Reviewers

John Hehmeyer

James Patterson

Tritium Focus Group

Technical Standard

Managers

Janet Westbrook
EG\&G Mound Applied Technologies

DOE Chicago Operations Office

U.S. Department of Energy

U.S. Department of Energy

Oak Ridge National Laboratory 


\section{DEPARTMENT OF ENERGY - COURSE PLAN}

Standardized Core Course

Material

Course Goal: $\quad$ Upon completion of this training the student will have a basic understanding of the characteristics of tritium and understand the precautions and safeguards needed for working in a tritium facility as outlined in the course objectives.

Target Audience: Individuals who have assigned duties in Tritium Facilities.

Description: $\quad$ This course illustrates and reinforces the skills and knowledge needed to provide personnel with an understanding of the characteristics of tritium and the precautions needed for working with or around it in a DOE facility. This course is designed to be consistent with Article 663 of the DOE Radiological Control Manual for individuals who have assigned duties in a tritium facility.

Prerequisites:

Training which is considered commensurate with site-specific hazards. Radiological Worker II or the equivalent is recommended prior to receiving or concurrently with this tritium facilities safety training. Some of the basic concepts contained in Radiological Worker II are used extensively throughout this training.

Length:

2 - 4 hours (depending on site-specific information) 
Course Objectives: EO1 IDENTIFY the following properties of tritium:

- physical/chemical

- radioactive.

EO2 IDENTIFY sources of tritium:

- natural

- by-product

- weapons.

EO3 IDENTIFY uses of tritium:

- weapons applications

- research

- fusion energy production

- industrial/commercial.

EO4 IDENTIFY modes of tritium exposure:

- inhalation

- ingestion

- absorption

- injection/wound.

EO5 IDENTIFY the biological effects of tritium:

- biological half-life

- dose.

EO6 IDENTIFY the radiological control methods for tritium:

- engineered

- administrative

- surface contamination limits

- personnel protective equipment

- application of ALARA principles.

EO7 IDENTIFY methods for monitoring for tritium:

- air sampling for worker safety

- contamination surveys

- bioassay.

EO8 IDENTIFY tritium waste minimization and handling techniques. (Site-Specific)

E09 IDENTIFY alarms and proper response to abnormal conditions in the tritium facility. (Site-Specific) 
Training Aids: Overhead transparencies (may be supplemented or substituted with updated or site-specific information)

$\begin{array}{ll}\text { Equipment Needs: } & \circ \text { Overhead projector } \\ & \circ \text { Screen } \\ & \circ \text { Flip chart } \\ & \circ \text { Markers }\end{array}$

Student Materials: $\quad$ Students Guide

Bibliography Next 
Bibliography: $\quad$ ANSI 13.12 (1987) DRAFT, ANSI N-13.12, "Surface Radioactivity Guides For Materials, Equipment, and Facilities To Be Released For Uncontrolled Use," HPS Standards Committee, November 1987.

DOE (1993), U.S. Department of Energy, 10 CFR Part 835, "Occupational Radiation Protection." Physics Procedures (HP) Committee, September 24, 1993.

DOE (1994), U.S. Department of Energy, Radiological Control Manual, DOE/EH-0256T, Washington, D.C.

LA-4400 (1970), LA-4400, Los Alamos Handbook of Radiation Monitoring, 1970.

Lorenzen (1994), W.A., Ring J.P., "The Management and Operation of a Large Scale Decay-In-Storage Program," paper presented at 27th Mid-Year Topical Meeting of the Health Physics Society, February 12-16, 1994, Albany, NY.

NCRP Report No. 62, National Council on Radiation Protection and Measurements, "Tritium in the Environment", Washington, D.C., 1979.

NRC (1991), U.S. Nuclear Regulatory Commission, 10 CFR Part 20, "Standard for Protection Against Radiation."

Stevens (1994), L., and Phillips, M., Health Physics Lessons Learned from the DOE Moratorium on Mixed Waste, 27th Mid-Year Topical Meeting of the Health Physics Society, February 12-16, 1994, Albany, NY.

Woehr (1994), W.J., Gatami, A. and Holodny, E. I., "Radioactive Waste Volume Reduction in a University/Hospital Setting, 27th Mid-Year Topical Meeting of the Health Physics Society, February 1216, 1994, Albany, NY. 


\section{LESSON SUMMARY}

\section{Introduction}

Welcome students to the course.

Show Title OT-1

Introduce self and instructor team.

Define logistics.

- safety briefing - exits

- restrooms

- hours

- breaks

- sign-in sheets

- test - accountability

- end of course evaluation

Remind the participants that they need to have completed Radiological Worker Training prior to this course. They should be familiar with terms like rem, contamination, etc.

\section{Course Goal}

At the end of this course, the participant should be able to demonstrate a basic understanding of the characteristics of tritium and precautions for working in a tritium facility as outlined in the course objectives. We will attempt to answer the following questions:

- Tritium, what is it?

Show OT 2

- How does it behave?

- What are the benefits and hazards?

- How do we control it?

\section{State Course Objectives}

Show OT 3, OT 4, and OT 5 


\section{Course Content}

Briefly review the content of the course, noting that there is a logical sequence ("flow"), and that as you present the material you will relate the material covered to the circumstances that they can expect to find in the facility workplace and procedures. (You will be inserting site-specific tritium information.)

1. Properties of Tritium

2. Sources and Uses of Tritium

3. Modes of Exposure and Biological Behavior of Tritium

4. Radiological Controls for Tritium

5. Monitoring for Tritium

6. Tritium Waste Minimization and Handling

7. Response to Abnormal Conditions in the Tritium Facility

8. Lessons Learned

9. Summary and Review 
Tritium is a radioactive isotope of hydrogen $(\mathrm{H})$. Hydrogen is the lightest and most abundant element in the universe. Hydrogen has only one proton in its nucleus. Tritium has, in addition to the single proton, two neutrons in its nucleus. This makes it three times heavier than the most common form of hydrogen.

A. Isotopes of Hydrogen

1. Protium $(\mathrm{H})(99.985 \%$ natural abundance $)$

2. Deuterium $=$ hydrogen +1 neutron (D) $(0.015 \%$ natural abundance)

3. Tritium $=$ hydrogen +2 neutrons $(T)$

B. Symbol for Tritium

Tritium is designated as:

T, $\mathrm{H}-3$, or ${ }_{1}^{3} \mathrm{H}$

C. Chemical Properties of Hydrogen/Tritium

Tritium "behaves" just like hydrogen chemically because it has one proton and one electron like ordinary hydrogen.
Show OT 8

Show OT 9

Show OT 10 
1. Substitution

Tritium atoms can easily substitute for hydrogen atoms. Examples:

a. elemental hvdrogen (tritium gas, HT, DT, or $T_{2}$ )

b. tritiated water (tritium oxide: HTO, DTO, or $\mathrm{T}_{2} \mathrm{O}$ )

c. organically bound tritium

d. metals and tritium (metal tritides)

2. Solubility

Exchanges with hydrogen in organic and other materials (oils, plastics, etc.)

3. Flammability

Tritium gas is flammable and can explode under certain conditions.
Show OT 11

Show OT 12

Show OT 13 - Tritium can replace a loosely bounded hydrogen atom of an organic molecule.

Show OT 14 - Hydride storage of elemental tritium is common. Uranium Hydride is most frequently used for this purpose. Tritium is released by heating the metals to $400^{\circ} \mathrm{C}$ for $1 \mathrm{~atm}$. dissociation pressure.

Instructor should emphasize that the biological exchange of tritium with hydrogen in the body is of concern.

Show OT 15 Approximately $1 \%$ of tritium gas in air or $4 \%$ of oxygen in tritium gas may be an ignitable mixture 
D. Physical Properties

1. Diffusion

Tritium gas is lighter than air and diffuses rapidly in air.

\section{Permeability}

Tritium gas permeates through most materials, that is, it travels through them by way of spaces or interstices in them. The rate depends upon the material and its thickness. Tritium's radioactive, chemically reducing and diffusive properties result in degradation of many useful polymeric materials, pump oils, plastics, and o-rings. This can cause loss of mechanical functions in certain situations within a short period of time.

E. Radioactive Decay of Tritium

${ }_{1}^{3} \mathrm{H}$ decays to ${ }_{2}^{3} \mathrm{He}+\beta^{-}+\overrightarrow{\mathrm{U}}$

$$
\begin{gathered}
{ }_{2}^{3} H=\text { Helium } \\
\beta^{-}=\text {beta minus } \\
\bar{U}=\text { anti-neutrino }
\end{gathered}
$$

Tritium "decays" by emitting a beta particle and becoming an atom of helium.

\section{Show OT 16}

Show OT 17

Show OT 18

Show OT 19 
1. Beta Energy

A very low energy beta is emitted.

\section{Beta Range}

Tritium is not an "external" radiation hazard.
a. Travels less than $1 / 4$ inch in air
b. Cannot penetrate through the dead layer of the skin
c. Cannot penetrate clothing or gloves

3. Half-life

Radioactive half-life $=12.3$ years

F.

\section{X-Ray Production}

Tritium betas can produce low energy $x$ rays. Because the beta particle is of such low energy. the $x$ rays it may produce are not very penetrating and are not normally considered a hazard and cannot be detected with typical portable instruments.
Max energy $=18.6 \mathrm{keV}$

Ave. energy $=5.7 \mathrm{keV}$

Instructor should emphasize the radiological controls are to keep tritium outside the body. Explain what is meant by "external" radiation hazard.

Show OT 20 


\section{G. Fusion}

Fusion is the process of two nuclei joining together. The energy source in most stars is nuclear fusion of hydrogen isotopes.

\section{SOURCES AND USES OF TRITIUM}

How is tritium produced and what is it used for?

\section{A. Sources of Tritium}

There are three primary sources of tritium in our environment. Tritium is present in our environment from both man-made and natural sources as discussed below. Natural tritium is indistinguishable from man-made tritium.

\section{Natural Sources}

Tritium occurs naturally. It is formed by the reactions between cosmic rays and the nitrogen in the upper atmosphere. Nitrogen makes up $80 \%$ of the earths atmosphere.

Cosmic rays generate àpproximately 4 million curies of tritium per year. With tritium being continually produced and at the same time decaying, the natural tritium in our environment is about 70 million curies.

\section{Show OT 21}

$$
\begin{gathered}
{ }_{1}^{2} \mathrm{H}+{ }_{1}^{2} \mathrm{H}-{ }_{2}^{3} \mathrm{H}+{ }_{0}^{1} \mathrm{n} \\
1 \text { mev per fusion } \\
{ }_{1}^{3} \mathrm{H}+{ }_{1}^{2} \mathrm{H}-{ }_{2}^{4} \mathrm{H}+{ }_{0}^{1} \mathrm{n} \\
17 \text { mev per fusion }
\end{gathered}
$$

Show OT 22

\section{Show OT 23}

Modes of production:

1. The nitrogen nucleus captures a neutron and decays to tritium and carbon.

$$
\begin{gathered}
{ }_{14}^{14} \mathrm{~N}+{ }_{0}^{1} \mathrm{n} \text { yields } \\
{ }_{1}^{3} \mathrm{H}+{ }_{6}^{12} \mathrm{C}
\end{gathered}
$$

\section{Two hydrogen-2 atoms} (deuterium) combine to form tritium and normal hydrogen.

$$
\begin{gathered}
{ }_{1}^{2} \mathrm{H}+{ }_{1}^{2} \mathrm{H} \text { yielas } \\
{ }_{1}^{3} \mathrm{H}+{ }_{1}^{1} \mathrm{H}
\end{gathered}
$$


2. By-Product of Reactor Sources

a. Lithium- 7 captures a neutron and decays with tritium as a product.

b. Boron captures a neutron and decays with tritium as a product.

c. Activation of deuterium in water.

d. Ternary fission

The production of tritium from power reactors around the world is less than onehalf that naturally formed (approximately 1 to 2 million curies a year).

3. Weapons Testing as a Source

The amount of tritium in the world from weapons testing has been steadily declining since the 1970's when atmospheric testing was curtailed.

Atmospheric testing from 1945-1975 produced about 8 billion curies. This has decayed to about 400 million curies.
Show OT 24

${ }_{3}^{7} \mathrm{Li}+{ }_{0}^{1}$ n yields

${ }_{1}^{3} \mathrm{H}+{ }_{0}^{1} \mathrm{n}+\alpha$

${ }_{5}^{10} \mathrm{~B}+{ }_{0}^{1} \mathrm{n}$ yields ${ }_{1}^{3} \mathrm{H}+2$

${ }_{1}^{2} \mathrm{H}+{ }_{0}^{1} \mathrm{n}$ yields ${ }_{1}^{3} \mathrm{H}$

A fission resulting in three fission products, one of which is tritium. This process has a $0.1 \%$ yield.

Show OT 25 
4. DOE Production of Tritium

DOE has produced tritium at the Savannah River Site with the use of a reactor. There are plans to use an accelerator to produce tritium at the site in the future. Tritium is commercially available from the DOE Complex at Mound and is also available from Canada and the European Community for non-weapons use.

B.

Uses of Tritium

1. Consumer Products

a. Gaseous tritium light sources - exit signs (1 Ci to tens of Ci's) - aviation landing aids (30-165 Ci per light)

(1 curie of tritium has a mass of approximately $0.1 \mathrm{mg}$ )

b. Luminizing industry: Self-luminous compounds for dials (several mCi's) and controls as well as other general industry uses.

2. Research - Tritium Labeling

Tracers for medical and laboratory research.

3. Department of Energy
a. Weapons development and applications
b. Fusion energy: As a fuel source

$$
\begin{gathered}
\mathrm{Li}+{ }_{0}^{1} \mathrm{n} \text { yield: } \\
{ }_{1}^{3} \mathrm{H}+\alpha
\end{gathered}
$$

Show OT 26

Instructor - emphasize that tritium has use in everyday activities.

Approximately $100,000 \mathrm{Ci}$ per runway

Show OT 27

Show OT 28 
III. MODES OF EXPOSURE AND BIOLOGICAL BEHAVIOR OF TRITIUM - How can I be exposed to tritium and what would it do to me?

\section{A. External Dose}

- Tritium is not an external hazard.

- Tritium is not a dose concem if it is located outside the body.

- Tritium betas will not penetrate a dosimeter.

- We are interested only in tritium inside the body.

B. Internal Dose

Tritium is an "internal" radiation hazard.

C. Modes of Exposure

Tritium can deliver a radiation dose if it gets inside our bodies. Modes of entry include:
- inhalation
- injection (cuts/wounds)
- absorption
- ingestion. 
Instructor's Notes

1. Inhalation

a. Tritium gas: is only slightly incorporated into the body when inhaled. Most tritium gas inhaled is subsequently exhaled. There are other chemical and physical processes to convert tritium gas to tritiated water.

b. Tritiated water: Nearly $100 \%$ of tritiated water inhaled is incorporated into body fluids/tissues.

c. Hazard: Exposure to tritiated water (HTO) is approximately, 10,000 to 25,000 times more hazardous than exposure to elemental tritium gas (HT).

2. Ingestion

Ingestion may occur by eating, drinking, chewing tobacco, and applying makeup where tritium contamination is present. Always wash hands thoroughly when leaving areas where there is a potential for contamination, and never eat, drink etc. where tritium contamination may be present.

Show OT 32

An extremely low percent (in the order of $0.005 \%$ ) of tritium gas inhaled is converted to tritiated water prior to being exhaled.

Tritiated water is more hazardous due to its ability to be almost $100 \%$ assimilated, increasing the dose received by the individual. 


\section{Absorption}

Absorption is also a hazard because an individual can receive, in certain situations, $1 / 3$ of their uptake from absorption through the skin if not properly using personal protective equipment.

a. Tritium gas: There is negligible skin absorption for tritium gas.

b. Tritiated water: Tritiated water can be absorbed through the skin. It has been observed that moisture on hands enhances absorption.

c. Solvents: Some solvents (organic) can also go through the skin.

Tritium will penetrate gloves, therefore gloves must be changed at a prescribed routine basis.

\section{Biological Behavior of Uptakes of Tritium}

Tritiated water in the body acts just like water.

1. Distribution

Tritiated water is rapidly and uniformly distributed throughout the entire body. The Committed Effective Dose Equivalent (CEDE) from an uptake of one curie of tritiated water is 63 rem.

\section{Show OT 33}

This is an important fact for maintenance workers to know.

Insert site specific information conceming gloves.

Show OT 34

Typical production reactor coolant has approximately 10 $\mathrm{Ci} / \mathrm{L}$ of tritium. So $100 \mathrm{ml}$ of such coolant has about $1 \mathrm{Ci}$ of tritium. If approximately $8 \mathrm{ml}$ was ingested a CEDE of 5 rem (the annual limit) would result. 


\section{Biological Half-life}

Half of the tritium is eliminated from the body in about 10 days. Through normal biological processes, it would take 70 days or more to eliminate $99 \%$ of the assimilated tritiated water.

\section{E. Medical Treatment}

The biological half-life can be shortened by increasing the water elimination in the body. Therefore, individuals who have uptakes of tritium are encouraged to drink liquids. Drinking copious amounts of liquids should not be done without a physician's guidance. Certain medical conditions may be affected by liquid intake.

IV.

\section{RADIOLOGICAL CONTROLS FOR TRITIUM - How can I} protect myself from exposures to tritium?

Tritium can be present in a variety of chemical forms. The form of tritium which gives the highest dose is tritiated water. If we are not sure what form the tritium is in, we assume it may be tritiated water.

The preferred hierarchy of control is as follows:

$\circ$

$\circ$

$\circ$ engineered

administrative

personal protective equipment
Show OT 35

Show OT 36

Insert site-specific policy.

Show OT 37

Show OT 38 


\section{A. Engineered Controls}

1.

Containment and Confinement

Containment or confinement is a series of physical barriers, minimizes exposure of workers.

Confinements such as glove boxes are almost always used when handling large quantities of tritium. However, hoods are acceptable for handling small quantities, such as in a laboratory.

2.

\section{Airflow}

Maintaining negative ventilation is essential for the safe operation of a tritium facility. Airflow should be from areas of LEAST to MOST contamination.

3.

\section{Local Exhaust Ventilation}

The primary advantage of local exhaust ventilation techniques is the removal of airborne tritium, regardless of its release rate or chemical or physical form. In addition, these techniques use relatively low volume rates compared to normal ventilation requirements.

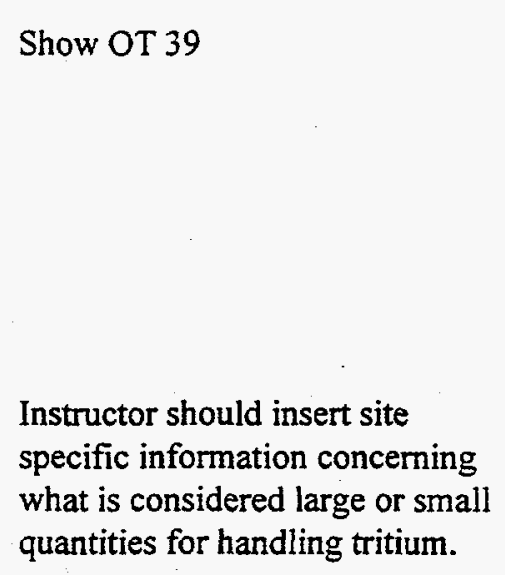

May need to use site specific terminology. 
4.

\section{Dilution Ventilation}

Dilution ventilation is the once-through flow technique of exchanging outside air for inside air for comfort and the reduction of airborne sources.

5.

\section{Storage}

Tritium can be stored in storage beds. Metal tritide and uranium hydride are the most common for these storage systems. Tritium is generally released by heating the metal tritide.

\section{B. Administrative Controls}

There are many administrative controls to reduce doses. The following are just a few that should apply to all sites:

$\begin{array}{ll}\circ & \text { limitation of access time } \\ \circ & \text { procedures/RWPs } \\ \text { postings }\end{array}$

For tritiated organic compounds, metal tritide aerosols, surfaces contaminated with HT \& HTO, the Radiological Control Manual recommends posting contamination areas based on contamination values of 10,000 $\mathrm{dpm} / 100 \mathrm{~cm}^{2}$.

C. Personal Protective Equipment

1. Air Supplied Respirators

In general, only air-supplied respirators are effective in preventing inhalation of airborne tritium.
Tritium is considered valuable and needs to be recovered. (i.e. not to send up the stack)

\section{Show OT 41}

Ask students to name other ways to prevent or reduce doses. Insert site specific posting requirements.

Show OT 42 
2. Air Supplied Suits

Because of the absorption through the skin associated with the use of respirators and other breathing apparatus, air-supplied plastic suits that completely enclose the body are widely used by facilities that handle large quantities of tritium.

3. Protective Clothing

Protective clothing (PC), or anticontamination clothing (anti-Cs), is used to reduce the uptake of and to prevent the spread of contamination from contaminated to clean areas.

In many operations, the hands and forearms of workers are vulnerable to contact with tritium surface contamination. The proper selection of gloves and glove materials is important. In many instances a plastic/water proof suit is required.

V. MONITORING FOR TRITIUM - How do I know if tritium is present?

Discuss site specific requirements

Insert site specific information concerning selection of PCS. Even with a plastic or water-proof PC suit, a stay time may be assigned due to the ability of tritium to permeate through plastic.

Show OT 43 


\section{A. Personnel Monitoring}

1.

\section{External Dose}

Dosimeters are not typically used to monitor for radiological doses resulting from tritium. The weak energy beta radiation will not penetrate the dosimeter. One exception is that finger rings may be worn by individuals handling large quantities of tritium. In this application it is possible to receive and monitor for external dose to the hands from low energy $x$ rays (bremsstrahlung).

2.

\section{Internal Dose}

The best method used to determine if an individual has an uptake of tritium is by bioassay (urinalysis). Routine urine samples, collected at some predetermined frequency and counted for the tritium content, provide a very sensitive measurement of tritium in the body. This is especially true if the time of uptake is known.

3.

\section{Routine Versus Non-Routine Bioassay} Monitoring

a. Routine: Routine urinalysis is conducted on a preset periodic basis.

b. Non-routine or Special: Nonroutine bioassay is done whenever a potential exposure to tritium is suspected.

(insert site specific bioassay procedures)
Show OT 44

Insert site specific requirements

Show OT 45

1. Prospective: Prospective bioassay is routine bioassay. 


\section{B. Workplace Monitoring}

Air monitoring and surface contamination surveys are used to verify that loose contamination is not present. They provide an early indication of potential problems.

1.

$$
\text { Airborne Tritium Monitoring }
$$

Airborne tritium monitoring is used for:
a. Prompt detection of airborne contamination for worker protection;
b. Determination of the status of processes; and
c. Identification of any leaks in primary or secondary containments or confinements.

2. Contamination Surveys

Despite contamination control measures, tritium is easily spread.

All workplaces shall be surveyed for contamination levels on a regularly scheduled basis. The frequency of such surveys will depend on the potential for dispersement of the tritium-contaminated material in the area and the quantity of tritium in the area. During routine surveys, all work enclosures, work surfaces, floors, equipment, etc., within the workplace should be surveyed.

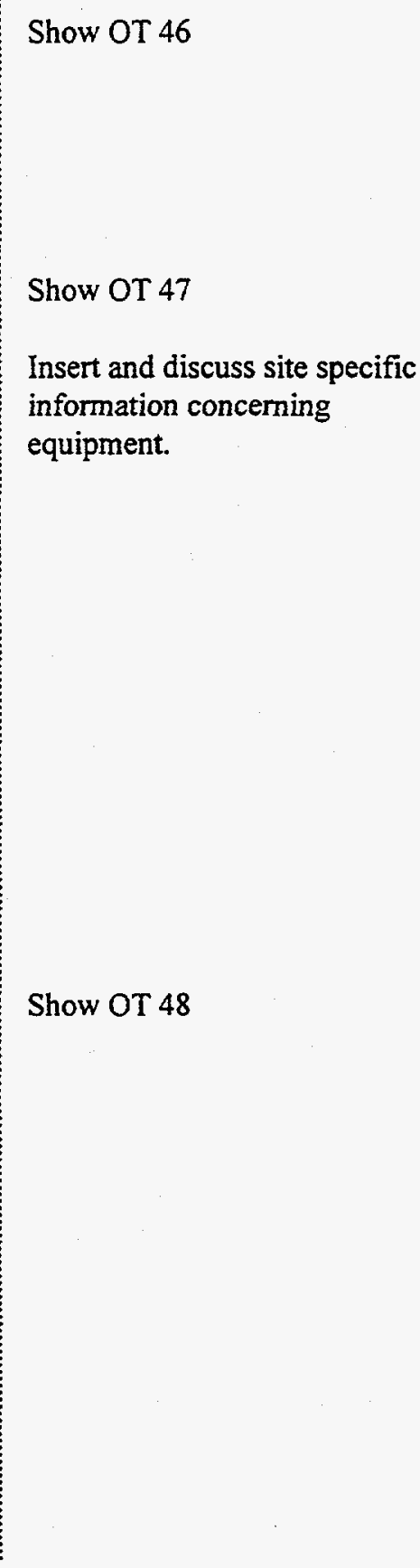


Tritium is difficult to measure directly because the low-energy beta is readily absorbed in air and the window of the detector. Normal frisking methods (use of pancake probe) will not detect tritiated water.

Surfaces are normally wiped (smeared) with a small paper, either dry or moistened, which will pick up loose tritiated material. The wipe is then normally counted by liquid scintillation techniques.

VI. TRITIUM WASTE MINIMIZATION AND HANDLINGWhy is it important and how do you minimize tritium waste?

(insert site specific controls)

Methods below are given as a reference only.

\section{A. Minimizing Tritium-Contaminated Waste}

1. Avoid generating wastes by not bringing unnecessary material into the controlled area.

2. Protect large pieces of equipment from contamination by wrapping them when bringing them into the area.

3. Whenever possible, avoid use of porous materials or those known to be highly permeable to tritium.

4. Designate an area to store contaminated tools for reuse.

Show OT 49

Show OT 50

This material maybe covered in Radiological Worker I or II training. Emphasis should be on site specific information. It is not necessary to repeat information. 
5. Plan work so that, whenever possible, construction and clean maintenance can be done in a clean area.

6. When transporting items contaminated with tritium, adequate contamination control such as wrapping in plastic or placing in sealed containers should be considered.

B. Minimizing Mixed Waste

(insert site specific controls)

Methods below are given as a reference only.

1. Use non-hazardous cleaning materials for decontamination whenever possible.

2. Segregate radioactive-only from hazardousonly at the source.

3. Explore the use of other materials which are non-hazardous for use in radiological areas to prevent the generation of mixed waste.

\section{RESPONSE TO ABNORMAL CONDITIONS IN THE} TRITIUM FACILITY- What should I do in an emergency involving tritium?

To properly deal with unexpected adverse situations occurring in a tritium facility, a well-thought-out response program and personnel trained to execute the response should be in place.

Insert site specific information concerning procedures for transporting tritium contaminated items.
Show OT 51

This material may be covered in Radiological Worker I or II training. Emphasis should be on site specific information. It is not necessary to repeat information. 
A. Abnormal Conditions

Abnormal conditions in a tritium facility could include:

- fire/explosion

- natural disaster

- tritium releases

- other hazards

Personnel found contaminated with tritiated water should follow site specific decontamination procedures which would typically include showering with cold water and the use of mild detergents.

B. Facility Alarms

(insert site specific alarms and emergency response procedures)

C. Facility Emergency Responses

(insert site specific alarms and emergency response procedures)

VIII. LESSONS LEARNED

(insert site specific lessons learned)

IX. SUMMARY AND REVIEW

Insert site specific emergency plan and hazards assessment documents.

Show OT 52

Show OT 53 
DOE-HDBK-1105-96

This page intentionally left blank. 
(Part 3 of 5)

\title{
Radiological Training for Tritium Facilities
}

\author{
Student's Guide
}

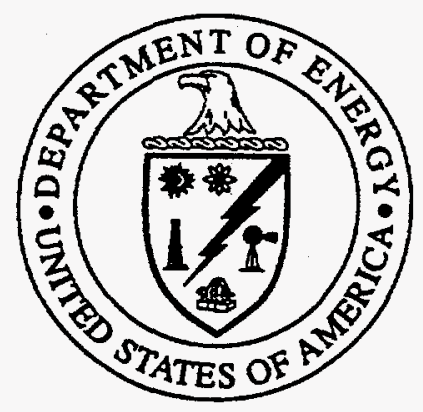

Coordinated and Conducted for

Office of Environment, Safety \& Health U.S. Department of Energy 


\section{Course Developers}

Richard Carlson

Los Alamos National Laboratory

Kevin Connolly

Westinghouse Savannah River Company

Jack Foster

Program Management, Inc.

Gary Mansfield

Lawrence Livermore National Laboratory

Burk D. Marler

EG\&G Idaho, Inc.

Peter O'Connell

U.S. Department of Energy

Doug Riddle

EG\& G Idaho, Inc.

Doug Serpa

Lawrence Livermore National Laboratory

Paula Trinoskey

Lawrence Livermore National Laboratory

\section{Course Reviewers}

John Hehmeyer EG\&G Mound Applied Technologies

James Patterson DOE Chicago Operations Office

Tritium Focus Group U.S. Department of Energy

Technical Standard

Managers

U.S. Department of Energy

Janet Westbrook

Oak Ridge National Laboratory 


\section{COURSE GOAL:}

At the end of this course, the participant should be able to demonstrate a basic understanding of the characteristics of tritium and precautions for working in a tritium facility.

The participant will be able to SELECT the correct response from a group of responses which verifies their ability to:

EO1 IDENTIFY the following properties of tritium:

- physical/chemical

- radioactive.

EO2 IDENTIFY sources of tritium:

- natural

- by-product

- weapons.

EO3 IDENTIFY uses of tritium:

- weapons applications

- research

- fusion energy production

- industrial/commercial.

EO4 IDENTIFY modes of tritium exposure:
- inhalation
0 ingestion
- absorption
- injection/wound.

EO5 IDENTIFY the biological effects of tritium:

- biological half-life

- dose.

EO6 IDENTIFY the radiological control methods for tritium:
- engineered
- administrative
- surface contamination limits
- personnel protective equipment
- application of ALARA principles.

EO7 IDENTIFY the monitoring and surveying techniques for tritium:
- air sampling for worker safety
- contamination surveys
- bioassay. 
E08 IDENTIFY tritium waste minimization and handling techniques. (Site Specific)

E09 IDENTIFY alarms and proper response to abnormal conditions in the tritium facility. (Site Specific)

\section{COURSE CONTENT:}

1. Properties of Tritium

2. Sources and Uses of Tritium

3. Modes of Exposure and Biological Behavior of Tritium

4. Radiological Controls for Tritium

5. Monitoring for Tritium

6. Tritium Waste Minimization and Handling

7. Response to Abnormal Conditions in the Tritium Facility

8. Lessons Learned

9. Summary and Review 


\subsection{PROPERTIES OF TRITIUM}

\section{What is tritium?}

Tritium is a radioactive isotope of hydrogen $(\mathrm{H})$. Hydrogen is the lightest and most abundant element in the universe. Hydrogen has only one proton in its nucleus. Tritium has, in addition to the single proton, two neutrons in its nucleus. This makes it three times heavier than the most common form of hydrogen, which contains only a proton and no neutrons in the nucleus.

glectron

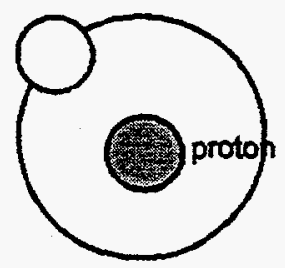

Atoms of a specific element can exist in several forms differing by the number of neutrons in the nucleus. These are called isotopes of an element. An analogy is that ice-cream can come in 31 flavors but it is still ice cream. Most elements in nature have several different isotopes. (They have the same number of protons, but a different number of neutrons). Hydrogen has 3 common isotopes. The simplest is the most abundant and consists of one proton and no neutrons. This isotope is referred to as PROTIUM. Its natural abundance is $99.985 \%$. If one neutron is added, we refer to the isotope as DEUTERIUM. Its natural abundance is $0.015 \%$. Deuterium is a stable isotope of hydrogen. If we add another neutron ( 2 neutrons total) we have TRITIUM which is unstable (radioactive) as it has too many neutrons.

$\mathbf{H}$

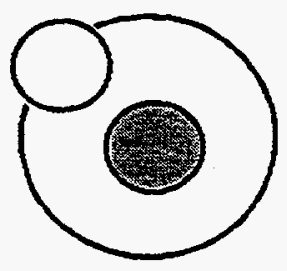

protium
D

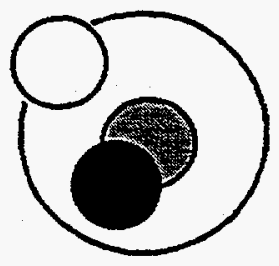

deuterium
$\mathbf{T}$

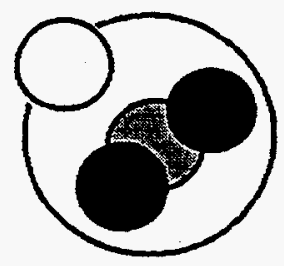

tritium 
The atomic weights, symbols, and abundance of the three best known isotopes of hydrogen are given below. Unless otherwise specified in this training, the term "hydrogen" means the element and includes protium, deuterium, and tritium.

- Protium (H-1 or just plain $\mathrm{H})$

- Deuterium $=$ hydrogen +1 neutron $(\mathrm{H}-2$ or $\mathrm{D})$

- Tritium $=$ hydrogen +2 neutrons $(\mathrm{H}-3$ or $\mathrm{T})$

Tritium is designated as $\mathrm{T}, \mathrm{H}-3$, or ${ }_{1}^{3} \mathrm{H}$.

Tritium gas interacts in some way with most materials. It may interact:

- chemically - hydrogen is a strong reducing agent

- physically - hydrogen easily penetrates substances

- radiologically - tritium is radioactive

\subsection{Chemical/Physical Properties of Tritium}

Tritium "behaves" chemically just like hydrogen because it has one proton and one electron like ordinary hydrogen. Tritium gas, like hydrogen gas, is flammable and can be explosive.

Tritium atoms can be exchanged with normal hydrogen atoms. Examples:

- Elemental hydrogen (tritium gas, $\mathrm{HT}, \mathrm{DT}$, or $\mathrm{T}_{2}$ )

- Tritiated water (tritium oxide, HTO, DTO, or $\mathrm{T}_{2} \mathrm{O}$ )

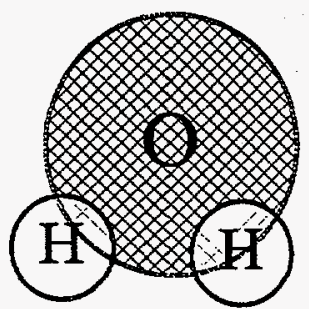

normal water

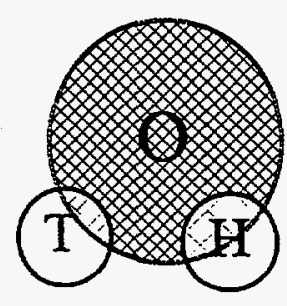

tritiated water 
Tritium may also exchange with hydrogen in organic and other materials (oils, metals, plastics, etc.)

Because tritium gas is lighter than air, it diffuses rapidly in air. In addition, tritium has a extremely small atomic radius, which results in a pronounced ability to diffuse into or through other materials. That is it travels through them by way of spaces or interstices in them. No known material is entirely impermeable to elemental tritium.

Tritiated water also has impressive abilities to penetrate seemingly impenetrable materials. In addition, the general reactivity of hydrogen causes a number of materials to have compatibility problems involving tritium containment. In organic materials, such as pump oils, plastics and O-rings, tritium perfuses and degrades the materials. This can cause a loss of mechanical properties within months or years.

The production of helium gas upon decay causes additional pressure problems with containment. Contamination control is thus very complicated for tritium. Surfaces of objects which appear to be clean following decontamination can become recontaminated when subsurface tritium diffuses back to the surface.

\subsection{Radiological Properties of Tritium}

The tritium nucleus consists of 1 proton and 2 neutrons. This is too many neutrons for stability (the most stable configuration for low atomic number nuclides is an equal balance of neutrons and protons) One of the excess neutrons in tritium ejects an electron (beta particle), transforming into a proton. The nucleus then contains 2 protons and 1 neutron, thus becoming a helium nucleus.

A beta particle is identical to an electron and its mass is thus equal to that of an electron. The tritium beta particles have a very low penetrating power and are shielded by skin.

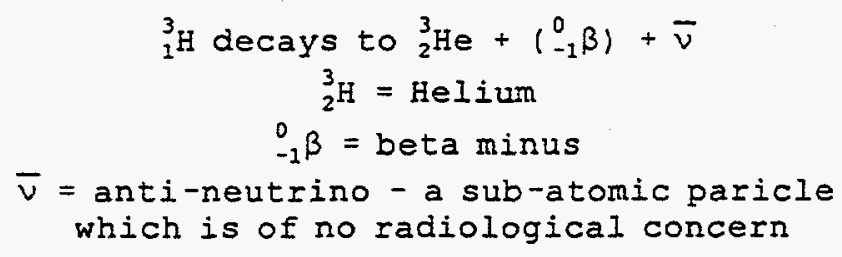

The radioactive half-life of tritium is 12.3 years.

\subsubsection{Beta Decay}

Beta Energy: The beta particle emitted in the decay of tritium is of very low energy (weak): 
$\circ \max$ energy $=18.6 \mathrm{keV}$

- ave. energy $=5.7 \mathrm{keV}$

Beta Range -Tritium is not an external radiation hazard (see section 3.0 for biological behavior). The beta particle has such a low energy that it:

- travels less than $1 / 4$ inch in air

- cannot penetrate through the dead layer of the skin

- cannot penetrate clothing or gloves (although the tritium atom itself may)

X-Ray Production: Tritium betas can produce low energy $\mathrm{x}$ rays. These $\mathrm{x}$-rays are produced when the beta particle is decelerated (brought to a stop) in material. Because the beta particle has such a low energy to begin with, the $\mathrm{x}$ rays are also low energy. These $\mathrm{x}$-rays are not very penetrating and are not normally considered a hazard. These $\mathrm{x}$-rays also cannot be detected with typical portable instrumentation.

\subsubsection{Fusion}

Fusion is the process of light nuclei joining together to form heavier nuclei. This produces an enormous release of energy. The energy source in most stars, including our sun, is nuclear fusion of hydrogen isotopes.

Man has learned to use fusion reactions to produce this tremendous energy. Tritium and deuterium will fuse, under the conditions of extreme heat and pressure, with the release of large amounts of energy and neutrons. This is the basis of the hydrogen bomb.

Facilities handling large quantities (insert site specific values) of tritium are subject to stringent safeguarding and material accounting requirements. Site specific information regarding tritium will often be classified.

Controlled nuclear fusion of hydrogen isotopes is the goal of several ongoing research efforts. The two leading candidates for an eventual fusion reactor design use different methods to confine and energize the materials required for controlled fusion. Inertial confinement involves compressing a pellet of tritium-deuterium gas with lasers. Magnetic confinement is the approach used in the Tokamak reactor design, where confinement and energizing are accomplished through the use of electromagnetic fields and currents. 


\subsection{SOURCES AND USES OF TRITIUM}

How is tritium produced and what is it used for?

\subsection{Source of Tritium}

There are three primary sources of tritium in our environment. Tritium is present in our environment from both man-made and natural sources as discussed below. Natural tritium is indistinguishable from man-made tritium.

\subsubsection{Natural Sources}

Tritium occurs naturally in the environment. It is formed by the reactions between cosmic rays and the nitrogen in the upper atmosphere. One reaction that produces tritium is listed below:

The nitrogen nucleus, which make up $80 \%$ of the earths atmosphere, captures a neutron and decays to tritium and carbon.

$$
{ }_{7}^{14} \mathrm{~N}+{ }_{0}^{1} \mathrm{n} \text { yields }{ }_{1}^{3} \mathrm{H}+{ }_{6}^{12} \mathrm{C}
$$

Cosmic rays generate approximately 4 million curies (approximately $.41 \mathrm{kgs}$.) of tritium per year. With tritium being continually produced and at the same time decaying, the natural tritium in our environment is about 70 million curies.

\subsubsection{By-Products of Reactors}

Tritium is produced as a by-product in nuclear reactors as follows:

- Boron captures a neutron and decays with tritium as a product.

$$
{ }_{5}^{10} B+\text { neutron }\left({ }_{0}^{1} n\right) \text { yields }{ }_{1}^{3} \mathrm{H}+2 \text { alphas }\left({ }_{2}^{4} \mathrm{He}\right)
$$

- Lithium-7 captures a neutron and decays with tritium as a product.

$$
{ }_{3}^{7} \mathrm{Li}+\text { neutron }\left({ }_{0}^{1} \mathrm{n}\right) \text { yields }{ }_{1}^{3} \mathrm{H}+\text { alpha }\left({ }_{2}^{4} \mathrm{He}\right)+\text { neutron }\left({ }_{0}^{1} \mathrm{n}\right)
$$

- Activation of deuterium in water.

$$
{ }_{1}^{2} \mathrm{H}+\text { neutron }\left({ }_{0}^{1} \mathrm{n}\right) \text { yields }{ }_{1}^{3} \mathrm{H}
$$


- Ternary Fission - A fission event that results in three fission products, one of which is tritium. This occurrence typically has a $0.1 \%$ yield.

Releases of tritium from power reactors around the world is less than one-half that naturally formed (approximately 1 to 2 million curies a year).

\subsubsection{Tritium From Weapons Testing}

The amount of tritium in the world from weapons testing has been steadily declining since the 1970's when atmospheric testing was curtailed.

Atmospheric testing from 1945-1975 produced about 8 billion curies. This has decayed to about 400 million curies.

\subsection{Production of Tritium}

Many potential and actual sources of tritium production exist in the U.S., UK, France, Russia, and other countries. They include light-water reactors, heavy-water reactors, fuel reprocessing plants, and production reactors.

DOE has produced tritium at the Savannah River Site with the use of a reactor. There are plans to produce tritium the site using an accelerator Tritium is commercially available from the DOE Complex at Mound and is also available from Canada and the European Community for non-weapons use. Tritium is produced in a reactor when lithium captures a neutron and decays by emission of an alpha particle.

$$
{ }_{3}^{6} \mathrm{Li}+\text { neutron }\left({ }_{0}^{1} \mathrm{n}\right) \text { yields }{ }_{1}^{3} \mathrm{H}+\operatorname{alpha}\left({ }_{2}^{4} \mathrm{He}\right)
$$

\subsection{Uses for Tritium}

\subsubsection{Consumer Products}

Tritium has replaced radium as an energy source for illuminating devices. The beta in tritium decay provides energy to a chemical substance that glows, thus illuminating the device. Tritium does not present an external hazard because the beta does not penetrate the device.

Gaseous tritium light sources (note: 1 curie of tritium has a mass of approximately $0.1 \mathrm{mg}$ )

- exit signs (1 to tens of Curies)

- aviation landing aids (30 to 160 curies per light $-100,000$ curies per runway) 
Luminizing industry self-luminous compounds for dials and controls (milli-curies per dial or control) as well as other general industrial uses.

\subsubsection{Tritium Labeling}

Tritium is frequently used in medical and laboratory research. Organic compounds are "labeled" or "tagged" with tritium by replacement of a hydrogen atom with a tritium atom. As tritium is easily detected and measured with a liquid scintillation counter, analysis can determine the pathways and metabolism of various organic compounds.

\subsubsection{Department of Energy}

Weapons development and applications Tritium is used in the weapons program.

Fusion energy Tritium is sometimes used as a fuel source in fusion research. 


\subsection{MODES OF EXPOSURE AND BIOLOGICAL BEHAVIOR OF TRITIUM} How can I be exposed to tritium and what would it do to me?

\subsection{External Dose}

Since the tritium beta lacks sufficient energy to penetrate the dead cell layer in skin, it is of little consequence as an external hazard.

\subsection{Internal Dose}

Tritium is an internal radiation hazard. The beta particle cannot penetrate the skin. But if the tritium atom has been taken into the body then the beta can interact directly with living tissue.

Modes of entry include the following:

Inhalation is the most frequent mode of uptake of tritium.

- Tritium gas is only slightly incorporated into the body when inhaled. Only $0.1 \%$ of tritium gas inhaled is converted to tritiated water prior to being exhaled. There are other chemical and physical processes which convert tritium gas to tritiated water.

- Tritiated water Nearly $100 \%$ of tritiated water inhaled is incorporated into body fluids/tissues. The water vapor crosses the lung membrane and is distributed by the blood.

- Hazard: Exposures to tritiated water is approximately 10,000 to 25,000 times more hazardous than exposures to tritium gas because it is incorporated and distributed to all body tissues.

Ingestion may occur by eating, drinking, chewing tobacco or gum, and applying makeup where tritium contamination is present. Always wash hands thoroughly upon exiting areas where there is a potential for contamination, and never eat, drink, etc. where tritium contamination may be present.

Absorption is also a hazard because an individual can receive $1 / 3$ of their uptake from absorption through the skin if not wearing adequate Personal Protective Equipment (PPE).

- Tritium gas: There is negligible skin absorption for tritium gas.

- Tritiated water: Tritiated water is absorbed through the skin. It has been observed that moisture on the hands enhances absorption.

- Other compounds: Some solvents (organic) can also go through the skin. This is important for workers to know. 
- Distribution: Tritiated water will be uniformly distributed in all biological fluids within one to two hours.

Because tritiated water will penetrate even the best available gloves, gloves must be changed at a prescribed routine basis.

\subsection{Behavior of Tritium in the Body}

Tritium when incorporated into the body as tritiated water acts chemically and physically like water in the body. Tritium is rapidly and uniformly distributed throughout the entire body. Half of the tritium that is taken into the body is eliminated from the body in about 10 days by the normal elimination of water. This is referred to as the biological half-life. Through normal biological process, it would take 70 days or more to eliminate $99 \%$ of the assimilated tritiated water.

\subsubsection{Medical Treatment}

Tritium's biological half-life of approximately 10 days can be shortened by increasing the water turnover in the body. Therefore, individuals who have uptakes of tritium are encouraged to increase their fluid intake. This will speedup the elimination of tritium. Drinking copious amounts of liquid should not be done without a physician's guidance. Certain medical conditions may be affected by liquid intake. 


\subsection{RADIOLOGICAL CONTROLS FOR TRITIUM} How can I protect myself from exposures to tritium?

Forms of Tritium - Tritium can be present in a variety of chemical forms.

- The form of tritium which gives the highest dose is tritiated water. Therefore, if we are not sure what form the tritium is in, we assume it may be tritiated water.

- An uptake of one curie will result in a dose of 63 rem to the whole body.

\subsection{Hierarchy of Controls}

The preferred hierarchy of controls are as follows:

- engineered

- administrative

- personal protective equipment

\subsection{Engineered Controls}

Several important engineered controls are available for tritium protection. The most commonly used methods to protect personnel against potential inhalation include containment and proper air flow (differential room pressure zones), dilution ventilation, systems to remove tritium from room air, and local exhaust ventilation.

\subsubsection{Containment/Confinement}

Confinement is a series of physical barriers, including a ventilation system, which control and containment hazardous/radioactive materials.

Glove boxes are almost always used when handling large quantities of tritium. However, hoods are acceptable for handling small quantities, such as in a laboratory.

Primary Containment: Process piping makes up the bulk of most primary containment systems. These systems usually consist of tanks and other containers for storing tritium and a means of pumping tritium through the system. Primary containment is the innermost barrier.

Glove boxes often form a primary or secondary containment. Glove boxes have ports with long plastic sleeves attached, that allow material to be "bagged-in" or "bagged-out" from the glove box without breaching the containment. The port gloves can also be replaced without a breach by placing the new glove inside the old one at the port. The old glove is then dislodged to the inside of the glove box and bagged as waste. 
Secondary Containment: The secondary containment system encloses the primary system and is intended to provide containment if the primary fails.

Tertiary Containment: Rooms often serve as tertiary containment, although in lower level operations the room may be the secondary and the building the tertiary.

\subsubsection{Storage}

Tritium is commonly stored in two forms: as a gas in tanks, and as a solid metal hydride (tritride). Other forms, such as tritiated water, are less commonly used because of increased radiological hazards. Tritium can be stored in storage beds as a metal tritide with uranium hydride. This combination is the most common type used. The tritium is released by heating the metal tritide.

\subsubsection{Airflow}

Maintaining negative ventilation is essential for the safe operation of a tritium facility. Airflow should be from areas of LEAST tọ MOST contamination.

Air balance is maintained by use of damper controls, air locks, controlling the position of inside doors, and backup safety systems. Ventilation control doors should not be blocked open, since ventilation balance could be lost.

Local Exhaust Ventilation: The primary advantage of local exhaust ventilation techniques is the removal of airborne tritium, regardless of its release rate or chemical or physical form. In addition, these techniques use relatively low volume rates compared to normal ventilation requirements.

Dilution ventilation: is the once-through flow technique of exchanging outside air for inside air for comfort and reduction of airborne sources.

\subsection{Administrative Controls}

There are many administrative controls to reduce doses. The following are just a few that should apply to all sites:

- procedures/RWPs

- postings - For tritiated organic compounds, metal tritride aerosols, surfaces contaminated with HT \& HTO, the Radiological Control Manual recommends posting contamination areas based on contamination values of $10,000 \mathrm{dpm} / 100 \mathrm{~cm}^{2}$.

\subsection{Personal Protective Equipment}


Personal protective equipment is intended to limit internal dose and the spread of contamination; it includes protective clothing and respiratory protection. Because tritium and HTO can diffuse through materials, personal protective equipment will be effective only until breakthrough of tritium occurs. The effectiveness of the equipment is determined at the site by the Radiological Control Organization. Since tritium can be easily absorbed through the skin or by inhalation, personal protective equipment must protect against both exposure routes.

\subsubsection{Respiratory Protection}

Respirators which rely on filtration (cartridges) for protection cannot be used to protect against tritium or tritiated water. When respiratory protection is necessary, individuals need to be provided with supplied air from a clean outside air supply. In addition, the positive air pressure can help keep tritium out of a full encapsulating suit.

\subsubsection{Protective Clothing}

Because tritium easily penetrates most material, special precautions are used with personal protective equipment. For low levels (as specified at each site) of tritium contamination, wearing gloves and lab coats is considered good practice to prevent transfer of material from surfaces to skin and personnel clothing. Larger quantities (as specified at each site) of tritium are handled in enclosures such as glove boxes. Individuals who handle large quantities of tritium and tritiated water in glove boxes must change their gloves on a frequent basis to prevent tritium breakthrough and personal contamination. Specific requirements for the periodicity of changing gloves can be found in site specific documents. 


\subsection{MONITORING FOR TRITIUM How do I know if tritium is present?}

\subsection{Personnel Monitoring}

\subsubsection{External Dose}

Dosimeters are not typically used to monitor for radiological doses resulting from tritium. This is due to the weak energy and therefore low penetrating power of the tritium beta. This beta cannot penetrate through the covering on a dosimeter. One exception is the use of finger rings for individuals handling large quantities of tritium. These finger rings are used in this special application to record doses to the hands from low energy $\mathrm{x}$-rays (bremsstrahlung).

\subsubsection{Internal Dose}

The best method used to determine if an individual has taken tritium into their body is by bioassay (urinalysis). Routine urine samples are collected at some predetermined frequency (weekly or monthly) and counted for the tritium content. This provides a very sensitive measurement of tritium in the body, especially if the time of uptake is known.

\section{Routine Versus Non-Routine Bioassay Monitoring:}

- Routine: Routine urinalysis is conducted on a preset periodic basis.

- Non-routine or Special: Non-routine bioassay is done whenever a potential exposure to tritium is suspected.

\subsection{Workplace Monitoring}

Air monitoring and surface contamination surveys are used to verify that loose contamination is not present, and provide an early indication of potential problems.

For monitoring, the low energy and short range of the beta particle has the consequence that the tritium must be taken right inside the detector. The instrument must be specifically designed to measure tritium. Other radiation measuring instruments will not do; they simply will not detect the tritium. (Exception: very high tritium concentrations can sometimes be detected with other instruments by the bremsstrahlung radiation given off when the beta particle is slowed and stopped.) Tritium is difficult to measure directly because the low-energy beta is readily absorbed in air and the window of the detector. Normal frisking methods (use of pancake probe) will not detect tritiated water.

Several types of instruments are used for monitoring tritium in air, on surfaces, and for counting tritium samples. Tritium is difficult to measure directly because of the low-energy beta which is readily absorbed in air and on the window of the detector. Special instruments allow the tritium to enter or "be taken into" the detector and be counted. Another standard technique is to take a swipe and place it directly into a 
counting medium called a liquid scintillation fluid or "cocktail." As the beta interacts with the liquid, light is given off. This light is measured and the tritium activity on the swipe can be determined.

Airborne radioactivity monitoring along with other types of monitoring should be performed for detection of airborne contamination for worker protection.

Contamination surveys - All workplaces should be surveyed for contamination on a regularly scheduled basis. The frequency of such surveys will depend on the potential for dispersement of the radioactive material in the area. During routine surveys, all work enclosures, work surfaces, floors, equipment, etc., within the workplace should be surveyed.

Surfaces are normally wiped (smeared) with a small paper (either dry or moistened), which will pick up loose tritiated material. The wipe is then normally counted by liquid scintillation techniques which puts the tritium in direct contact with the counting medium. 


\subsection{TRITIUM WASTE MINIMIZATION AND HANDLING Why is it important and how do you minimize radioactive waste?}

(Insert site specific information)

\subsection{Minimizing Tritium-Contaminated Waste}

Practices which can be used to minimize the quantity of waste are:

- Avoid generating wastes by not bringing unnecessary material into the controlled area.

- Protect large pieces of equipment from contamination by wrapping them in plastic or other impervious material when bringing them into the area.

- Whenever possible, avoid use of porous materials and those known to be highly permeable to tritium.

- Designate an area to store contaminated tools for reuse.

- Plan work so that, whenever possible, construction and maintenance can be done in a clean area.

- Allow tritiated water to evaporate.

\subsection{Minimizing Mixed Waste}

Ways to avoid generating mixed waste:

- Use non-hazardous cleaning materials for decontamination whenever possible.

- Segregate radioactive-only waste from hazardous-only waste at the source.

- Explore the use of other materials which are non-hazardous for use in radiological areas to prevent the generation of mixed waste. 


\subsection{EMERGENCY RESPONSE FOR TRITIUM INCIDENTS What should $I$ do in an emergency involving tritium?}

(Insert site specific information)

Personnel found contaminated with tritiated water should follow site specific decontamination procedures which would typically include showering with cold water and the use of mild detergents. To properly deal with unexpected adverse situations occurring in a tritium facility, a well-thought-out response program and personnel trained to execute the response should be in place.

The philosophy that should apply in an emergency situation will reflect these goals:

- Protect personnel from further injury and hazards;

- Avoid actions that might create greater hazards;

- Bring the emergency under control;

- Prevent property damage;

- Limit the extent of any contamination;

- Limit movement or go to a designated location until assistance arrives, when contamination is suspected; and

- Above all, don't become part of the problem.

8.0 LESSONS LEARNED Insert site specific lessons learned.

\subsection{SUMMARY}

\section{What is Tritium?}

Tritium is a radioactive isotope of hydrogen. Tritium has a radioactive half-life of 12.3 years, and decays by emitting a weak beta particle. Tritium "behaves" just like hydrogen - it is usually in the form of a gas, it is lighter than air, it permeates through most materials, and it exchanges very readily with hydrogen atoms in organic materials (oils, plastics, etc.) Another common form of tritium is tritiated water or water vapor which is a water molecule where one or more atoms of hydrogen have been exchanged for tritium.

\section{What Are the Radiological Hazards of Tritium?}

Tritium is not an "external" radiation hazard. The beta particle emitted by tritium has a maximum energy 
of only $18.6 \mathrm{keV}$ - it will only travel about $1 / 4$ inch through the air, and cannot penetrate clothing, gloves or through the dead layer of the skin. Therefore, tritium is not a radiation hazard if it remains outside of your body.

Tritium can deliver a radiation dose if it gets inside a person's body - either by inhalation ingestion, or absorption through the skin. As a gas or as water vapor, tritium can be inhaled into the body. Tritium gas is not absorbed very readily by the body, and is therefore far less hazardous than tritiated water. As tritiated water or water vapor, tritium is much more likely to be inadvertently taken into the body. Therefore, tritiated water is much more hazardous that the elemental forms of tritium.

Airborne tritium can result from leaks in gas-handling systems or enclosures, upsets in ventilation systems or from high levels of surface contamination.

Tritium contamination on surfaces can be absorbed thorough the skin, or can be inadvertently transferred from hand to mouth. Tritium contamination may be present on surfaces (hoods, glove boxes, floors). This contamination can be inadvertently spread by moving contaminated items from room to room, by touching contaminated surfaces, and by walking on contaminated floors.

\section{Radiological Safety in the Tritium Facility}

Tritium is safely controlled by using containment, ventilation control, contamination control and monitoring. Most of the tritium in the facility is contained within vessels or gas-handling systems. The facility ventilation system is designed to sweep air from the clean areas into potentially contaminated areas. The spread of contamination is controlled by using good work practices in conjunction with appropriate protective clothing.

There may be industrial, chemical, toxic and fire hazards present in the facility. Be aware of these other hazards. All waste generated in the facility must be appropriately disposed.

\section{Facility Alarms and Emergency Response Actions}

Insert site specific information

\section{Do's and Don'ts}

Do not eat, drink, use tobacco products, or put on cosmetics.

Do not remove any tools or equipment without monitoring.

Do not leave doors open that may disrupt proper ventilation control.

Do pay attention to postings. 
Do assume that surfaces may be contaminated. Do not touch surfaces unnecessarily.

Do check with Radiological Control if you have any questions.

\section{Review of course objectives}

EO1 IDENTIFY the following properties of tritium:

- physical/chemical

- radioactive.

EO2 IDENTIFY sources of tritium:

- natural

- by-product

$\circ$ weapons.

EO3 IDENTIFY uses of tritium:

- weapons applications

- research

- fusion energy production

- industrial/commercial.

EO4 IDENTIFY modes of tritium exposure:

- inhalation

$\circ$ ingestion

- absorption

- injection/wound.

EO5 IDENTIFY the biological effects of tritium:

- biological half-life

- dose.

EO6 IDENTIFY the radiological control methods for tritium:

- engineered

- administrative

- surface contamination limits

- personnel protective equipment

- application of ALARA principles.

EO7 IDENTIFY the monitoring and surveying techniques for tritium:

- air sampling for worker safety 
- contamination surveys

$\circ$ bioassay.

E08 IDENTIFY tritium waste minimization and handling techniques. (Site Specific)

E09 IDENTIFY alarms and proper response to abnormal conditions in the tritium facility. (Site Specific) 


\section{Bibliography}

Anderson, H.F., et al., Draft Health Physics Manual of Good Practices for Tritium Facilities, EG\&G Mound Applied Technologies, Miamisburg, OH, December 1991.

Department of Energy, Handbook Primer on Tritium Safe Handling Practices, DOE-HDBK-1079-94, April 1994.

Fuller, T.P., Easterly, C.E.; Tritium Protective Clothing; Oak Ridge National Laboratory, ORNL/TM6671; June 1979.

Jacobs, D.G.; Source of Tritium and its behavior upon release to the environment; AEC Critical Review Series, U.S. Atomic Energy commission/Division of Technical information, 1968.

LLNL, Draft Technical Guide Control of Tritium Exposure at DOE Sites, December 1993.

McElroy, R.G.C. et. al.; Chalk River Nuclear Laboratories Section, Tritium Safe Handling Course; Atomic Energy of Canada Limited; Scientific Document Distribution Office (SDDO), Atomic Energy of Canada Limited, Research Company Chalk River, Ontario, KOJ 1JO; September 1989.

NCRP Report No. 47, Tritium Measurement Techniques, National Council on Radiation Protection and Measurements, 7910 Woodmont Avenue, Washington, D. C.; May 1976.

NCRP Report No. 62, Tritium In the Environment, National Council on Radiation Protection and Measurements, 7910 Woodmont Avenue, Washington, D. C.; Second printing 1989. 
(Part 4 of 5)

\title{
Radiological Training for Tritium Facilities
}

\author{
Overhead Transparencies
}

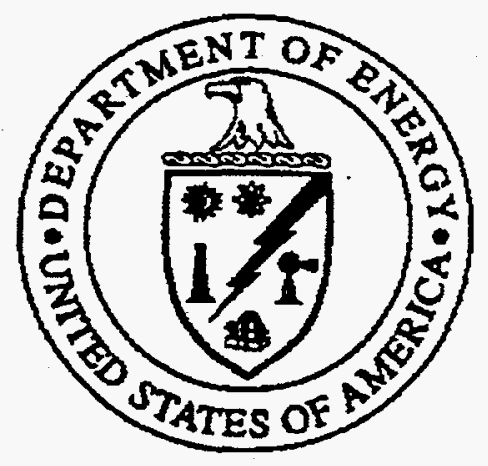

Coordinated and Conducted

for

Office of Environment, Safety \& Health

U.S. Department of Energy 
This page intentionally left blank 


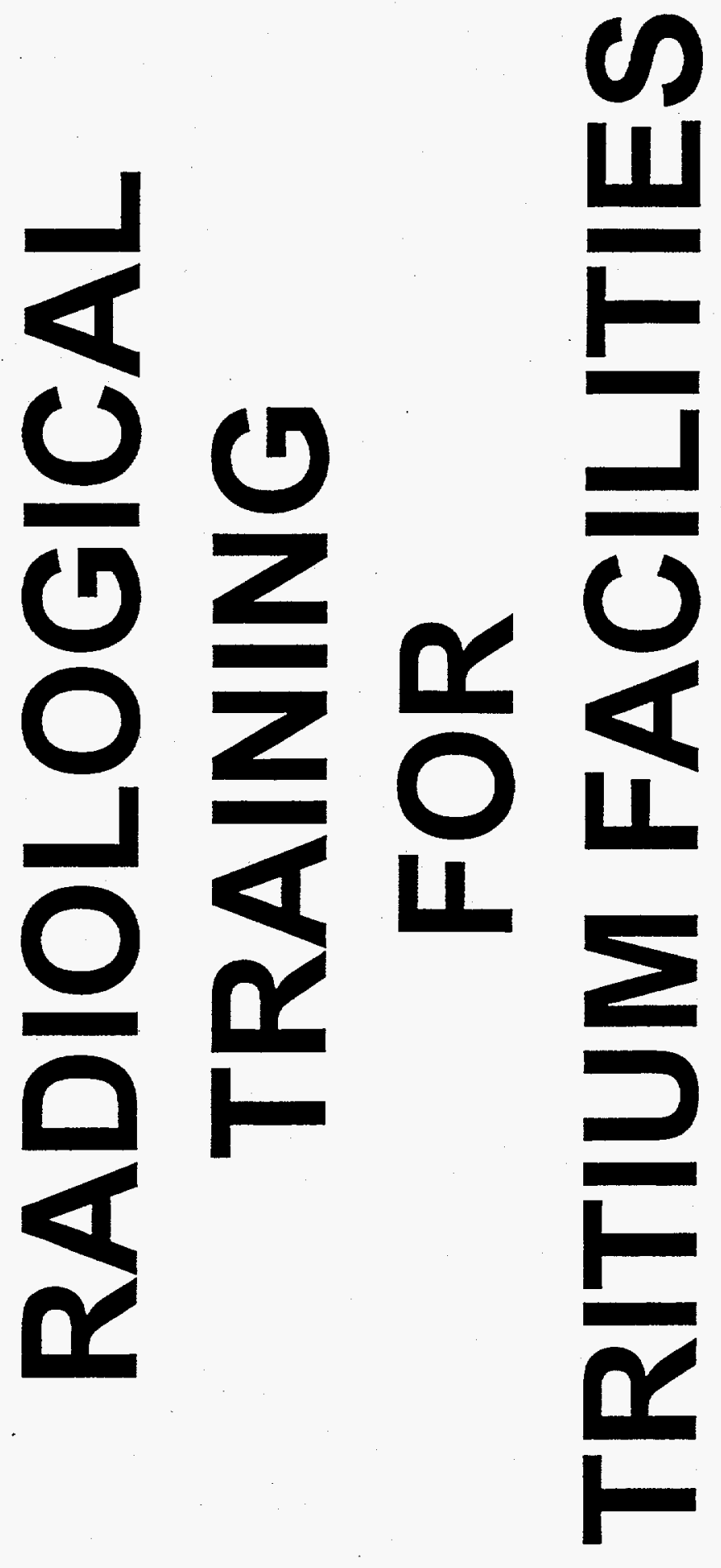

풍 
Tritium - what is it?

- How does it behave?

What are the benefits and hazards?

How do we control it? 


\section{Radiological Training for Tritium Facilities}

\section{Objectives}

1. IDENTIFY the following properties of tritium

- physical/chemical

- radioactivity

2. IDENTIFY sources of tritium

- natural

- by-product

- weapons

3. IDENTIFY uses of tritium

- weapons applications

- research

- fusion energy production

- industrial/commercial 


\section{Objectives}

\section{(Continued)}

4. IDENTIFY modes of tritium exposure

- inhalation

- ingestion

- absorption

- injection/wounds

5. IDENTIFY biological effects of tritium

- biological half-life

- dose

6. IDENTIFY radiological control methods for tritium

- engineered

- administrative

- surface contamination limits

- personal protective equipment

- application of ALARA principles 


\section{Objectives}

(Continued)

7. IDENTIFY methods for monitoring tritium

- air sampling for worker safety

- contamination surveys

- bioassay

8. IDENTIFY tritium waste minimization and handling procedures

9. IDENTIFY alarms and proper response to abnormal conditions in the tritium facility 


\section{Outline}

1. Properties of tritium

2. Sources and uses of tritium

3. Modes of exposure and biological effects of tritium

4. Radiological controls for tritium

5. Monitoring for tritium

6. Tritium waste minimization and handling

7. Response to abnormal condition in the tritium facility

8. Lessons learned

9. Summary and Review 


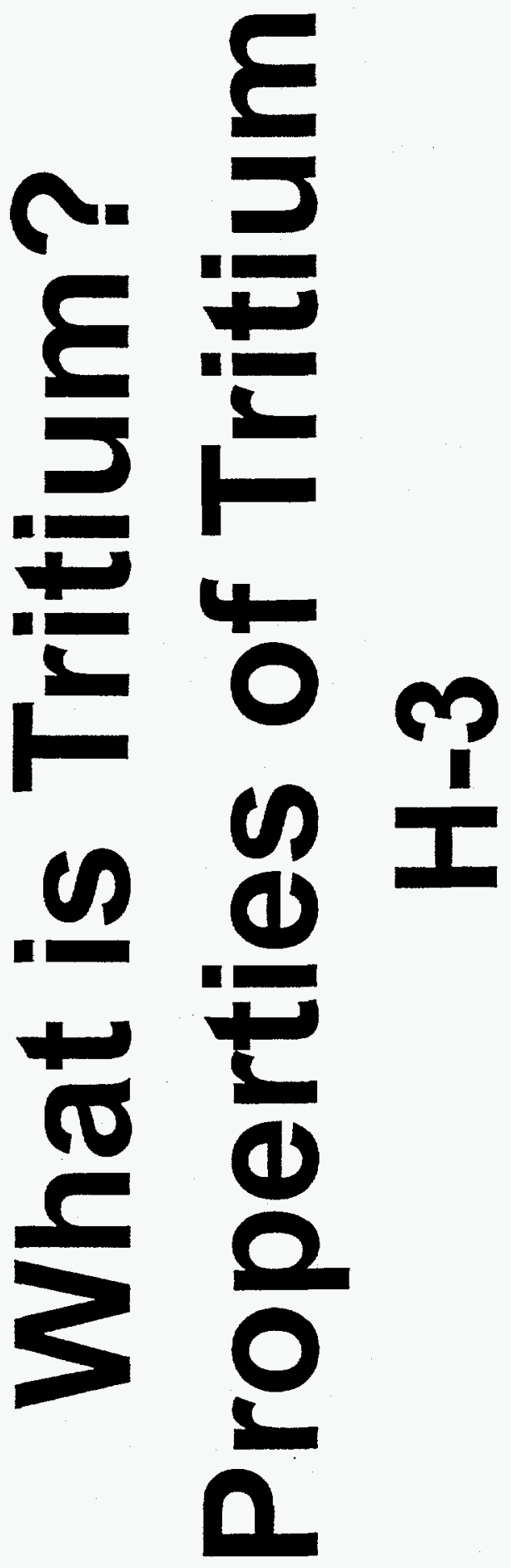

동 


\section{All hydrogen atoms have one proton $(\mathrm{H})$.}

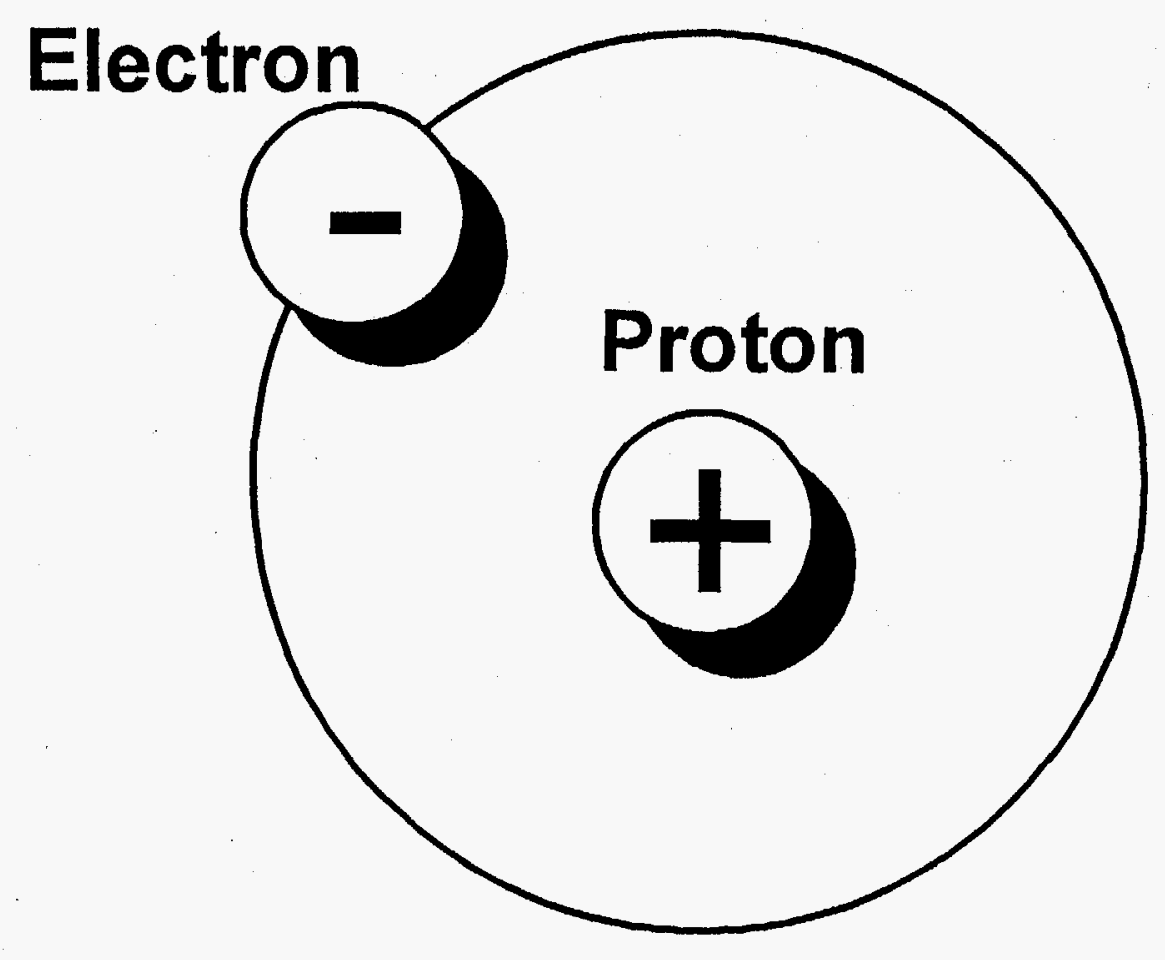




\section{The number of neutrons may vary - ISOTOPES of hydrogen.}

Protium H

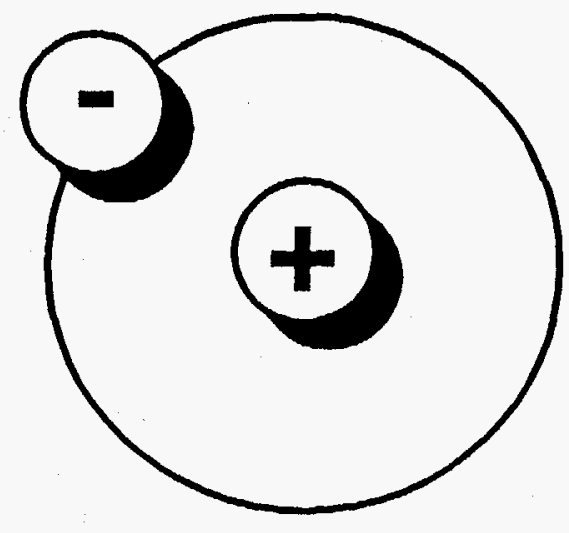

No neutrons

$\mathrm{H}$
Deuterium D

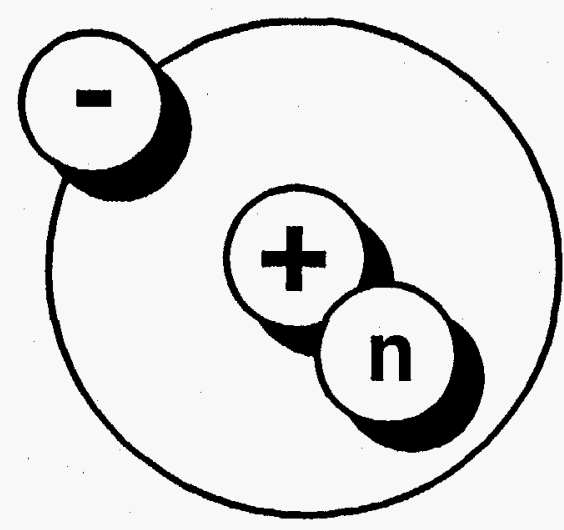

1 neutron

D
Tritium T

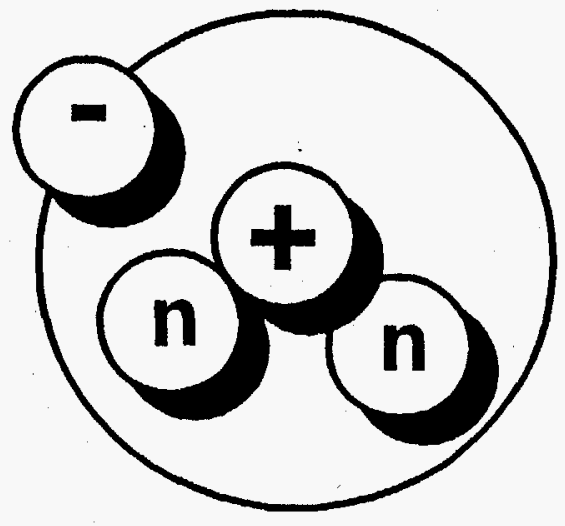

2 neutrons

$\mathrm{T}$ 


\title{
Tritium is designated as:
}

\author{
T or H-3 or ${ }_{1}^{3} \mathrm{H}$
}




\section{Tritium can easily substitute for protium $(\mathrm{H})$.}

Normal Hydrogen Gas

Tritiated Gas

Tritium Gas
H(H $\mathrm{H}_{2}$

TH $H T$

T $T$ TT or $T_{2}$ 
Tritium behaves just like hydrogen.

Normal Water

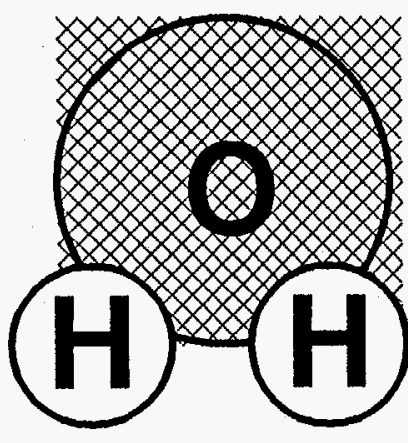

$\mathrm{H}_{2} \mathrm{O}$

Tritiated Water

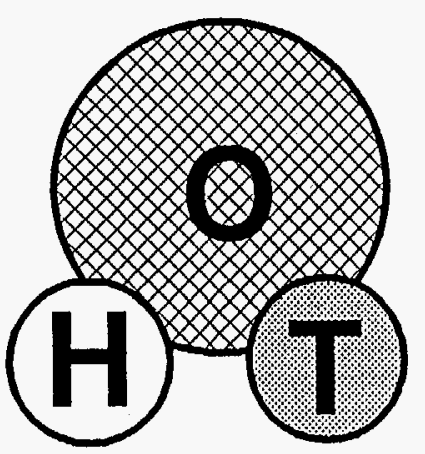

HTO 


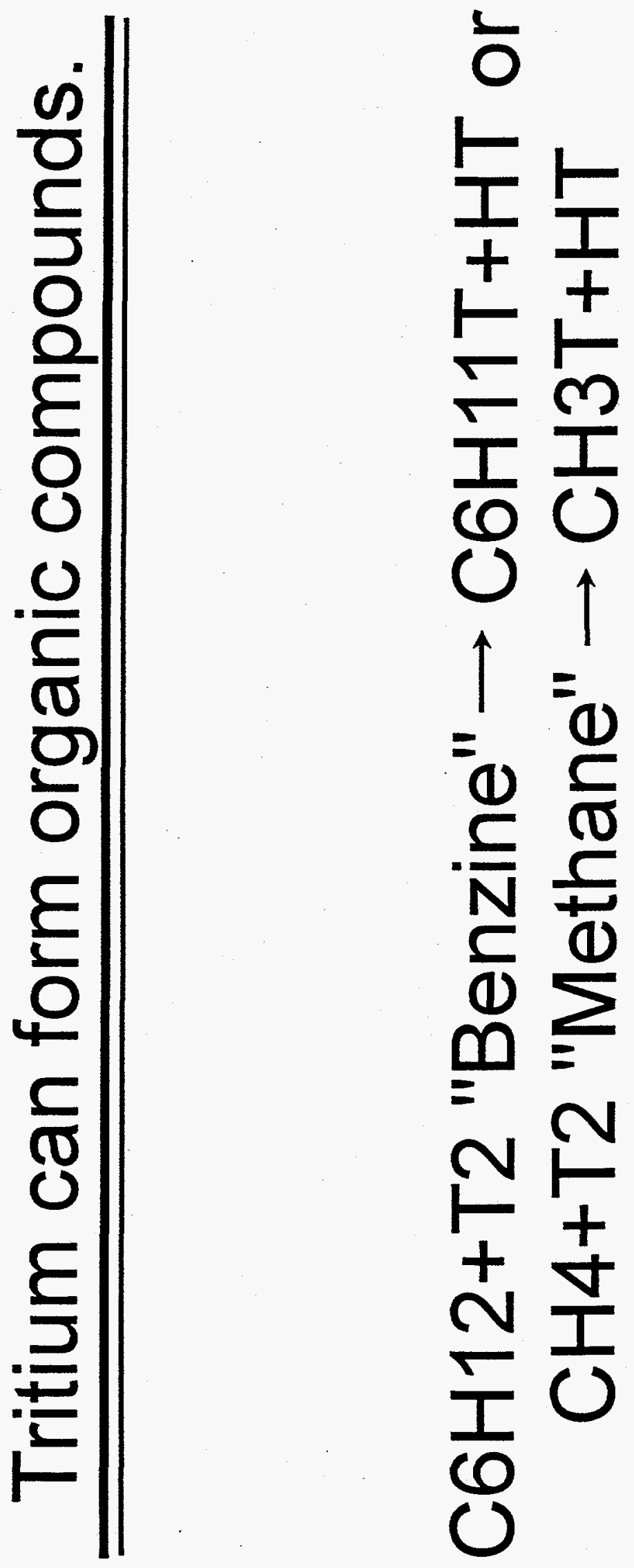

总 
Tritium can be captured in metallic compounds called "Hydrides" and then released by heating.
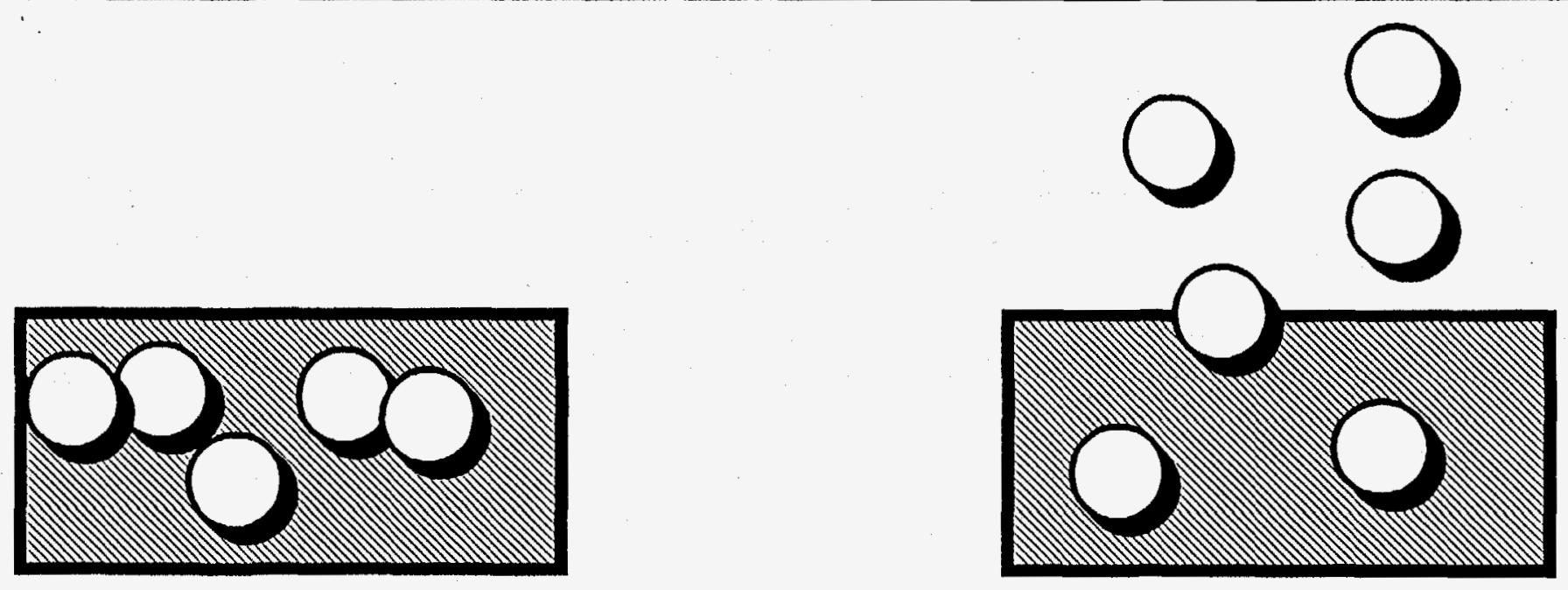

Heat 
Hydrogen/tritium gas is flammable.

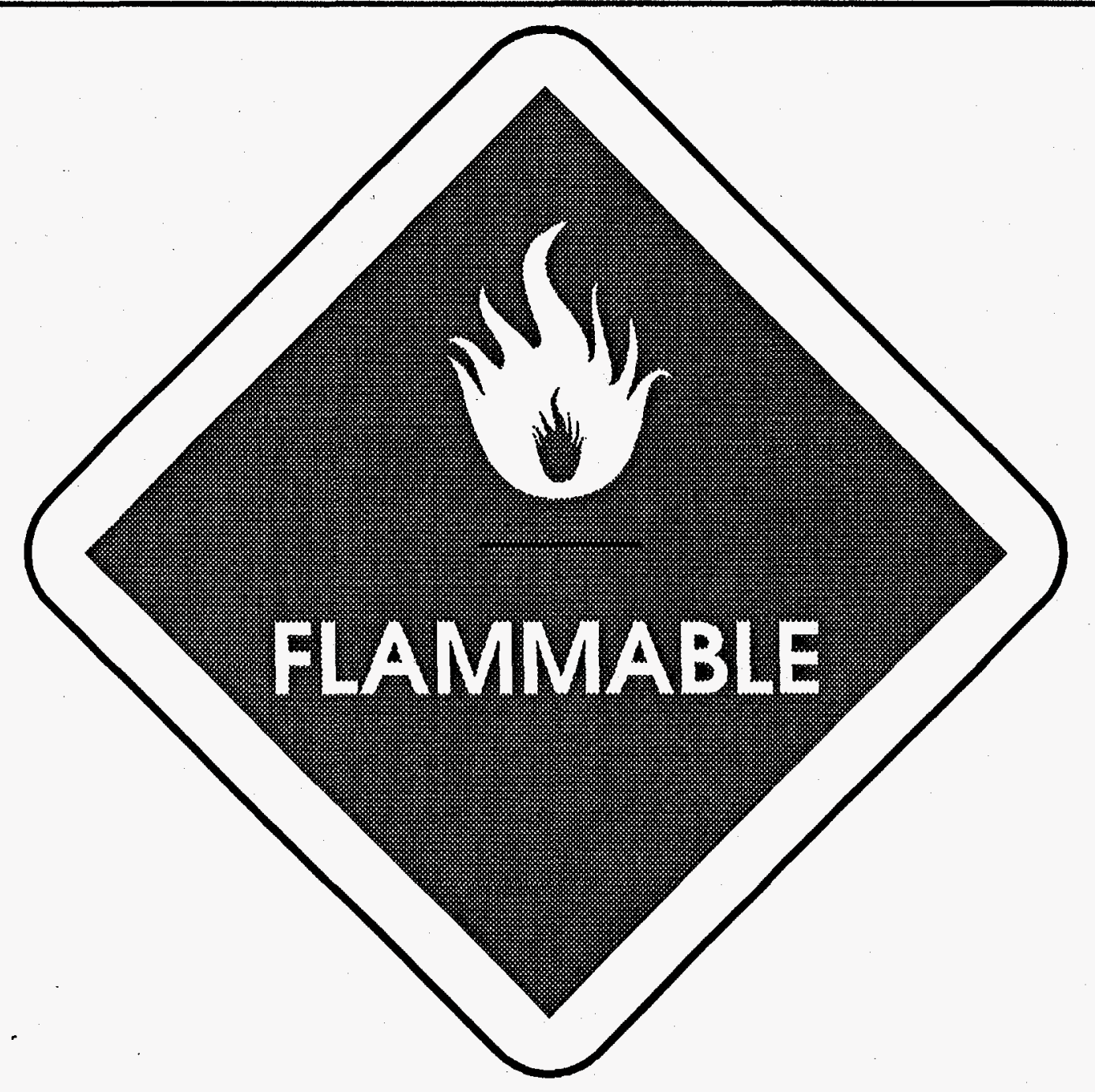




\section{Hydrogen/tritium gas is lighter than air.}

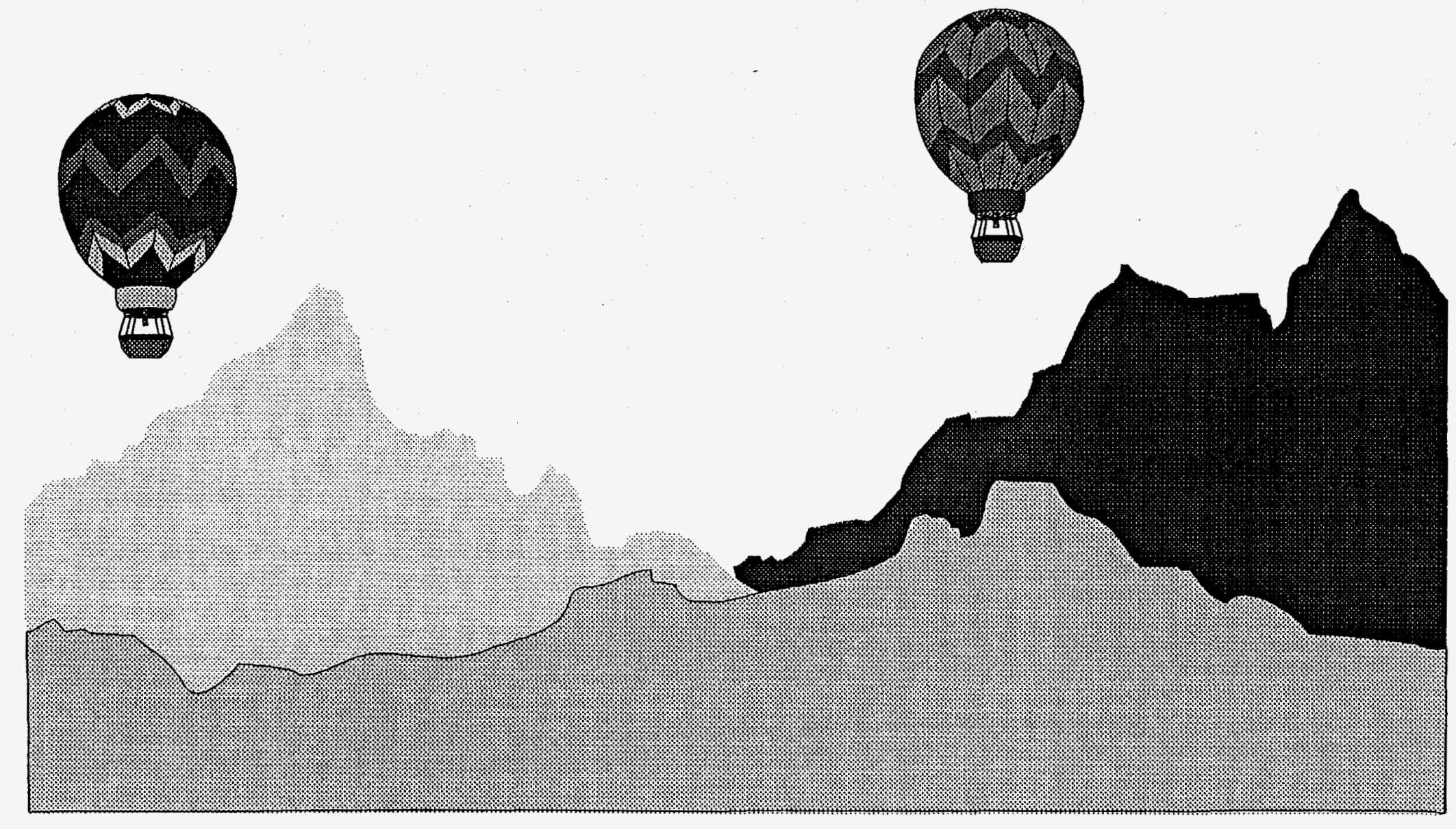

OT-16 


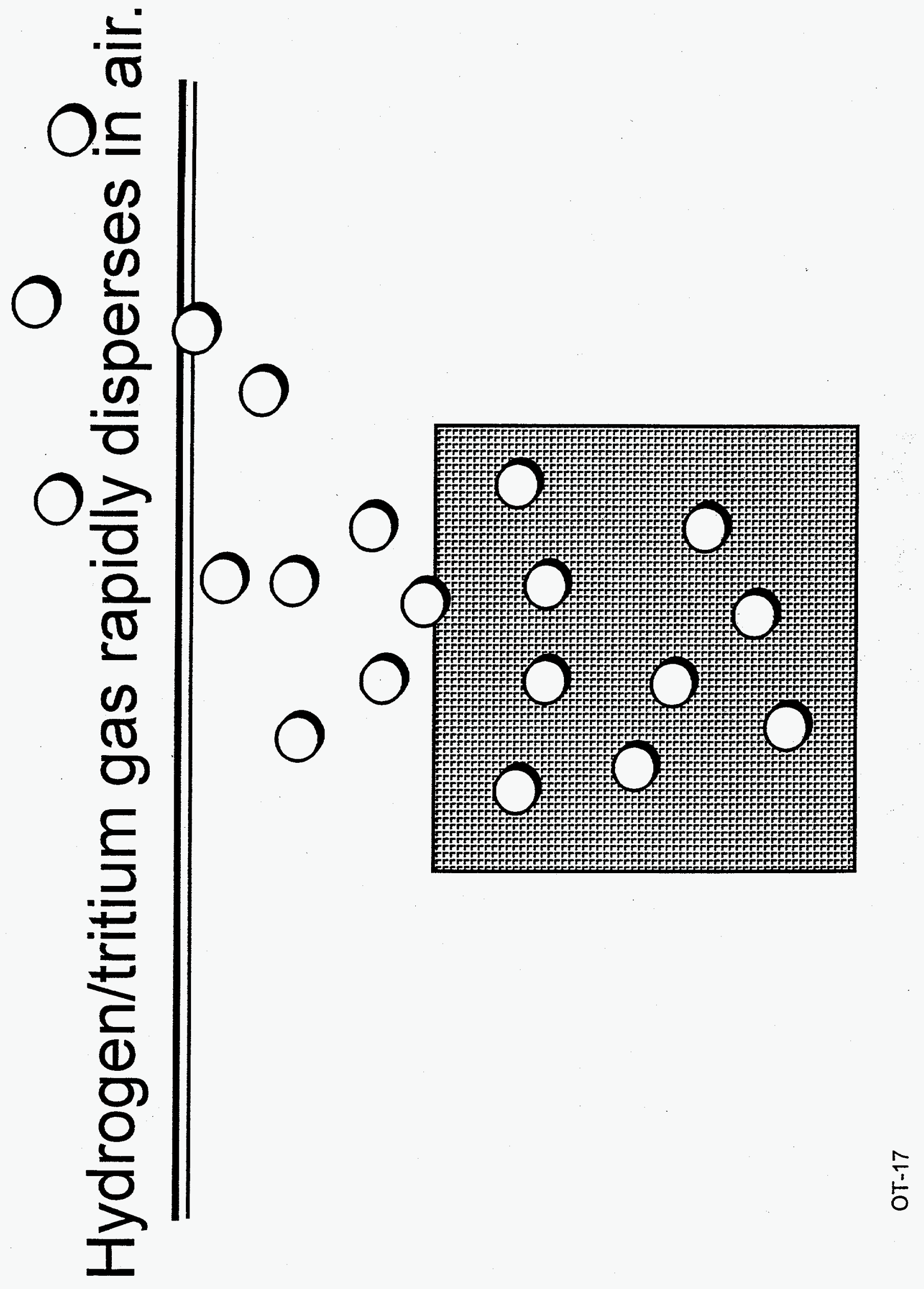


Hydrogen/tritium gas and tritiated water penetrates through most materials, including gloves.

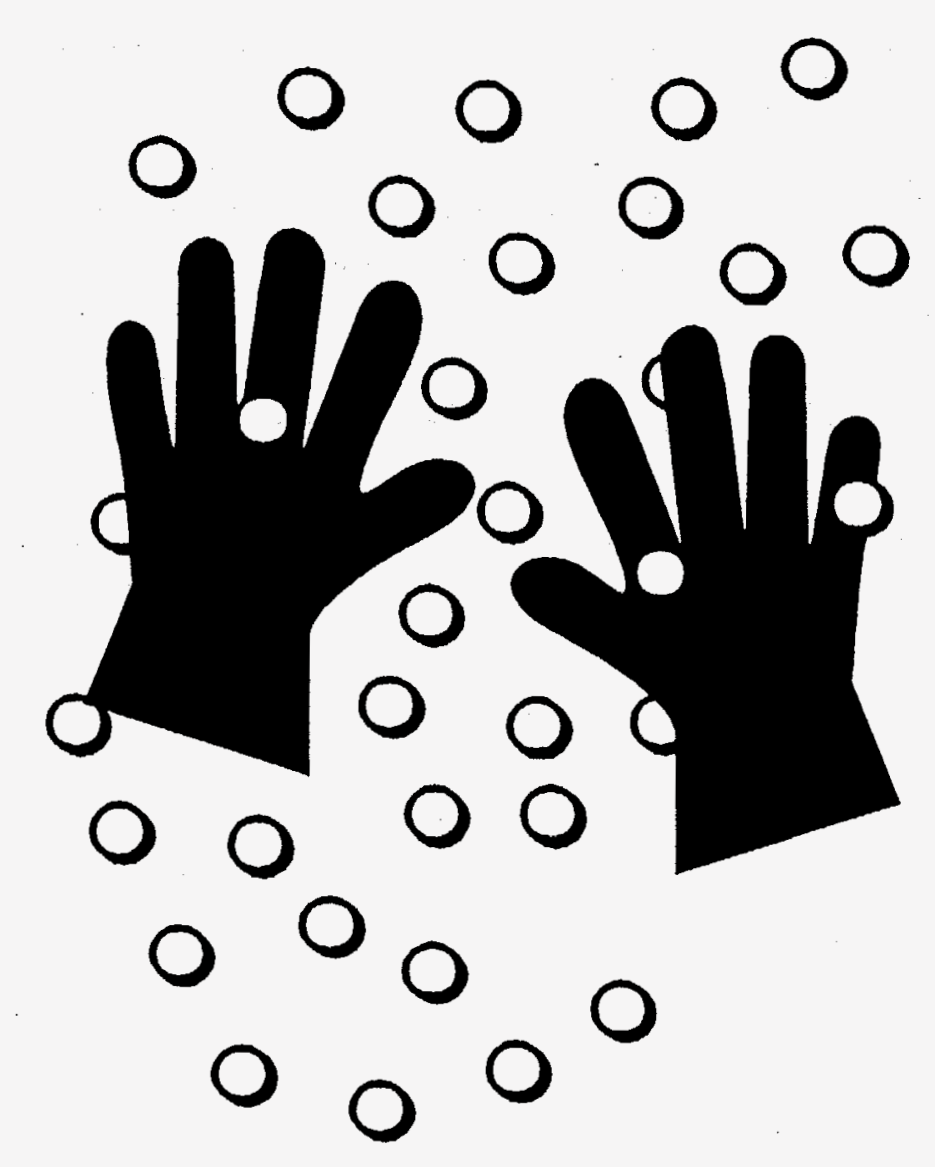




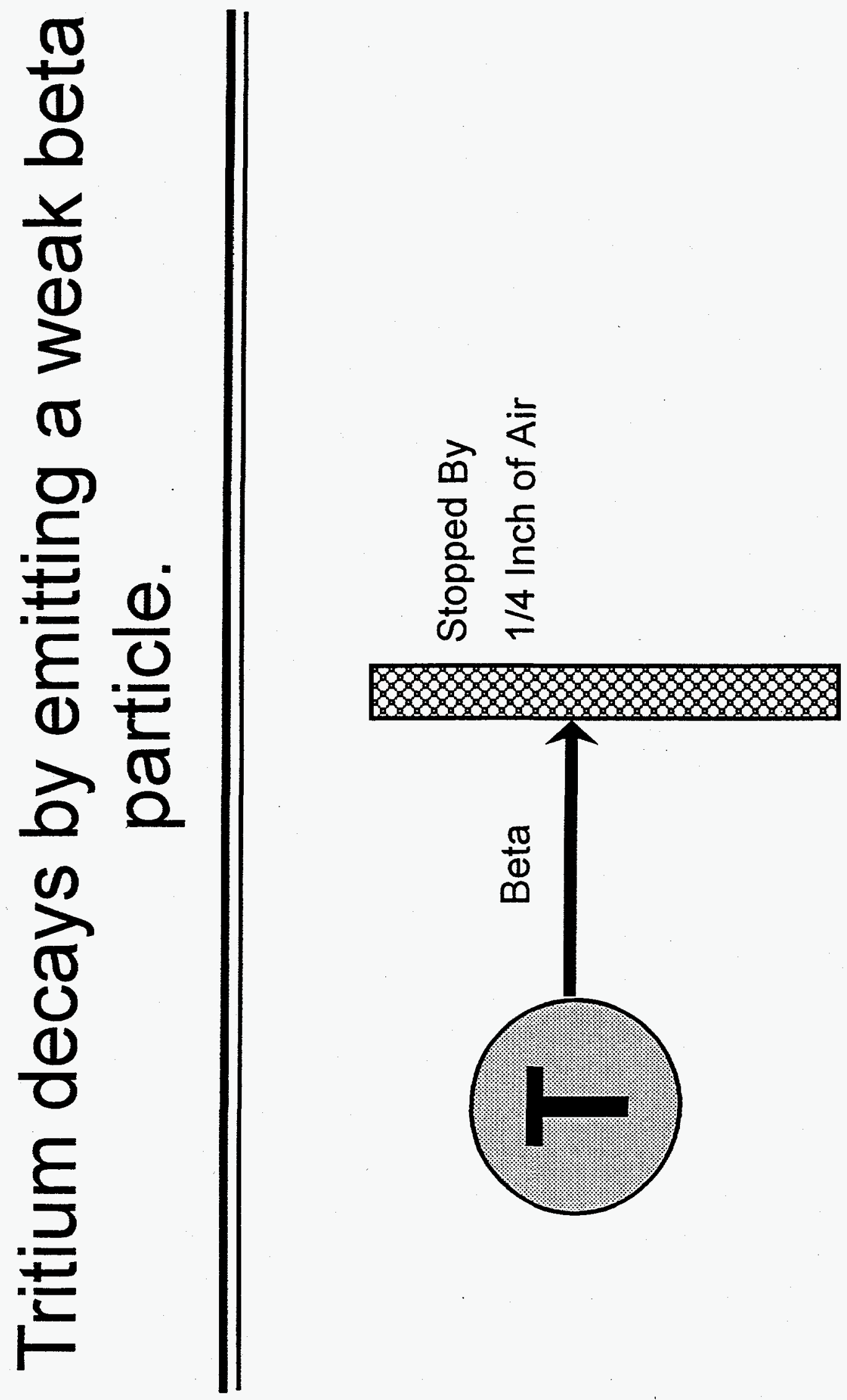




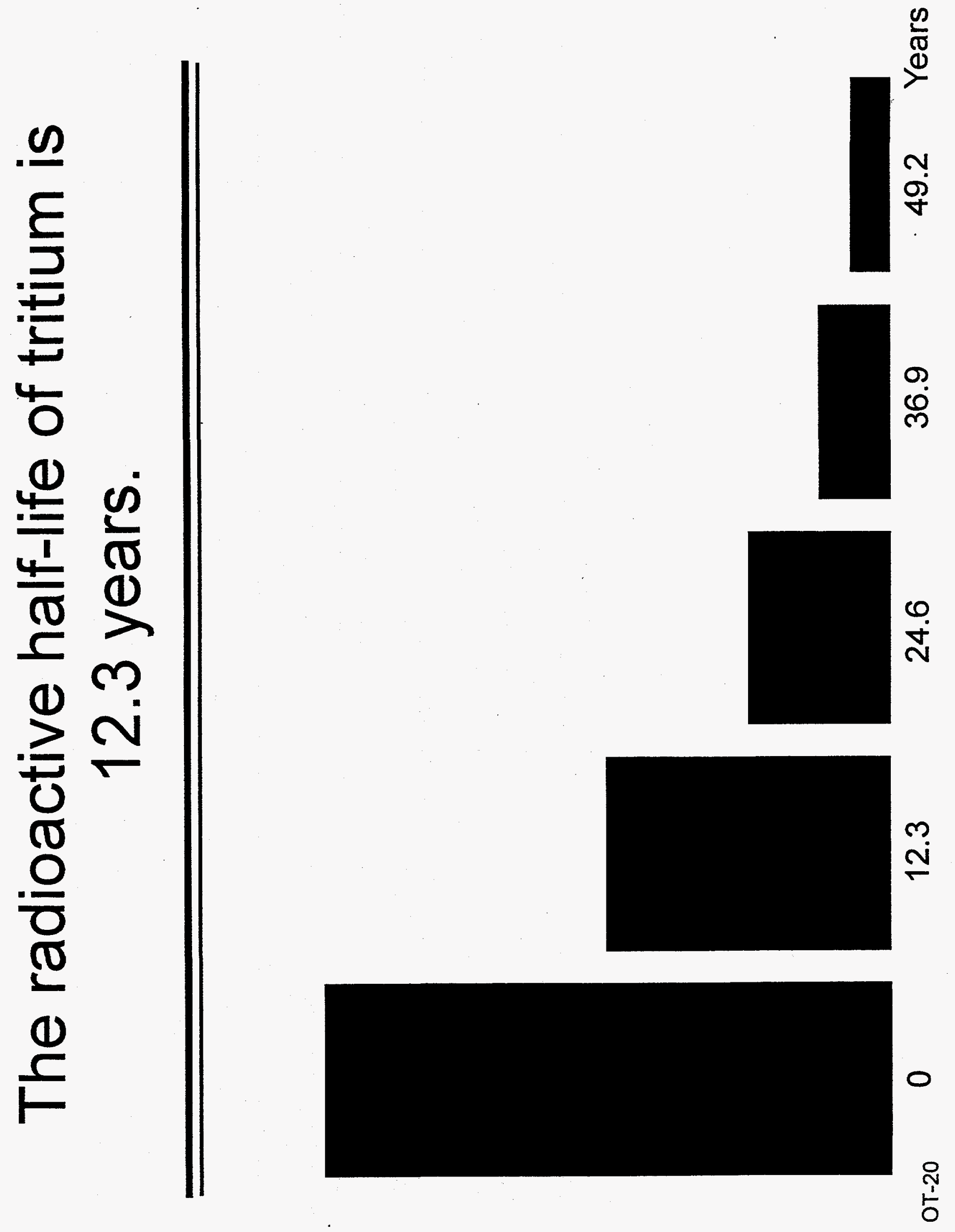



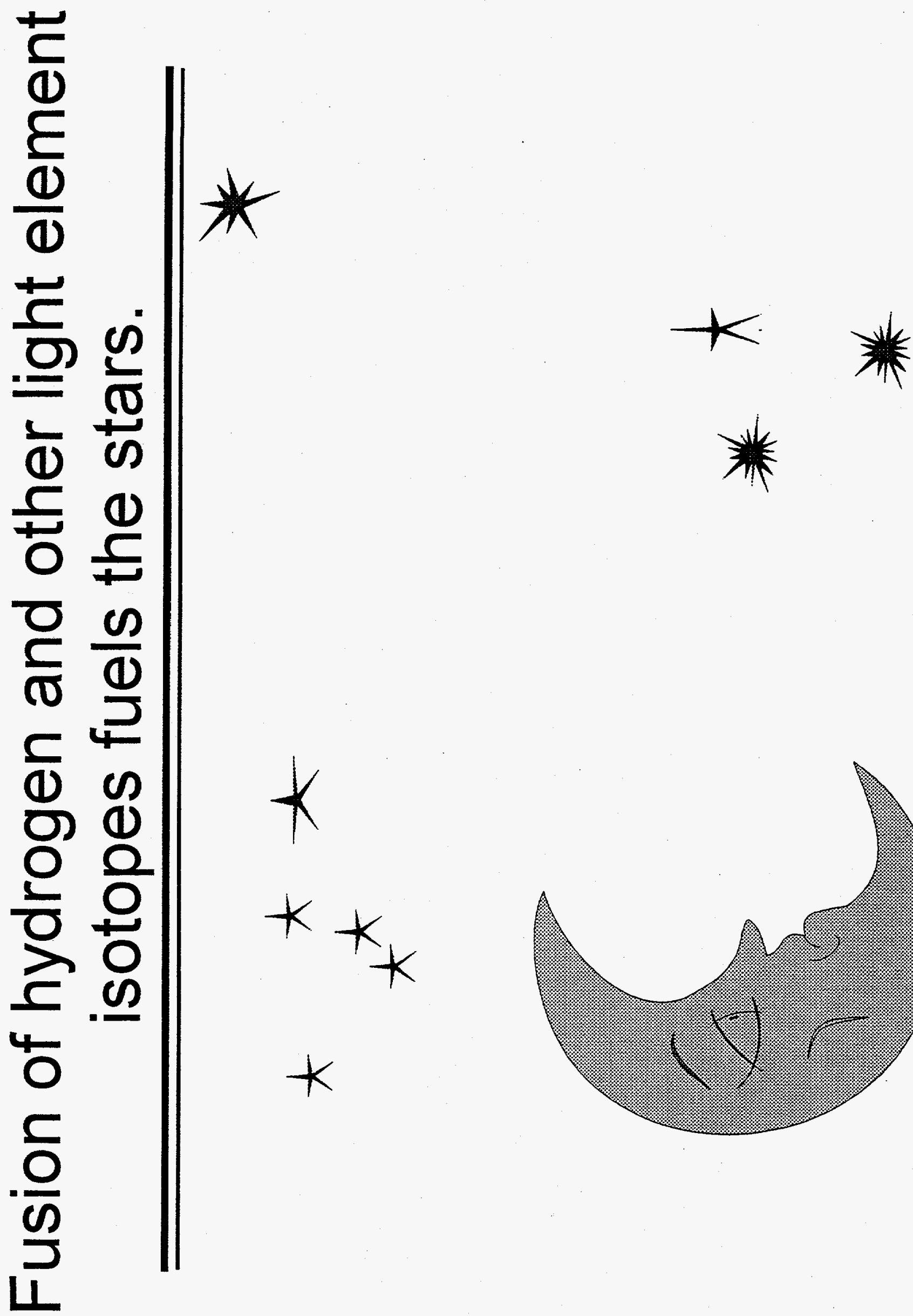

$\sum_{11}$

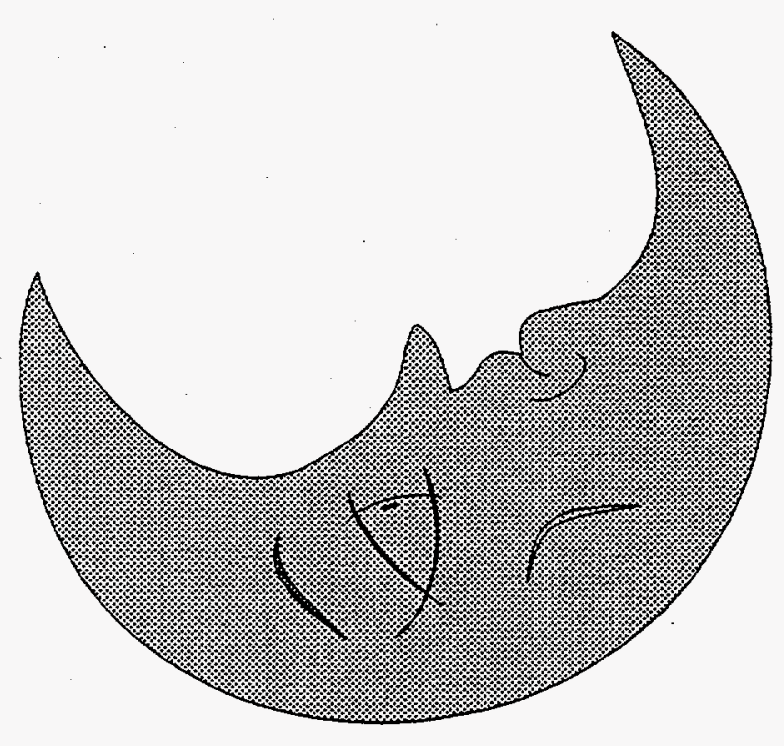

$\overline{\mathrm{g}}$ 


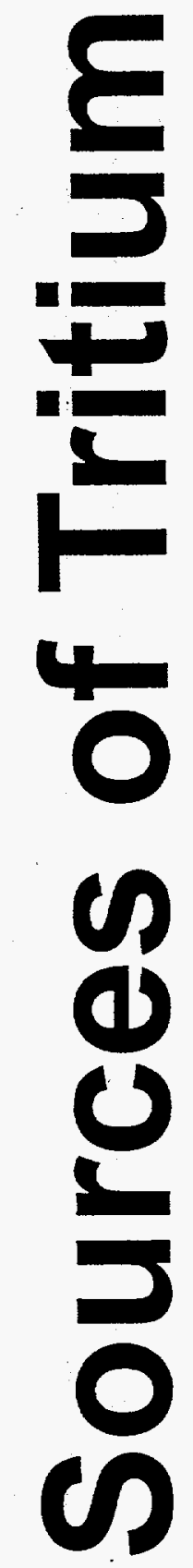

พับ 


\section{Tritium is produced naturally by cosmic rays and is carried to the earth's surface by rain.}

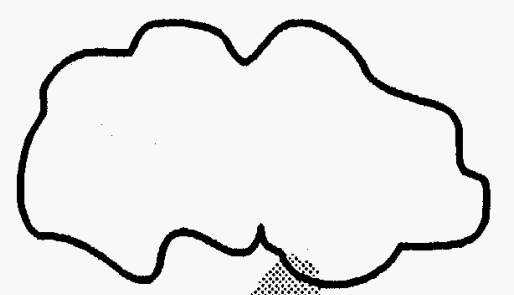

4 million curies (approximately $0.41 \mathrm{~kg}$ ) produced per year

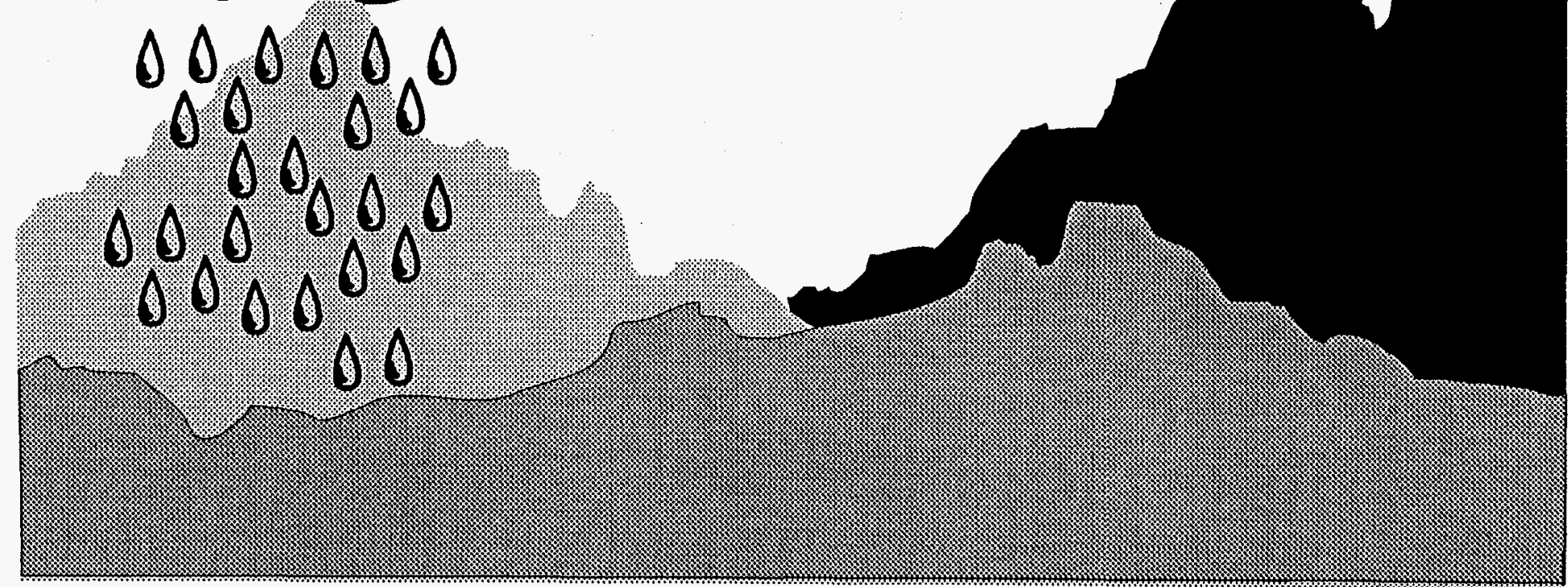

World inventory of natural tritium from cosmic ray От-23 interactions is approximately 70 million curies. 


\section{Tritium is formed in reactors by ternary fission and activation of light elements.}

Commercial production - 1 million curies per year

Nuclear reactors

- $\quad$ 1-2 million curies per year 


\section{Environmental tritium from atmospheric testing will be at natural levels about 2030 .}

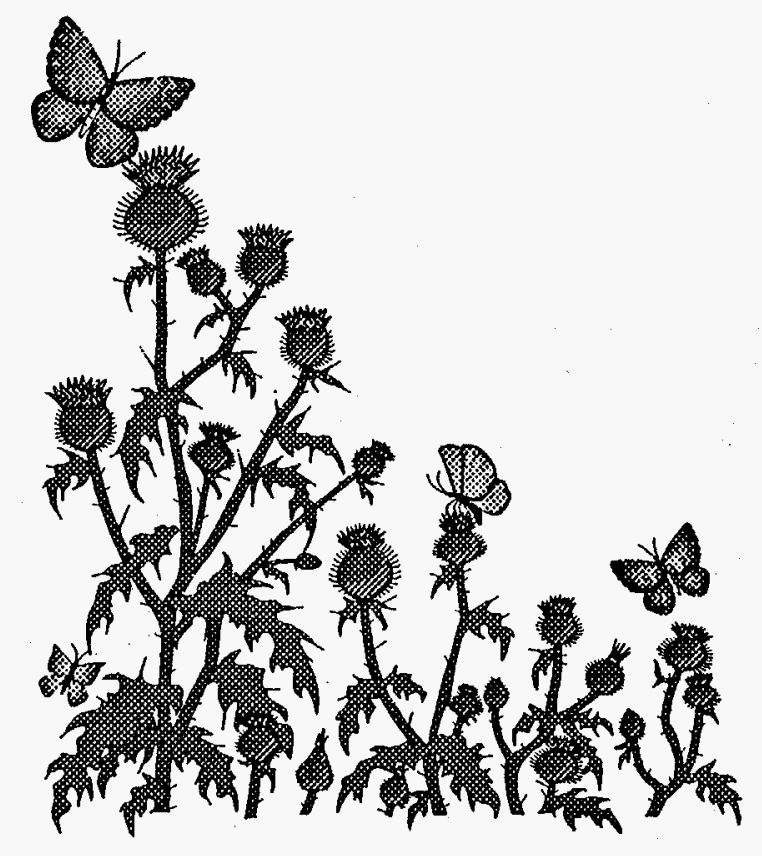

The world inventory of tritium from atmospheric testing is approximately 400 million curies (approximately $41 \mathrm{~kg}$ ). 


\section{Tritium is used commercially in a variety of products.}

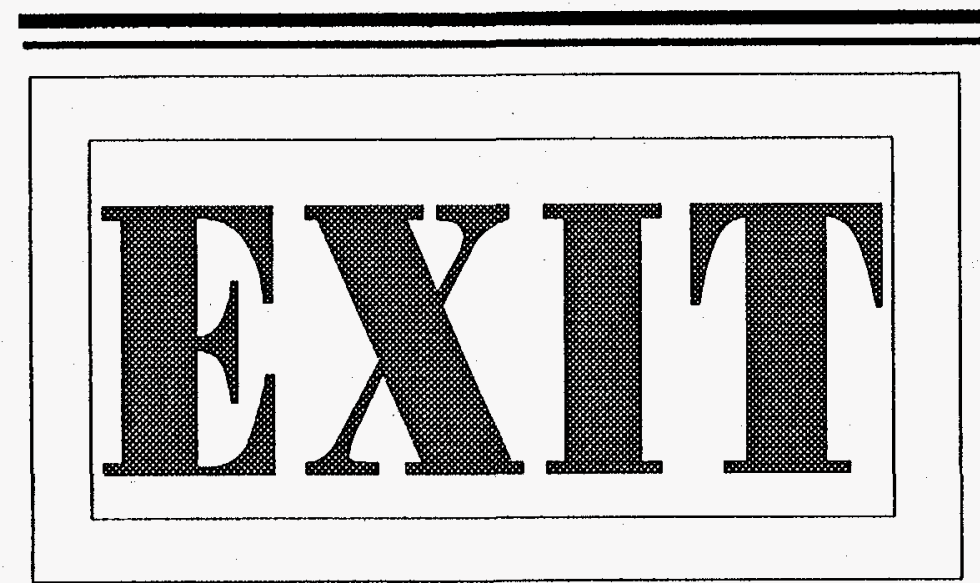

Illuminating Signs

- . 1.1.1.1.

-1.1.1.1.1.

Runway Lights 


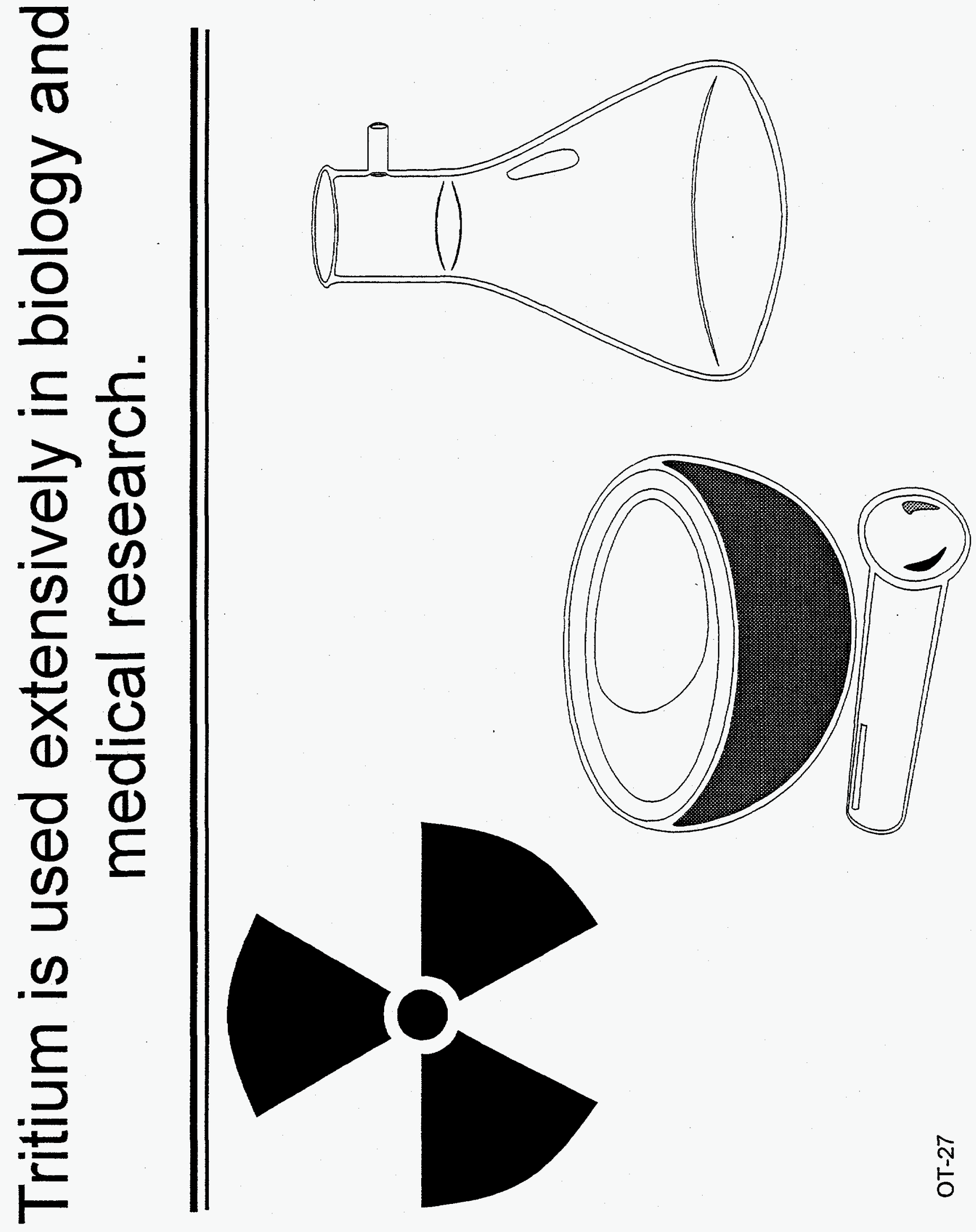




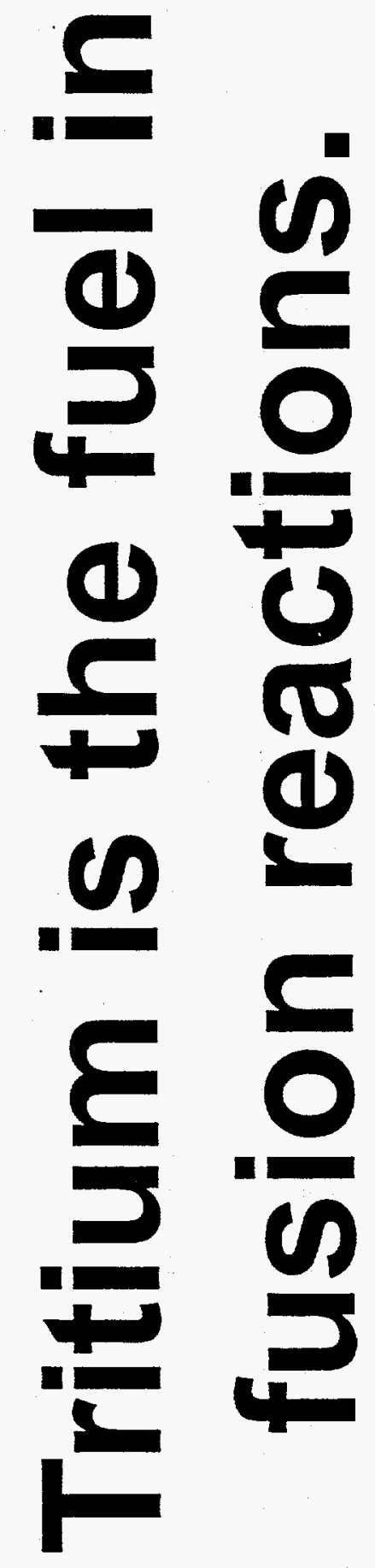

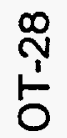


Modes of Exposure and

Biological Behavior of Tritium 


\section{Tritium is NOT an external radiation hazard-It is an internal hazard when taken into the body.}

\section{external}

\section{internal}

The beta particle cannot penetrate through the dead layer of the skin.
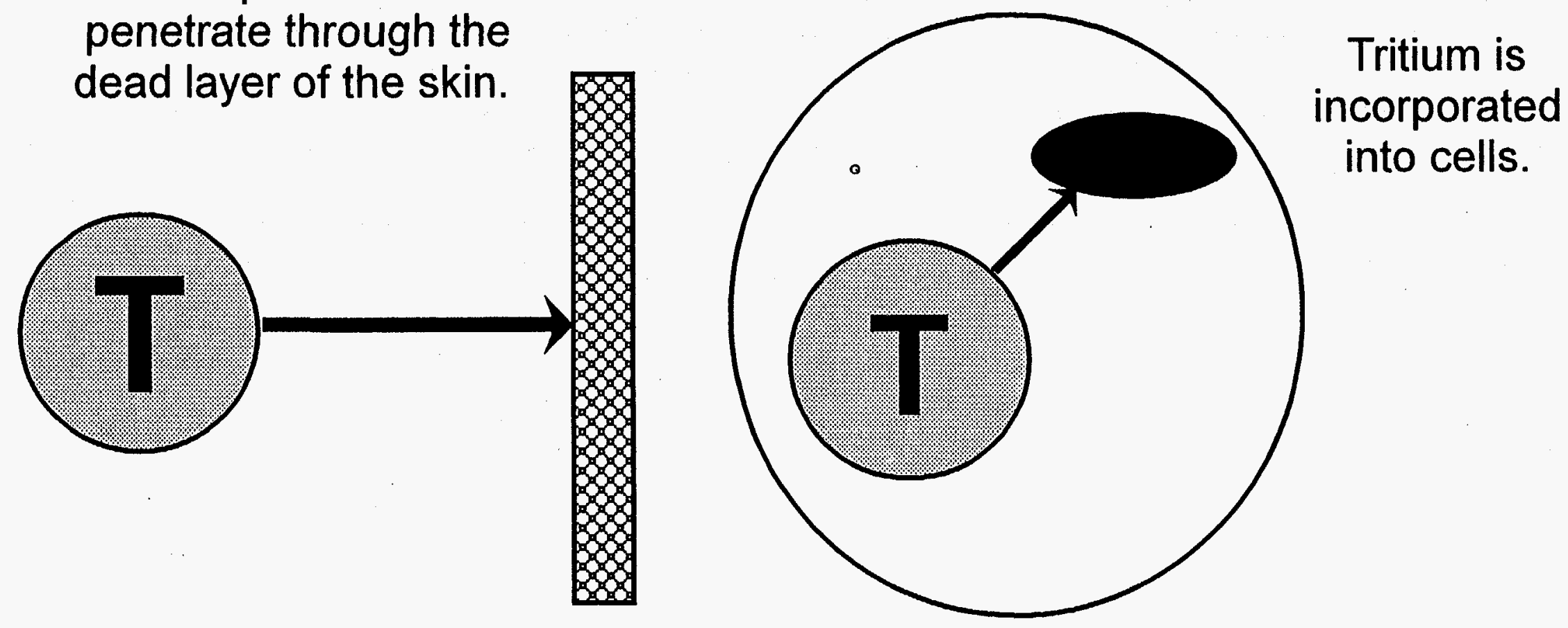


\section{The main pathways for uptake of tritium are:}

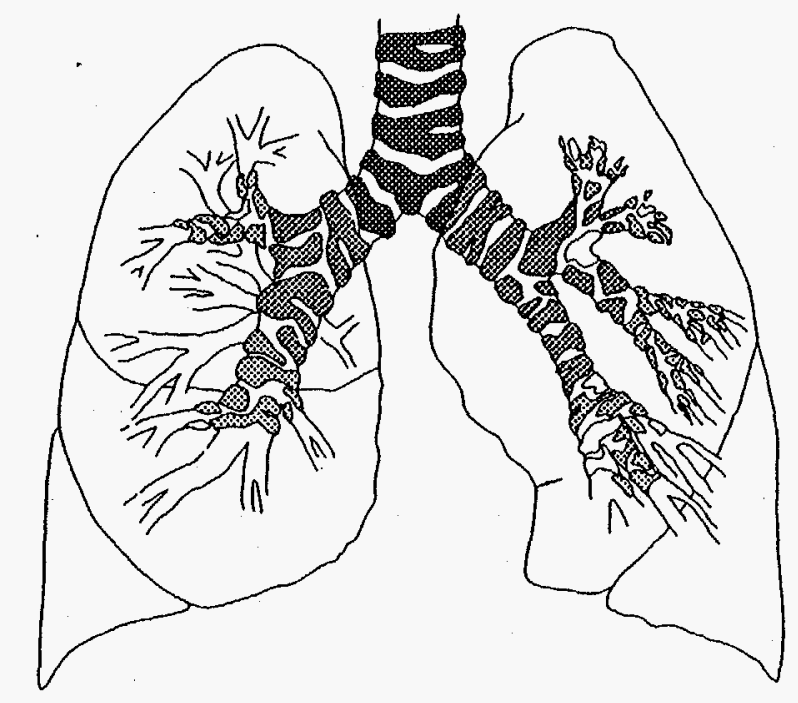

Inhalation

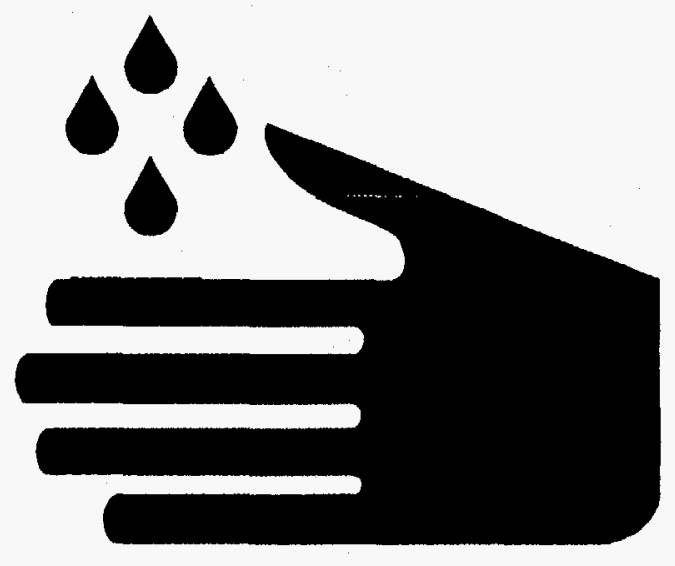

Absorption 
Tritiated water is more hazardous than tritium gas, as it is readily incorporated into the body.

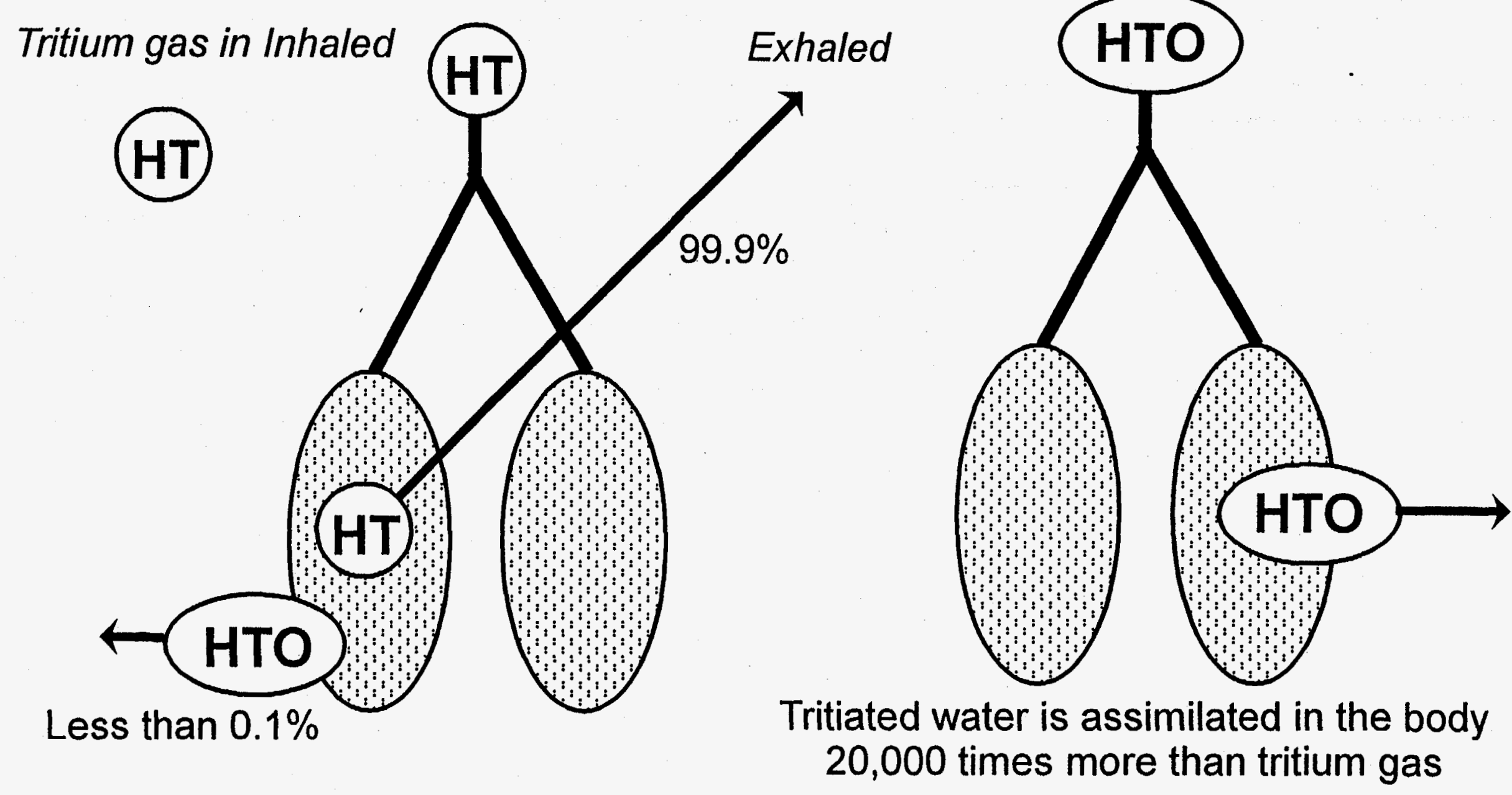




\section{Tritiated water can also be absorbed through skin into body water.}

HTO
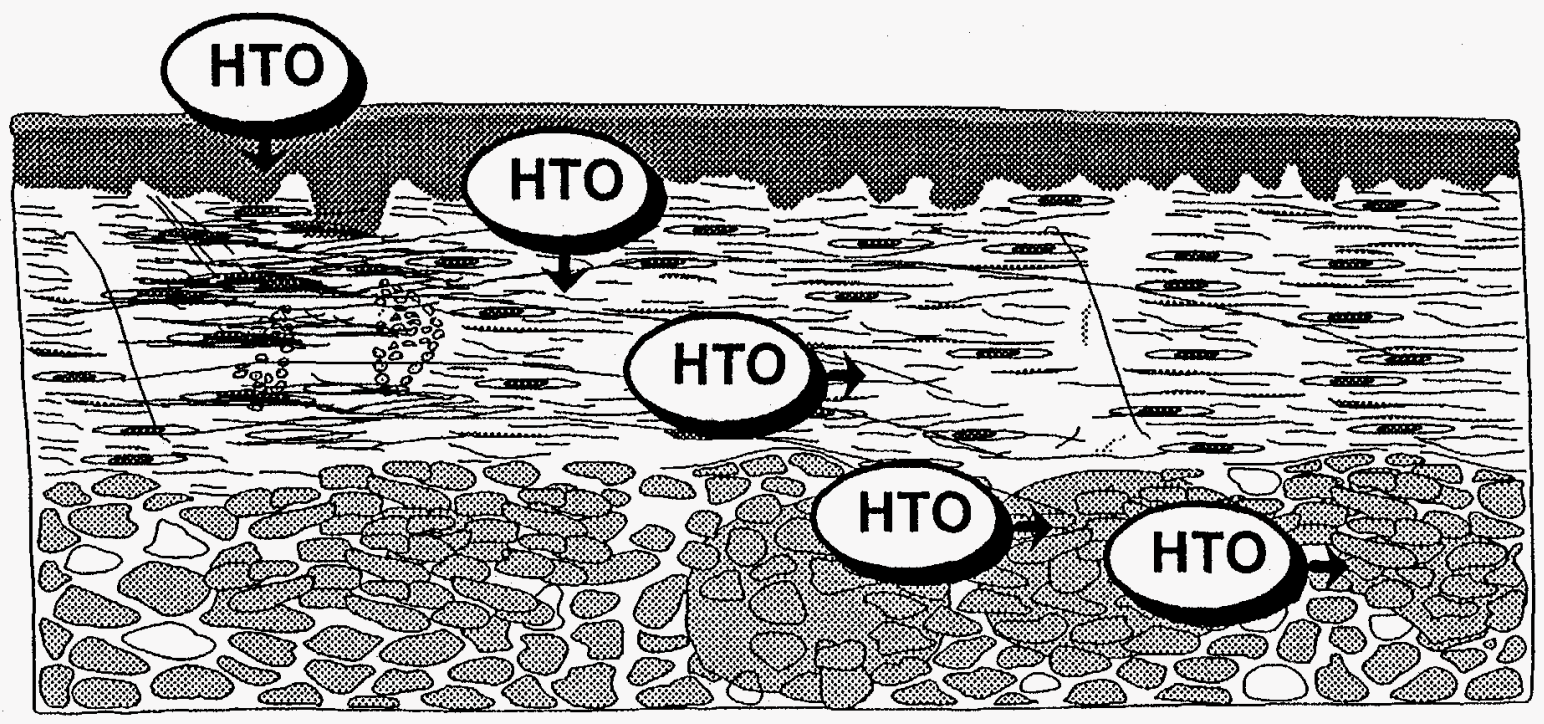


\section{Tritium taken into the body is distributed throughout the body.}

10CFR835

establishes $5 \mathrm{rem} / \mathrm{year}$

as the occupational

dose limit.

1 Curie of tritiated water 
$\frac{0}{\dot{1}}$

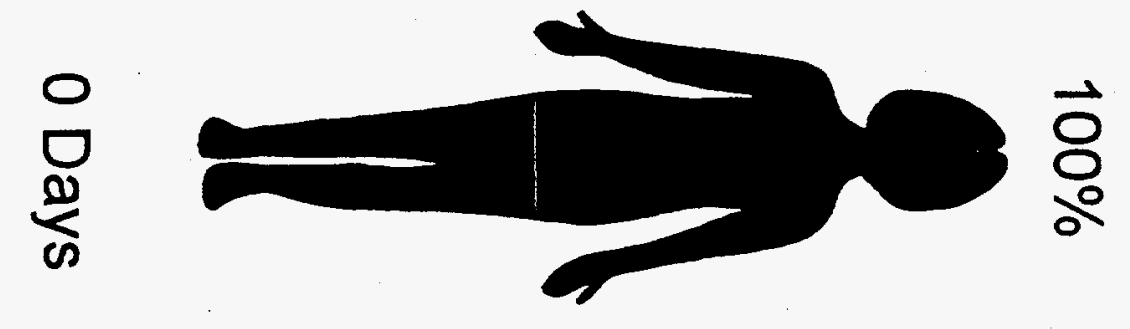

함

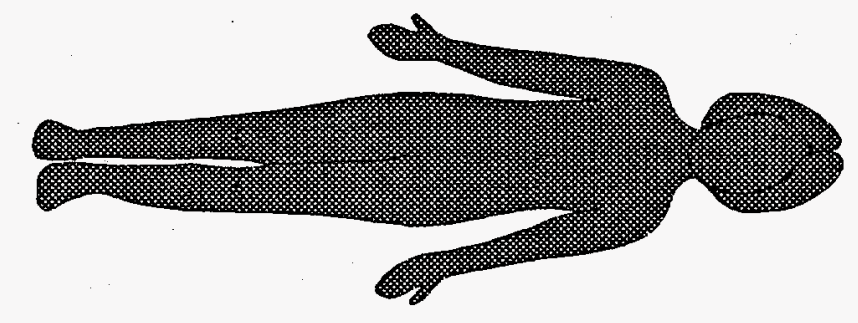

$\bigotimes_{0}^{0}$

$\underbrace{0}_{\infty}$

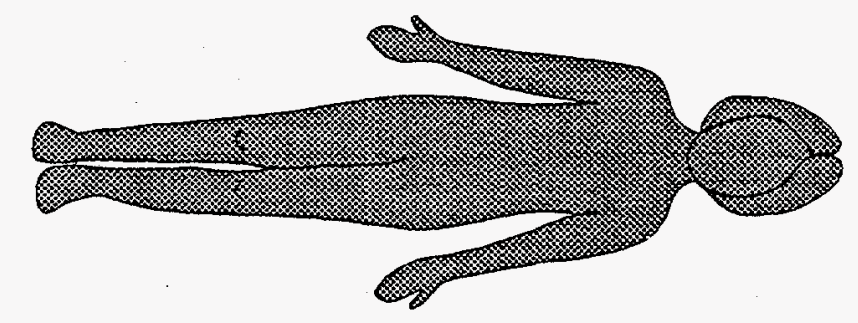

$\underbrace{N}_{0}$

$\underbrace{\omega}_{\infty}$

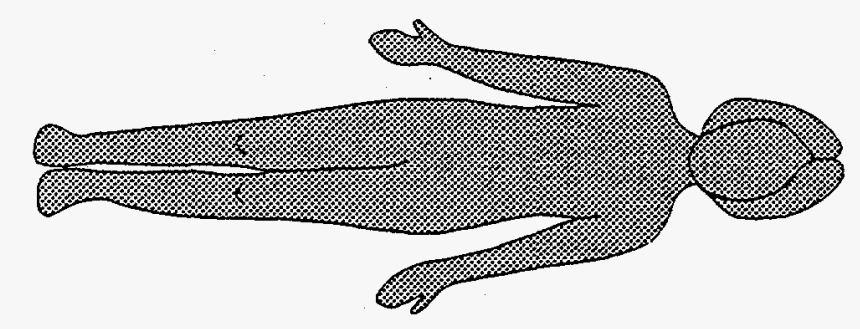

$\vec{N}$

on

$\underbrace{\infty}_{\infty}$

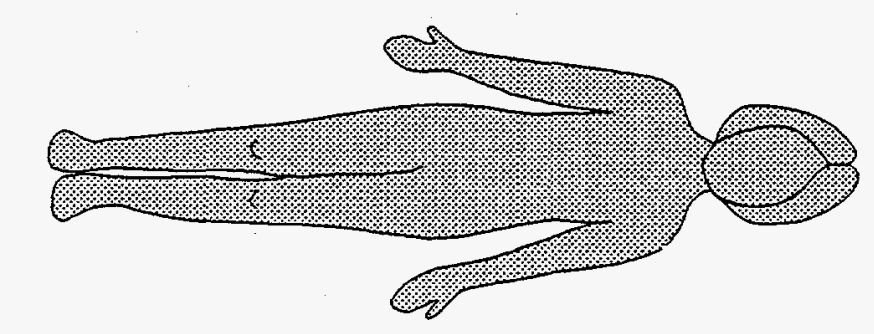

$\infty$

N

O
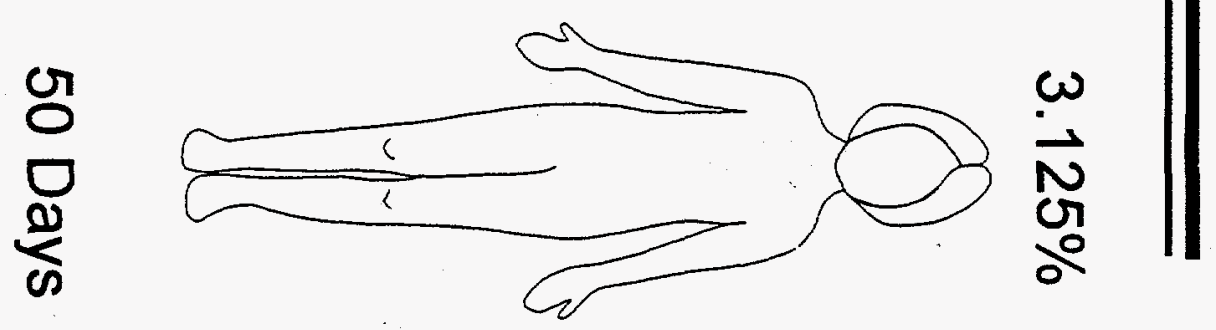

๘. 응

(1)

므.

으

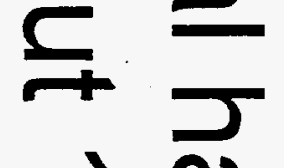

$\rightarrow 0$

$\infty \frac{1}{1}$

$\frac{1}{a} \frac{1}{a}$

0

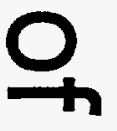

5 
The elimination of tritium from the body can be increased by increasing liquid intake.
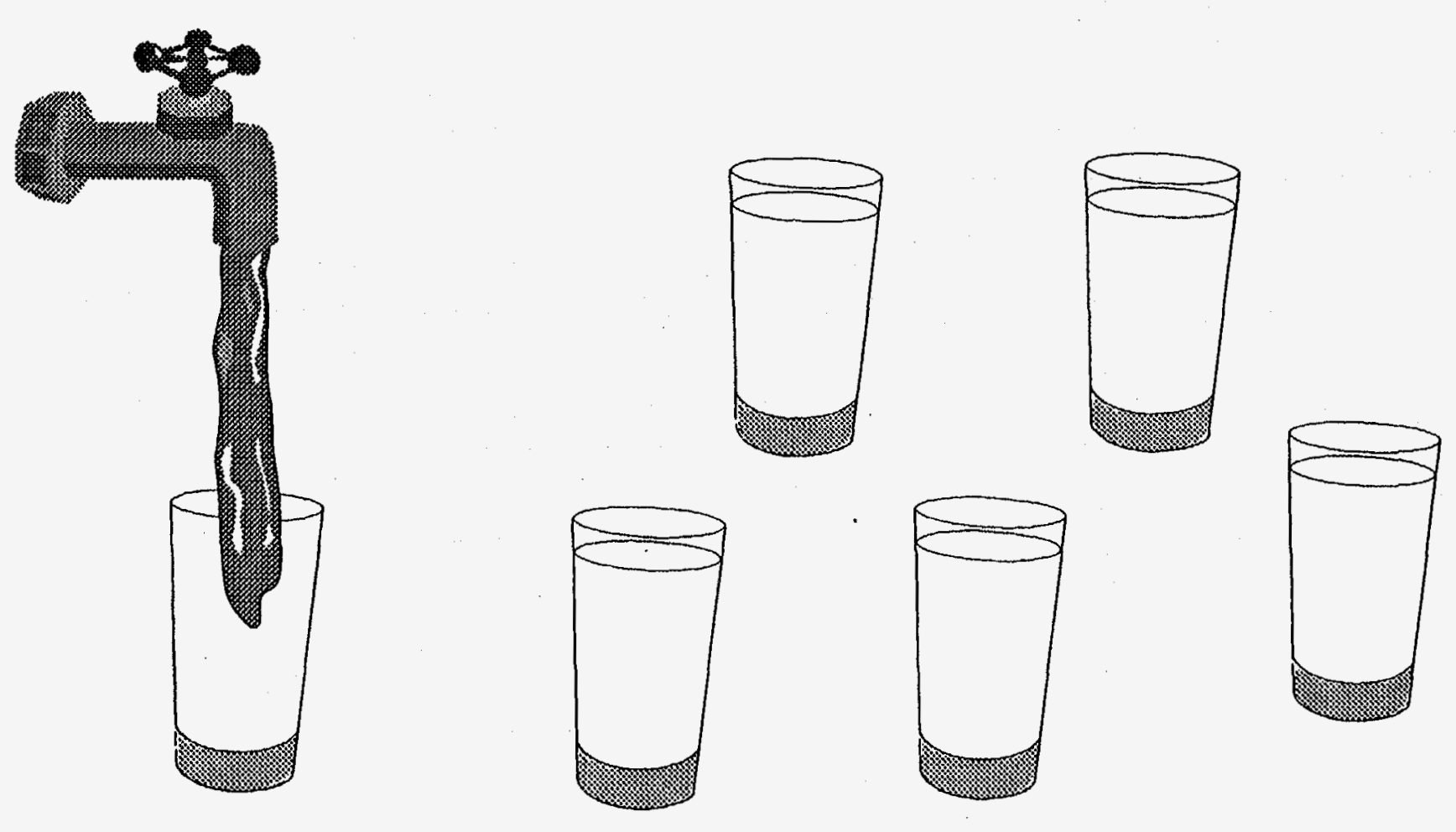


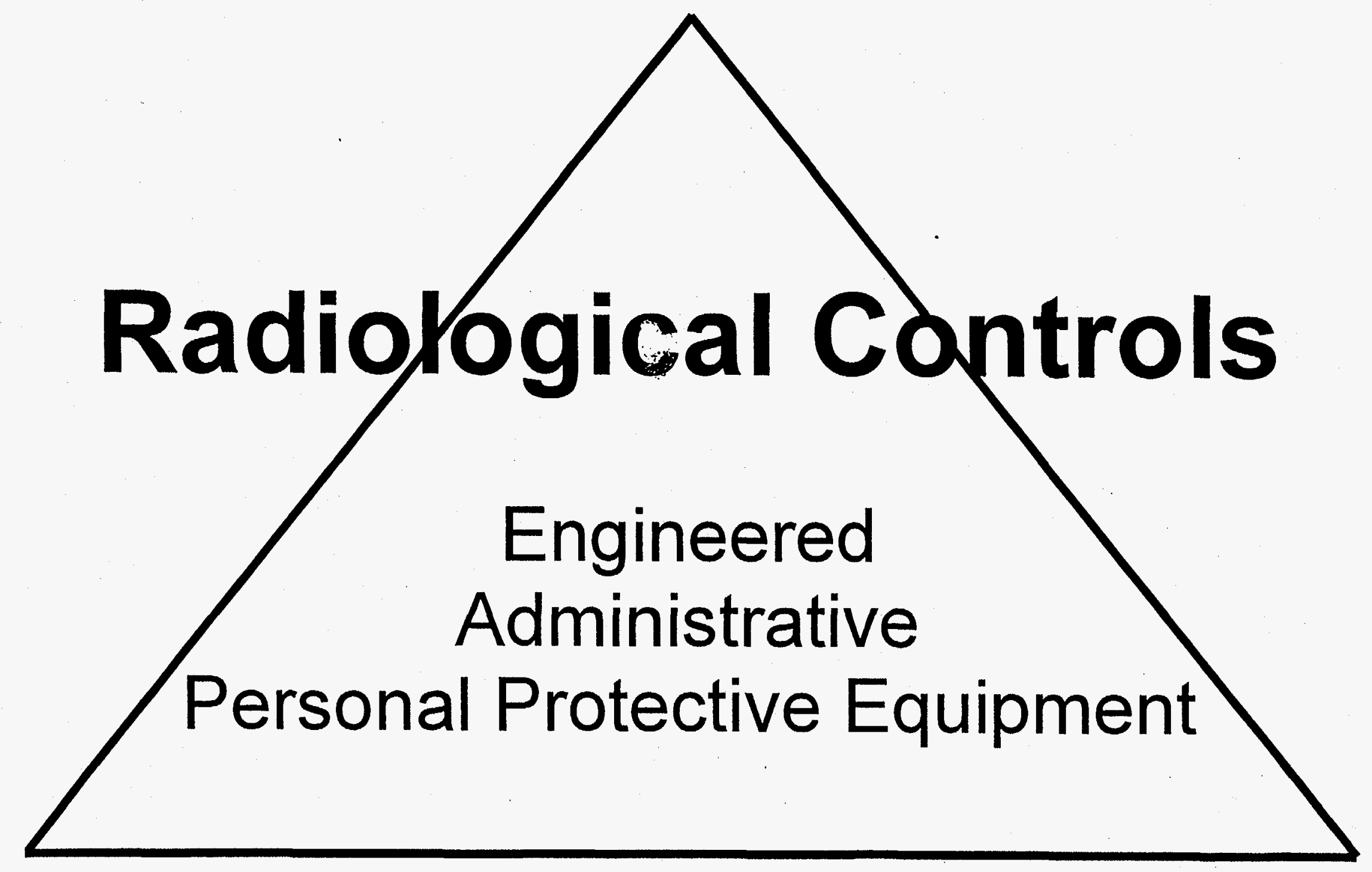

OT-37 


\section{Engineered controls are preferred over administrative ones.}

Engineered

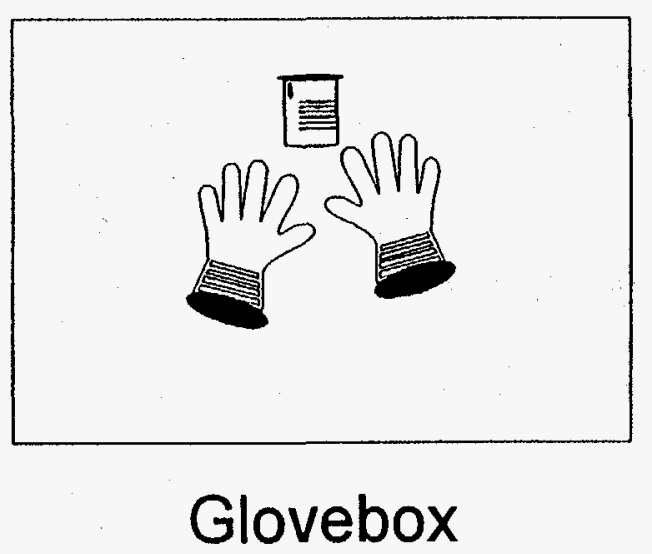

Administrative

- DANGER

RADIOACTIVE MATERIALS 


\section{Larger quantities of tritium are handled in engineered containment systems.}

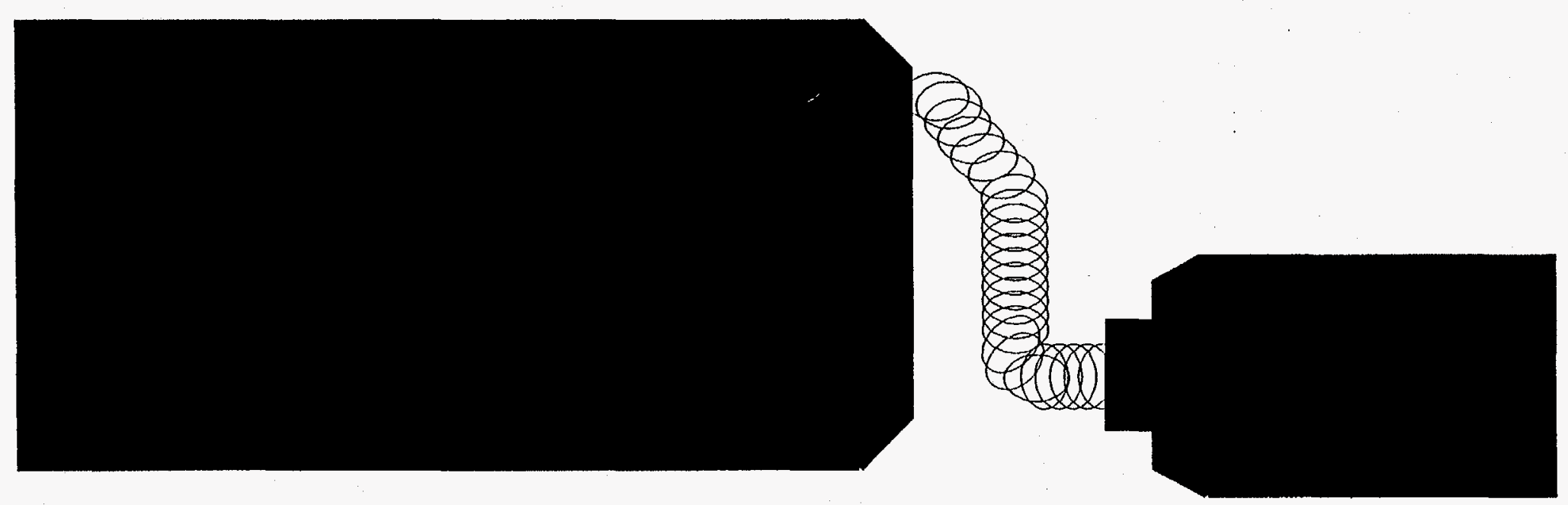




\section{Airflow should be from areas of LEAST to MOST contamination in tritium facilities.}

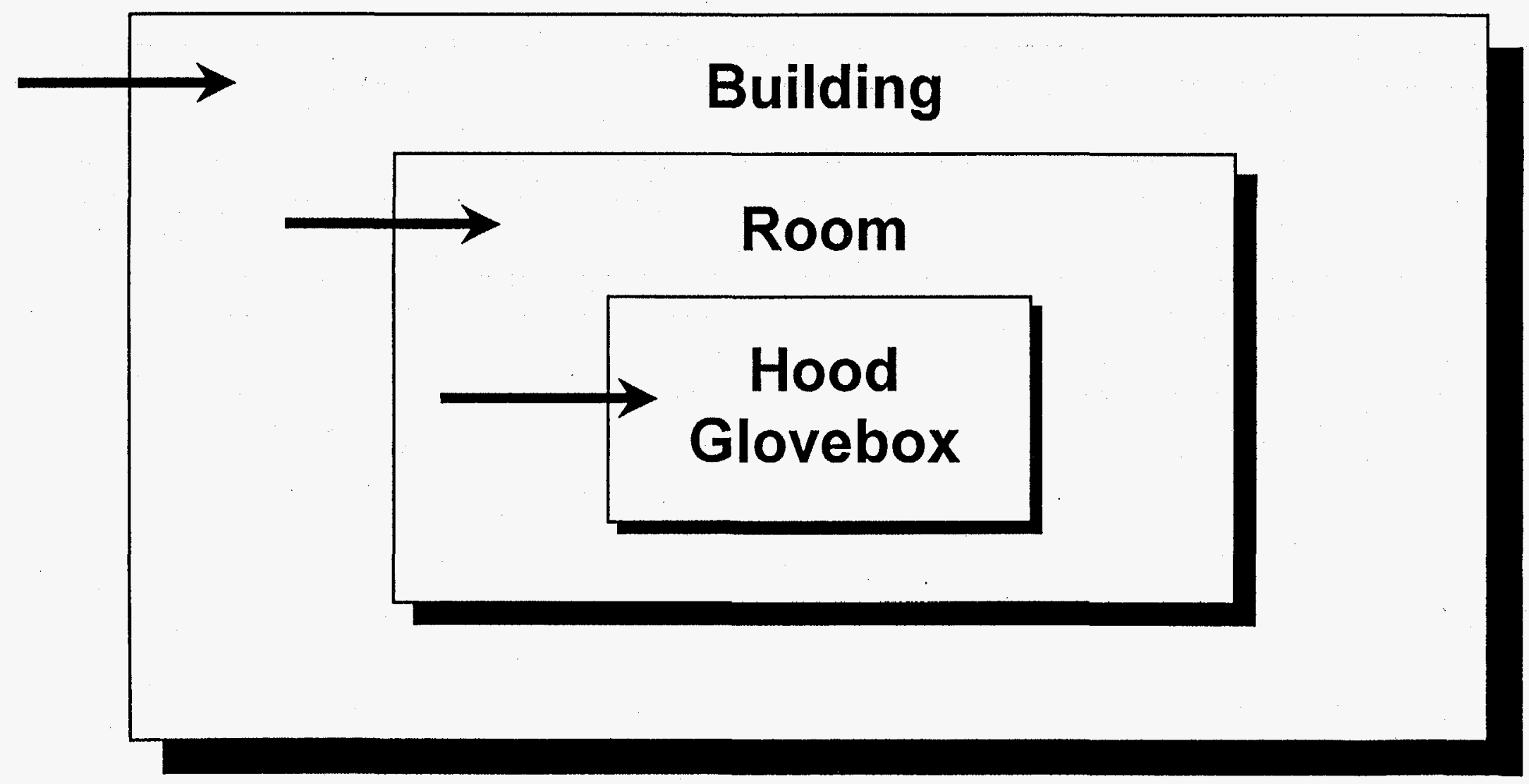




\section{Access controls may also be administrative.}

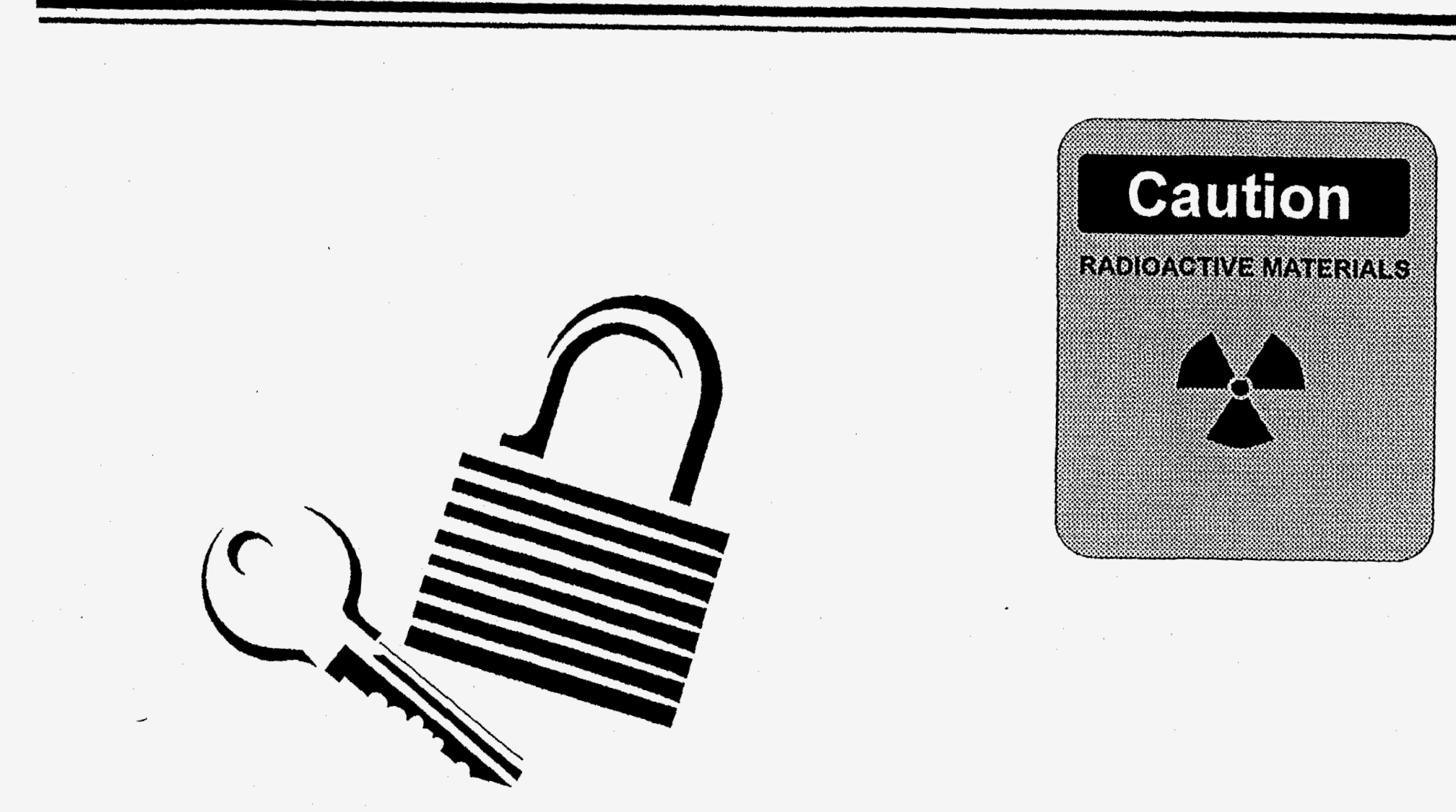


Because of the permeability of tritium, large quantities must be handled using air supplied suits.

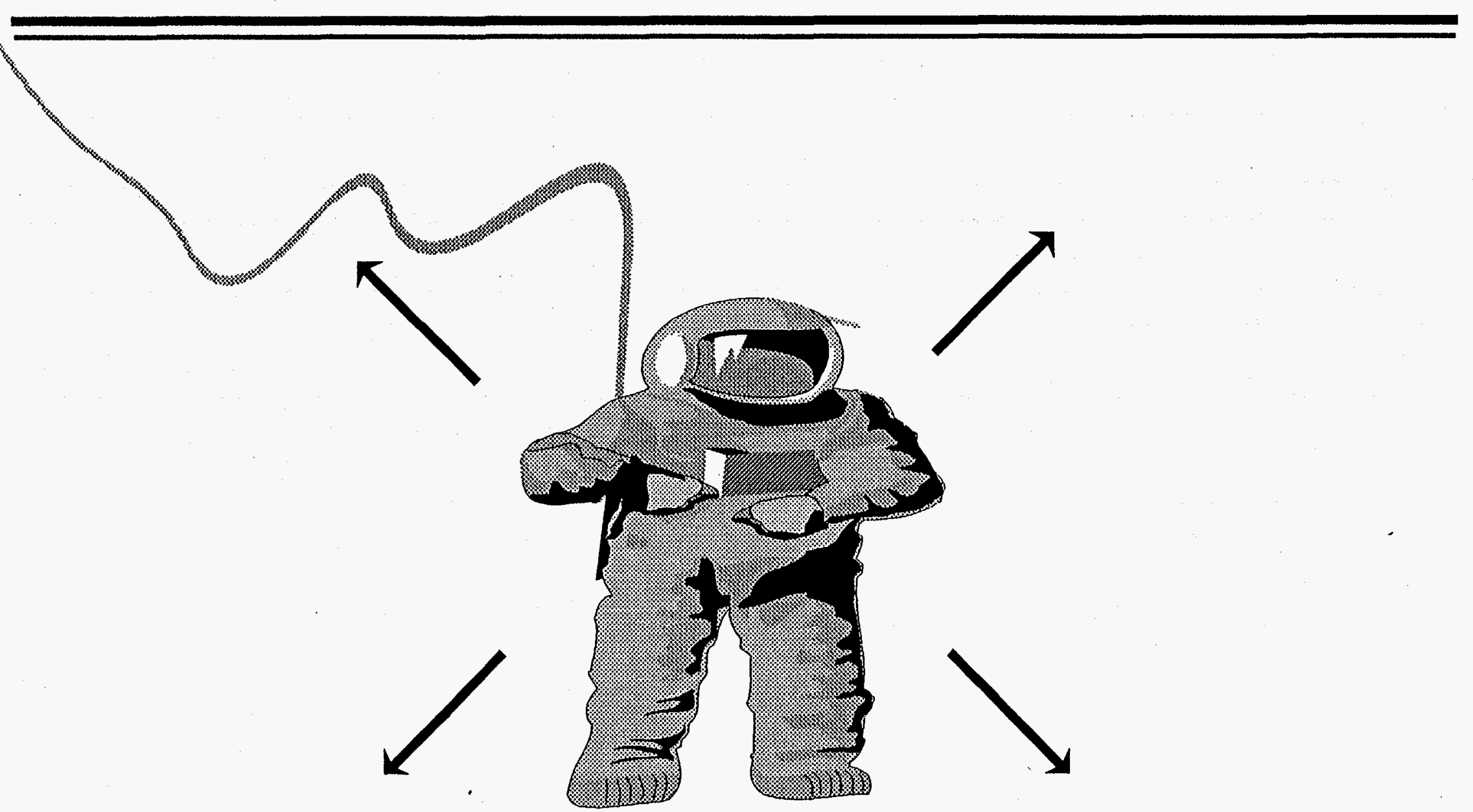




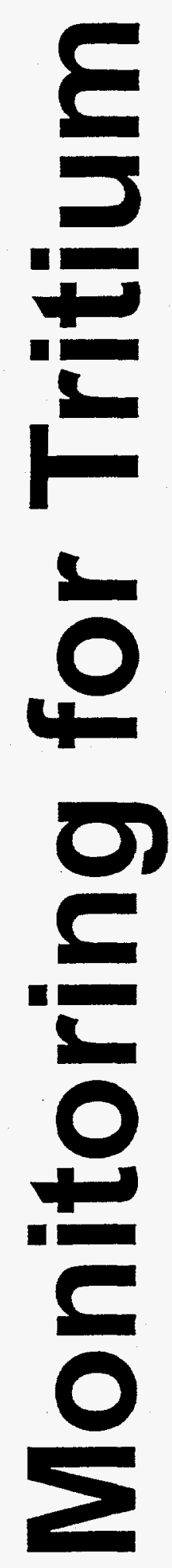

$\frac{9}{5}$ 


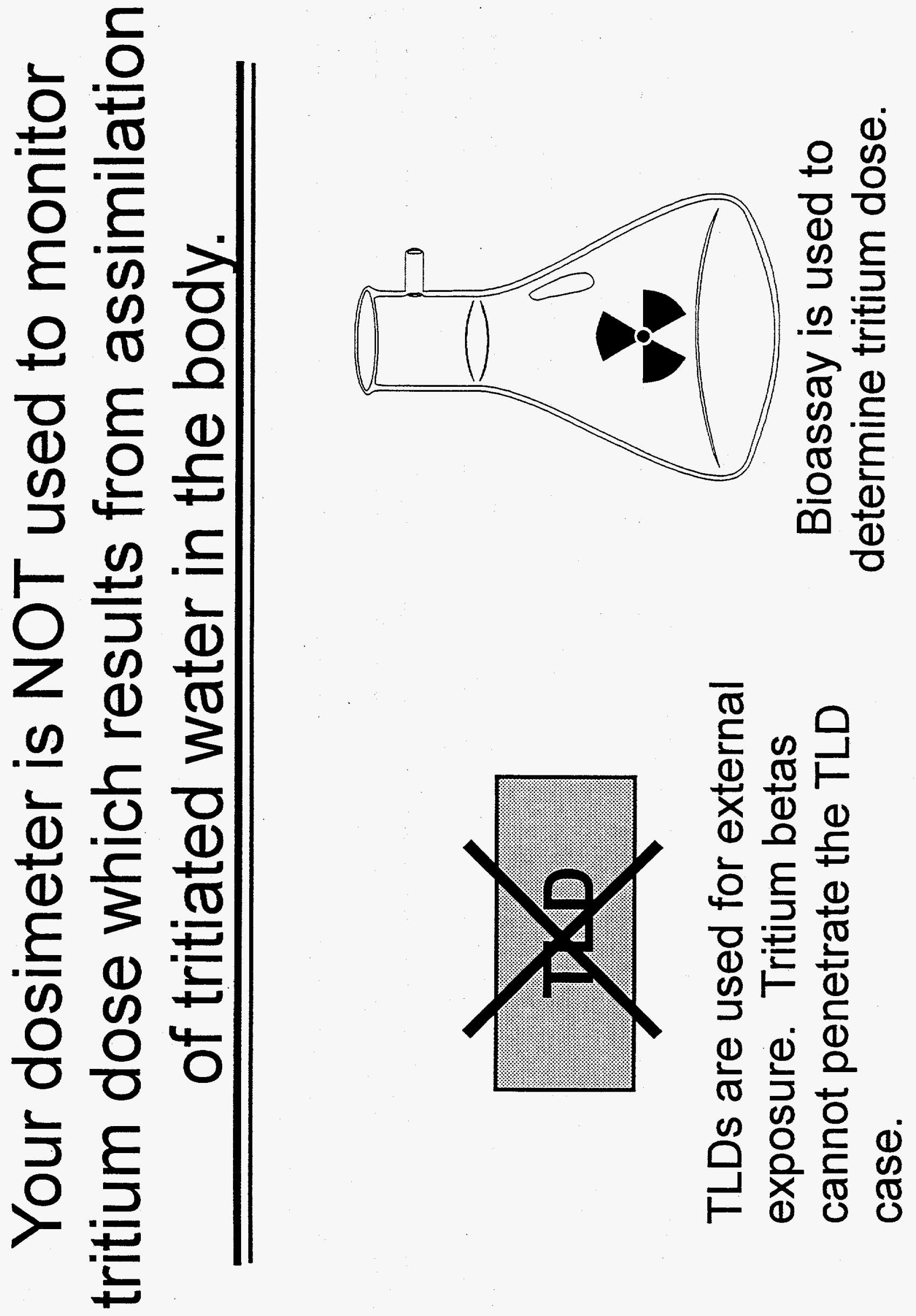

喜 


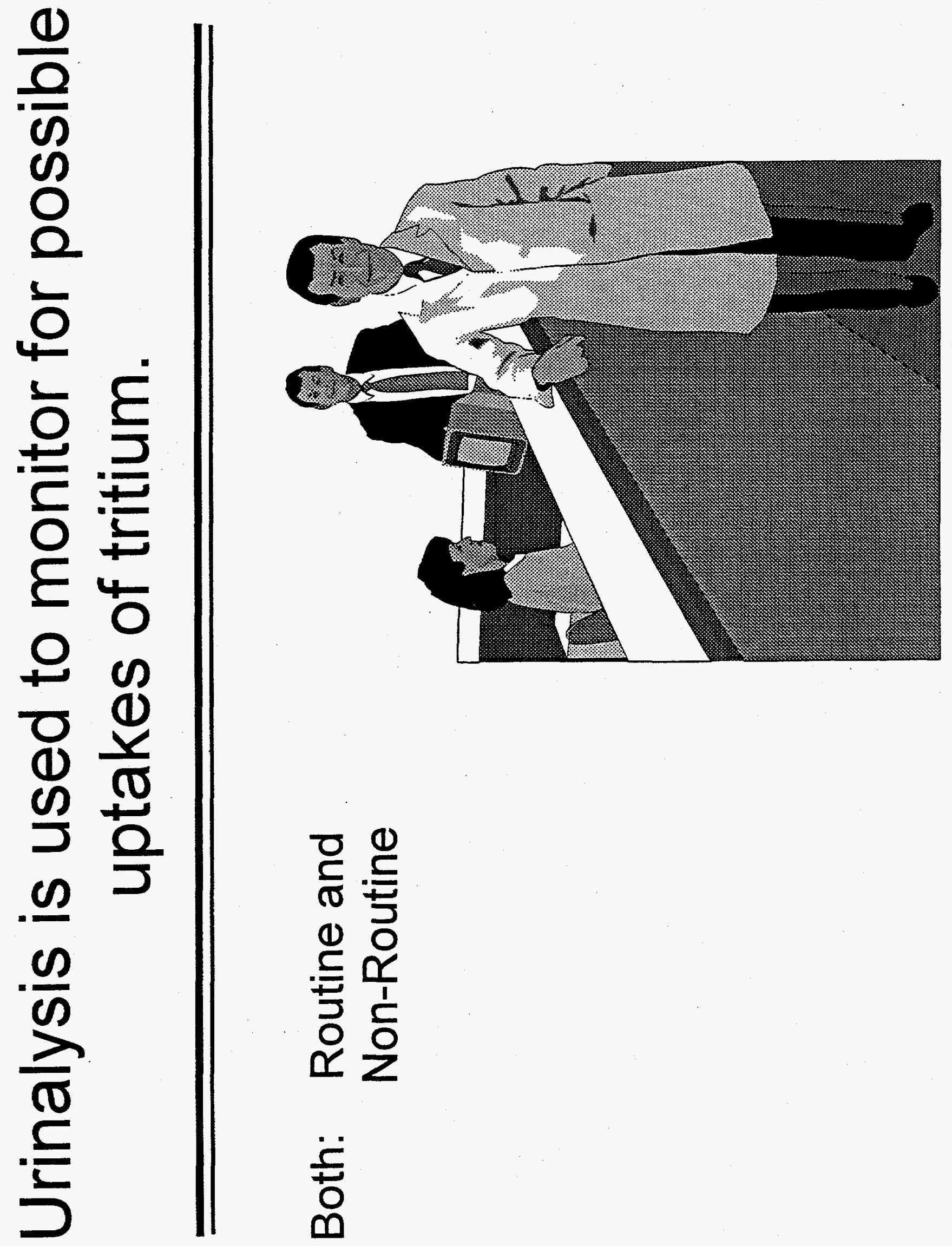

$\frac{1}{1}$ 

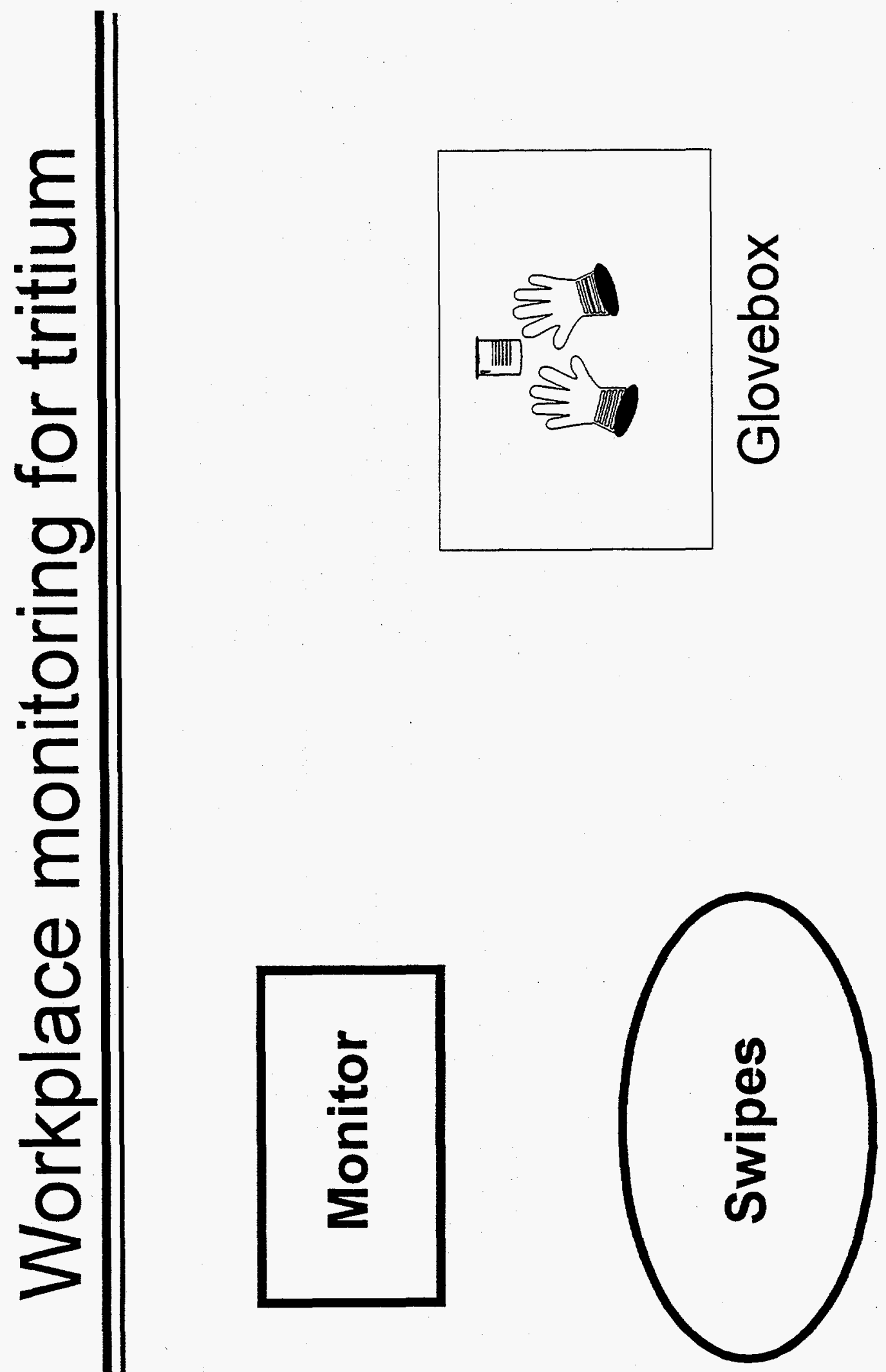

$\frac{1}{1}$ 


\section{Area fixed air monitors and tritium sniffers are used to detect tritium leaks/releases.}

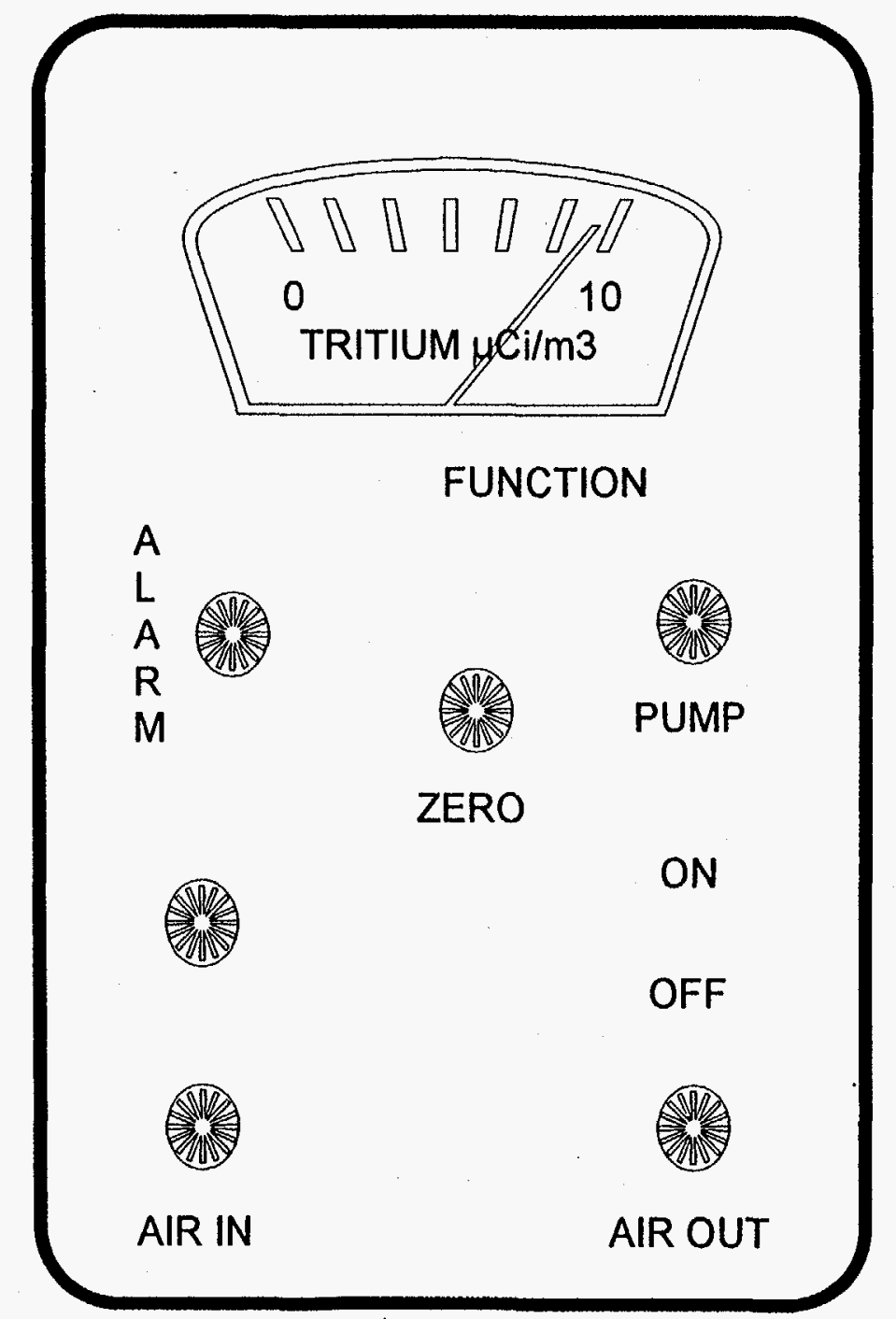




\section{Tritium spreads easily, therefore contamination control requires constant vigilance.}

Tritium is like sand at the beach... 


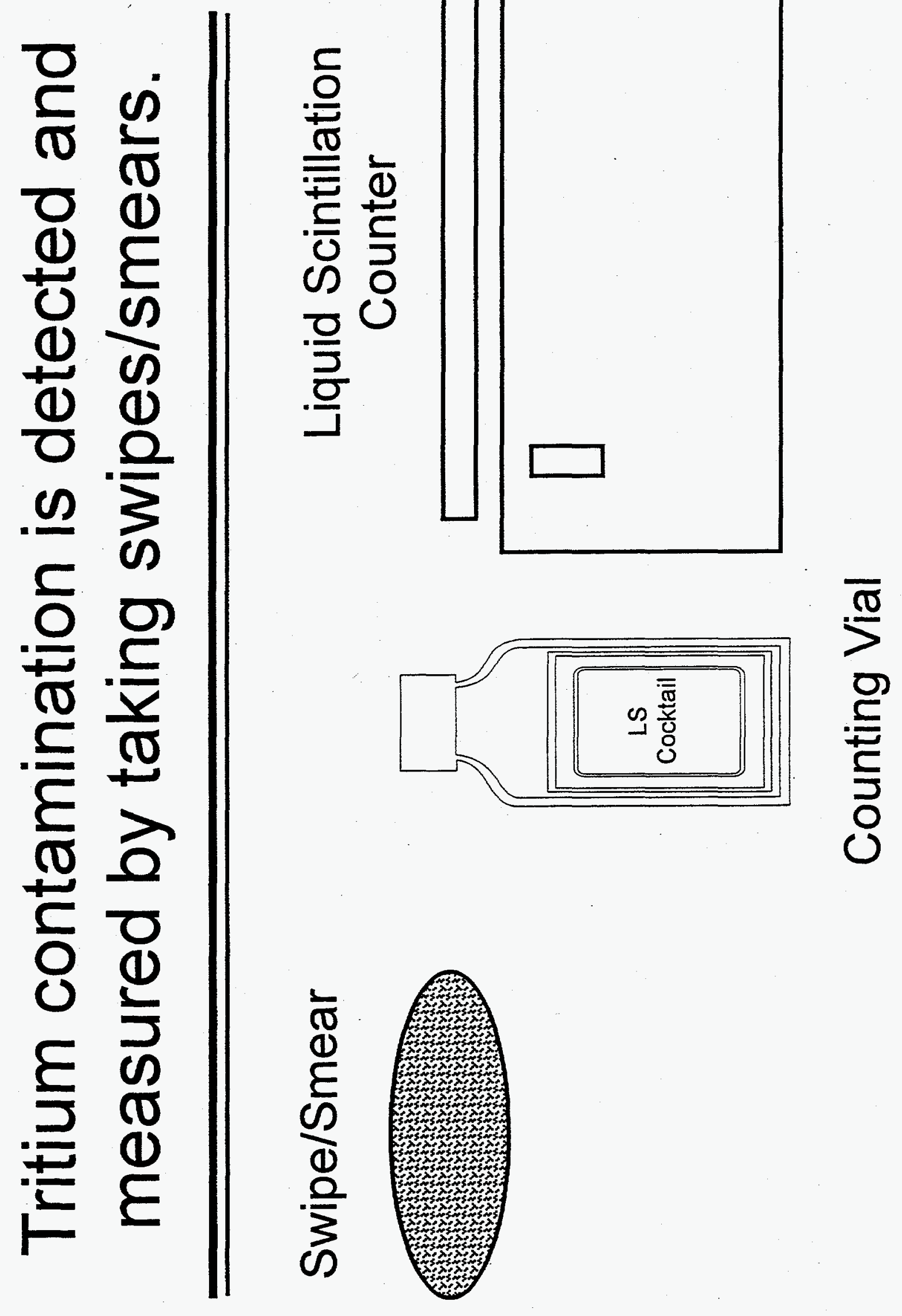

疍 


\section{Tritium Waste Minimization and Handling}

- Avoid generating waste by not bringing unnecessary material into the controlled area.

- Protect large pieces of equipment from contamination by wrapping them when bringing them into the area.

- Whenever possible, avoid use of porous materials or those known to be highly permeable to tritium.

- Designate an area to store contaminated tools for reuse.

- Plan work so that, whenever possible, construction and clean maintenance can be done in a clean area. 


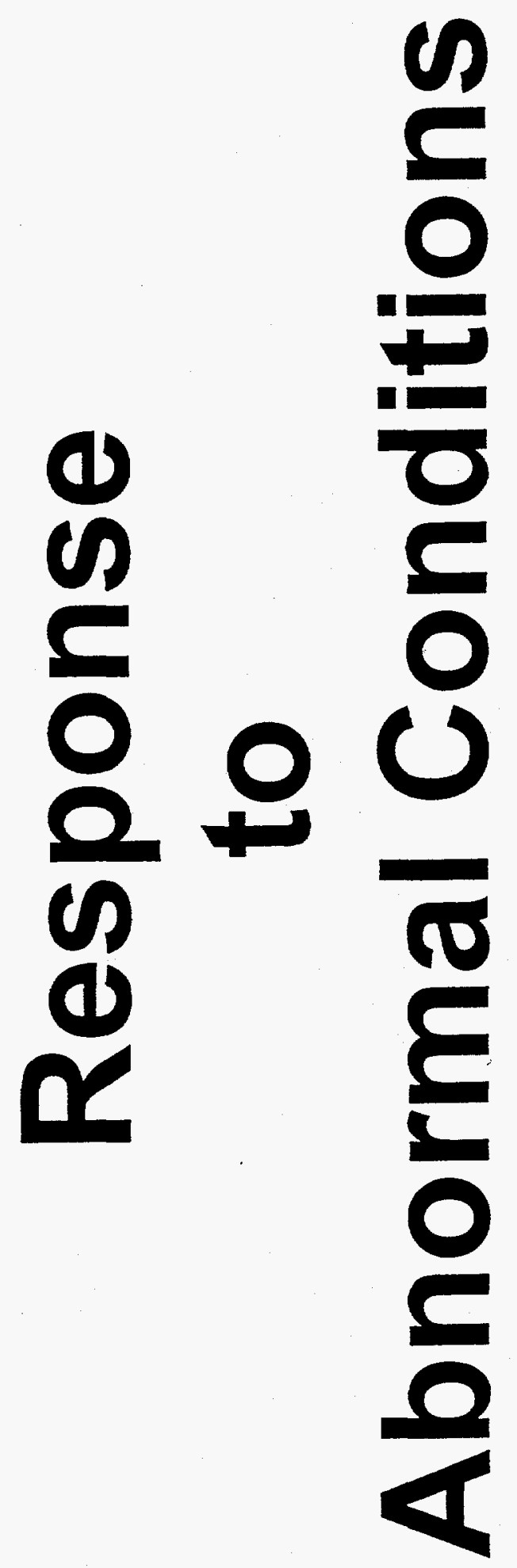

$\frac{5}{5}$ 


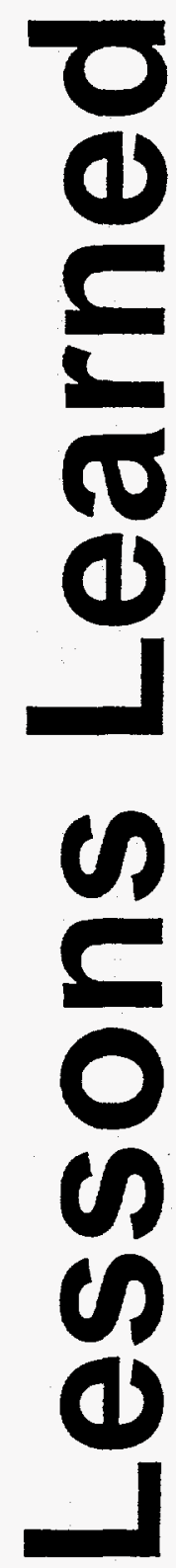

㸃 

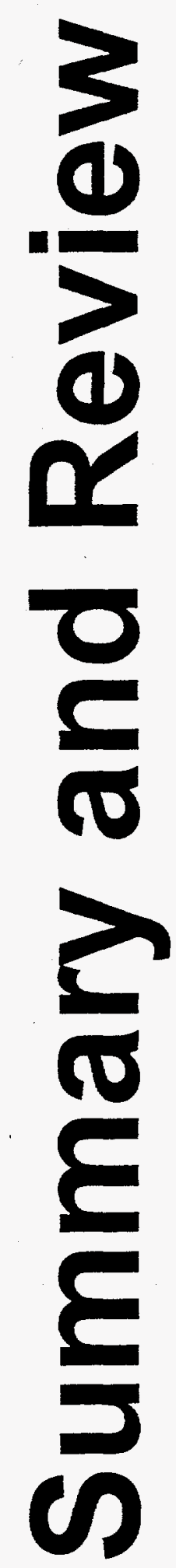

曽 


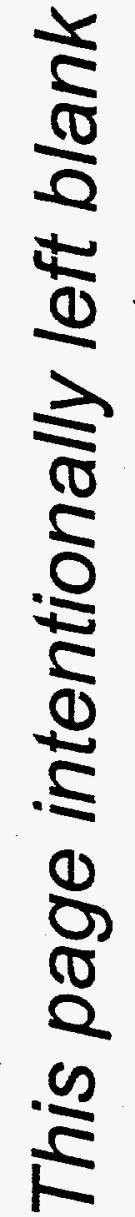


(Part 5 of 5)

DOE-HDBK-1105-96

Radiological Training for Tritium Facilities

Lessons Learned

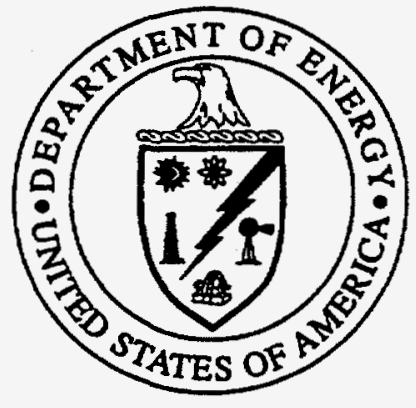

Coordinated and Conducted for

Office of Environment, Safety \& Health

U.S. Department of Energy 
Lessons Learned are to be provided by the training facilities for site specific information. As part of the Environmental Safety \& Health (ES\&H) Technical Information System (TIS), access to lessons learned across the DOE complex can be obtained via the internet at:

http://venus.hyperk.com/trl/1l/1l.html

Lessons learned may also be found in different documents (i.e., Office of Nuclear and Facility Safety, Safety Notice) as well as the internet and should be researched. 


\section{CONCLUDING MATERIAL}

Review Activity:

DOE

$\mathrm{DP}$

$\mathrm{EH}$

EM

$\mathrm{NE}$

NN

ER

National Laboratories

BNL

LLNL

LANL

PNL

Sandia

Area Offices

Amarillo Area Office

Ashtabula Area Office

Carlsbad Area Office

Columbus Area Office

Miamisburg Area Office

Fernald Area Office

Los Alamos Area Office

West Valley Area Office

Kirtland Area Office

Pinellas Area Office
Preparing Activity:

Operations/Field Offices

AL

$\mathrm{CH}$

ID

NV

OR

RL

SRO

GFO

OAK

$\mathrm{OH}$

RFFO

\author{
DOE-EH-52
}

Project Number:

6910-0054 


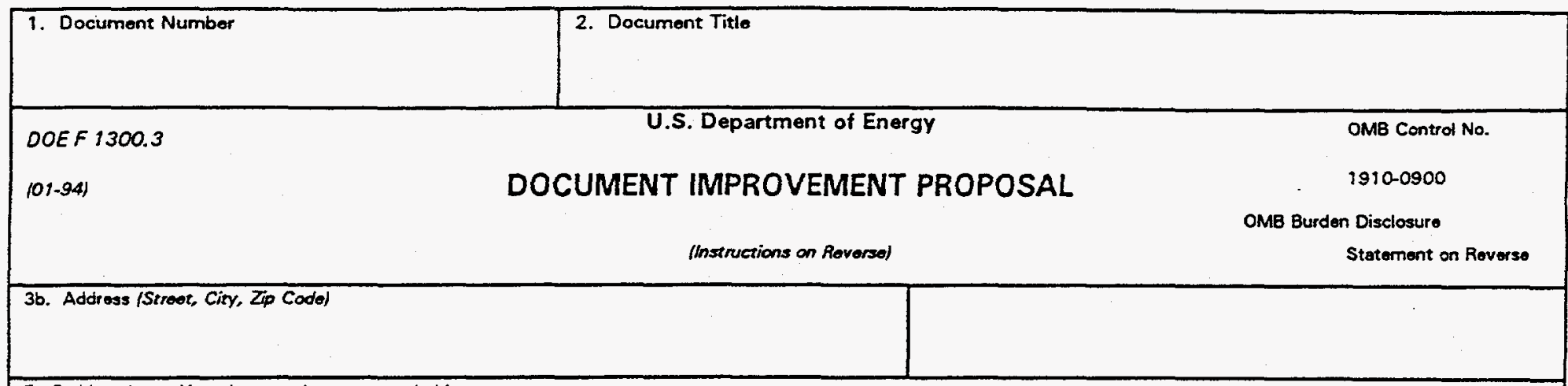

5. Problem Areas (Attach oxtra sheats as noeded.)

a. Paragraph Number and Wording

b. Recommended Warding

c. Reason/Rationalo for Recommendation

6. Remarks

7a. Neme of Submitter (Lest, First, MI)

7b. Work Tolephone Number (Include Area Code)

7c. Mading Addross (Stroot, Ciry, State. Zio Codo)

8. Date of Subrrission 
INSTRUCTIONS: In a continuing effort to improve the U.S. Department of Energy (DOE) Technical Standards, this form is provided for use in submitting comments and suggestions for improvements. All users of DOE Technical Standards are invited to provide suggestions. This form may be detached, folded along the lines indicated, taped along the loose edge (DO NOT STAPLE) mailed to the address indicated or faxed to (423) 574-0382.

1. The submitter of this form must complete blocks 1 through 8.

2. The Technical Standards Program Office (TSPO) will forward this form to the Preparing Activity. The Preparing Activity will reply to the submitter within 30 calendar days of receipt from the TSPO.

NOTE: This form may not be used to request copies of documents, nor to request waivers, deviations, or clarification of specification requirements on current contractors. Comments submitted on this form do not constitute or imply authorization to waive any portion of the referenced document(s) or to amend contractual requirements.

\section{OMB Burden Disclosure Statement}

Public reporting burden for this collection of information is estimated to average 30 minutes per response, including the time for reviewing instructions, searching existing data sources, gathering and maintaining the data needed, and completing and reviewing the collection of information. Send comments regarding this burden estimate or any other aspect of this collection of information, including suggestions for reducing this burden, to Office of Information Resources Management Policy, Plans, and Oversight, Records Management Division, HR-422 - GTN, Paperwork Reduction Project (1910-0900), U.S. Department of Energy, 1000 independence Avenue, S.W., Washington, DC 20585; and to the Office of Management and Budget (OMB), Paperwork Reduction Project (1910-0900), Washington, DC 20503.

U.S. Department of Energy Technical Standards Program Office

c/o Performance Assurance Project Office

P.O. Box 2009, Bldg. 9201-3

Oak Ridge. Tennessee 37831-8065 